\title{
WestVirginiaUniversity
}

THE RESEARCH REPOSITORY @ WVU

Graduate Theses, Dissertations, and Problem Reports

2001

\section{Computer usage by building -level administrators in West Virginia public schools}

\author{
Kevin Gail Cain \\ West Virginia University
}

Follow this and additional works at: https://researchrepository.wvu.edu/etd

\section{Recommended Citation}

Cain, Kevin Gail, "Computer usage by building -level administrators in West Virginia public schools" (2001). Graduate Theses, Dissertations, and Problem Reports. 2337.

https://researchrepository.wvu.edu/etd/2337

This Dissertation is protected by copyright and/or related rights. It has been brought to you by the The Research Repository @ WVU with permission from the rights-holder(s). You are free to use this Dissertation in any way that is permitted by the copyright and related rights legislation that applies to your use. For other uses you must obtain permission from the rights-holder(s) directly, unless additional rights are indicated by a Creative Commons license in the record and/ or on the work itself. This Dissertation has been accepted for inclusion in WVU Graduate Theses, Dissertations, and Problem Reports collection by an authorized administrator of The Research Repository @ WVU.

For more information, please contact researchrepository@mail.wvu.edu. 


\title{
Computer Usage by Building-Level Administrators in West Virginia Public Schools
}

\author{
Kevin G. Cain
}

Dissertation submitted to the College of Human Resources and Education at West Virginia University in partial fulfillment of the requirements for the degree of

Doctor of Education

In

Educational Leadership Studies

\author{
Paul Leary, Ed.D., Chair \\ Ronald Childress, Ed.D. \\ Ernest Goeres, Ph.D. \\ Powell Toth, Ph.D. \\ Pamela S. Cain, Ed.D. \\ Department of Educational Leadership Studies
}

Morgantown, West Virginia

2001

Keywords: Administrators, Computers, Principals, Technology Copyright 2001 Kevin G. Cain 


\section{ABSTRACT \\ Computer Usage by Building-Level Administrators in \\ West Virginia Public Schools}

Kevin G. Cain

By gaining a better understanding of the general computer usage of building-level administrators, effective training programs can be designed to enhance the leadership roles of the school principal. Administrators, supervisors, directors, and program coordinators at the West Virginia Department of Education will be able to use the information found through this study to assist administrators in becoming more effective leaders within their respective schools. More effective leaders will lead to more effective schools. Further, the technologically literate principal will be better equipped to take on a more active role in the technological advancements at his/her respective school.

The purpose of this study was to determine the frequency with which building-level administrators, principals, in West Virginia use office productivity software to complete their management tasks of organizing information, communicating, making presentations, and preparing budgets. Further, this study examined the relationships between specific computer usage by building-level administrators and the independent variables in the category of general computer usage, the category of computer training received, perceptions and attitudes of computer usage, and the three different individual leadership outcomes of extra effort, effectiveness, and satisfaction. Demographic data were examined to determine predictors for computer usage by building-level administrators, principals.

Surveys were sent to all principals in West Virginia public schools. Five hundred three surveys were returned which gave a response rate above 60 percent. Spearman's Rho and the MannWhitney $U$ tests were utilized to determine relationships between variables. A stepwise forward multiple linear regression analysis was conducted on the demographic data to determine demographic predictors of computer usage.

The results of this study indicated that building-level administrators were using word processing software and e-mail software for the management function of communicating fairly often. Database and spreadsheet usage for the management functions of organizing information and preparing budgets were used less frequently. Further, this study showed a statistically significant relationship between the frequency of presentation and desktop publishing software and the leadership outcomes of extra effort, effectiveness, and satisfaction. 
Acknowledgements

I wish to thank my committee chair, Dr. Paul Leary, for his infusion of humor during stressful periods. I would also like to thank Dr. Teresa Eagle for her assistance with the statistical pieces to this research project. Finally, I would like to thank my wife, Natasha, for her patience, encouragement, and understanding throughout this entire process. 
Table of Contents

$\underline{\text { Page }}$

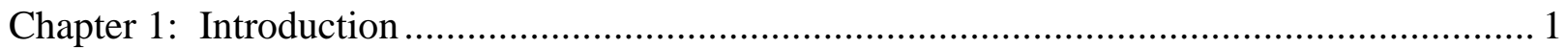

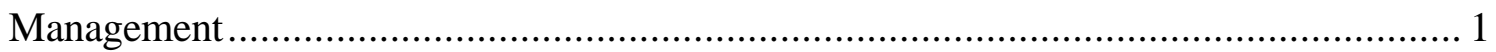

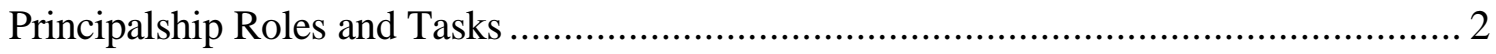

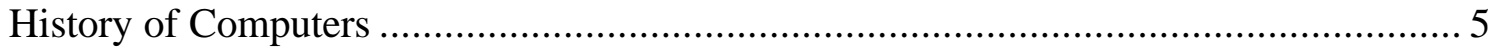

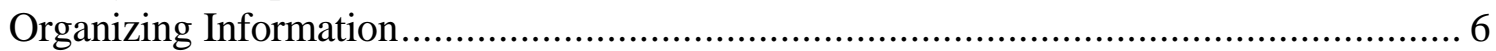

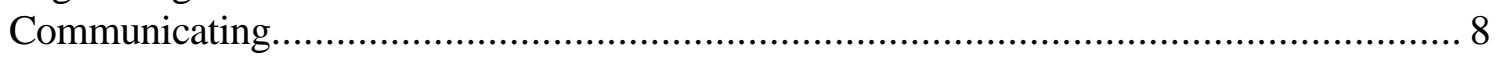

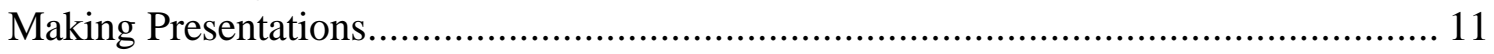

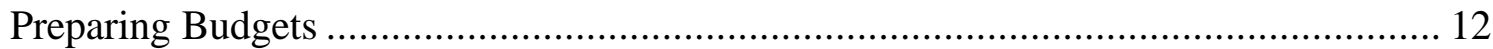

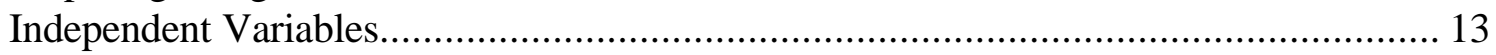

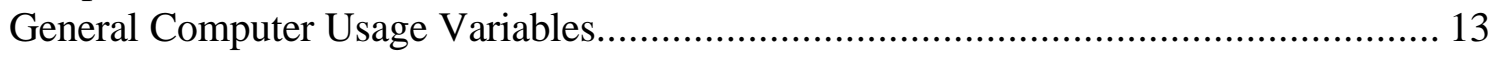

Variables Concerning Computer Training Received................................................ 14

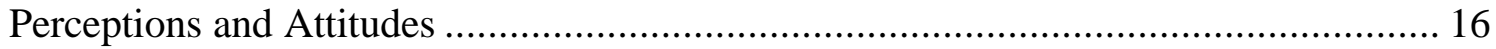

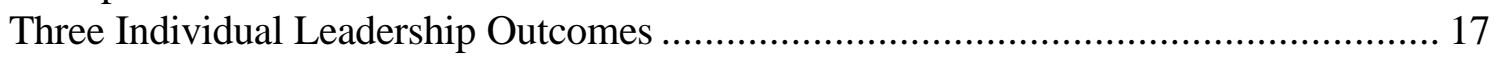

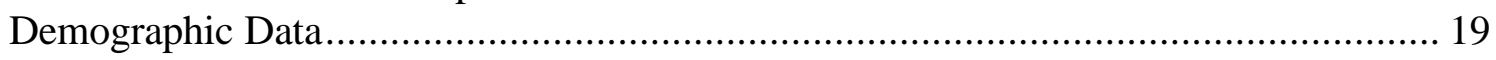

Statement of the Problem.................................................................................. 20

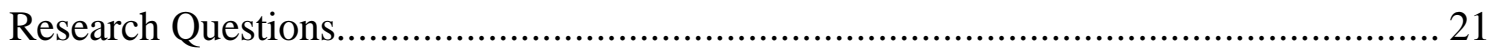

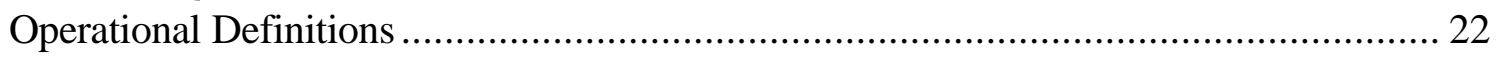

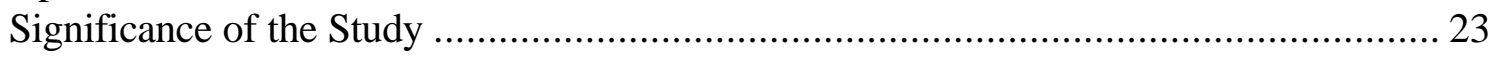

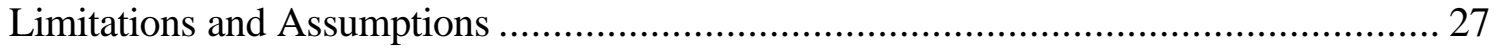

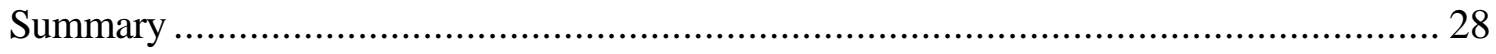

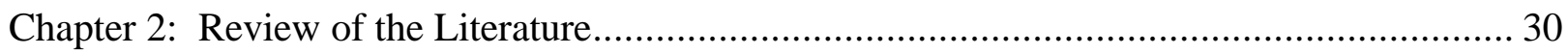

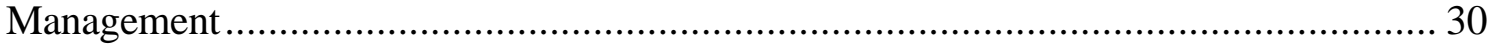

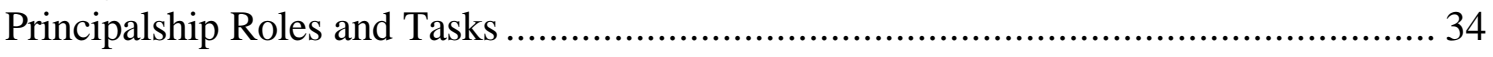

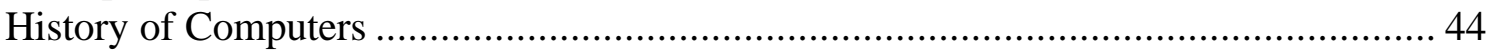

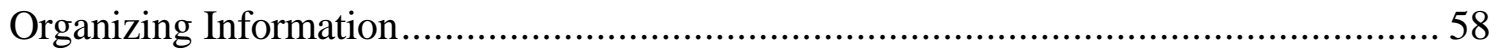

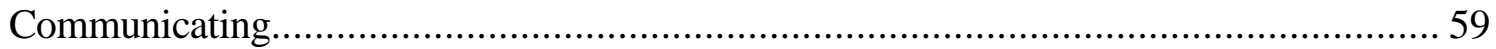

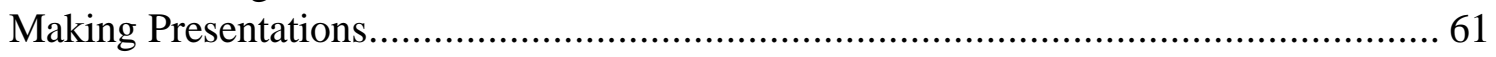

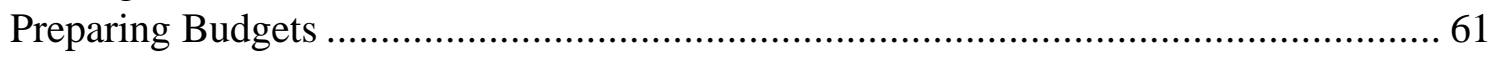

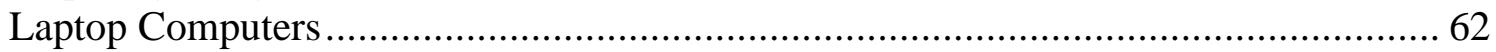

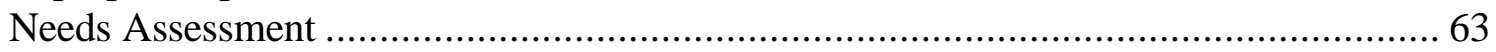

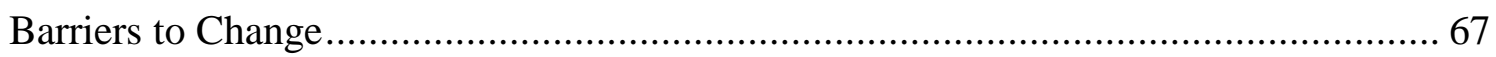

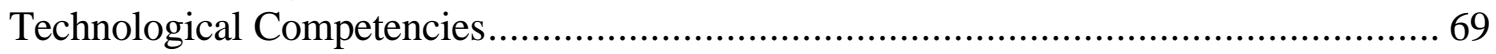

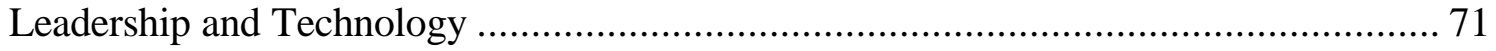

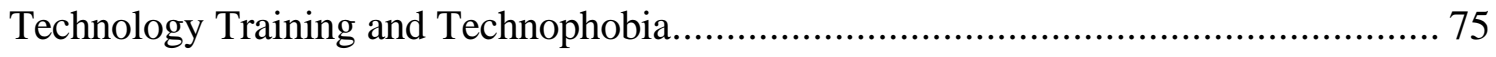

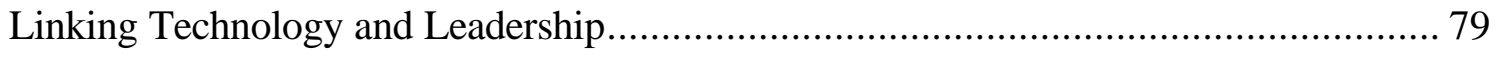


Chapter 2 (Continued)

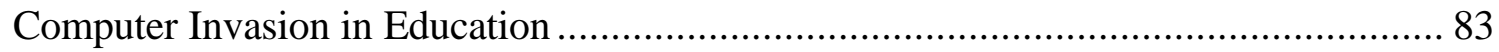

Technologically Competent Administrators ................................................... 85

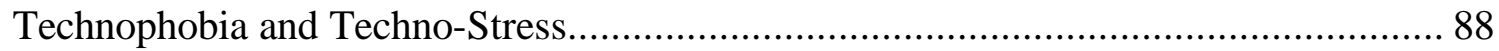

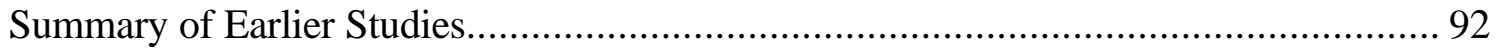

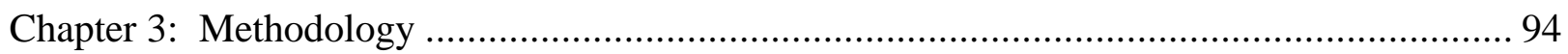

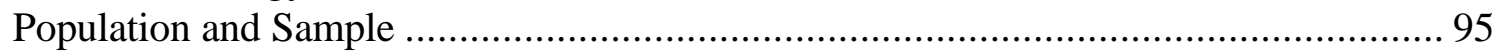

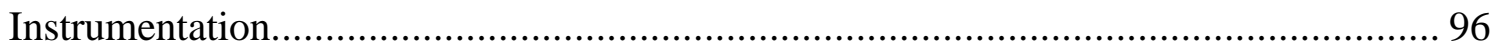

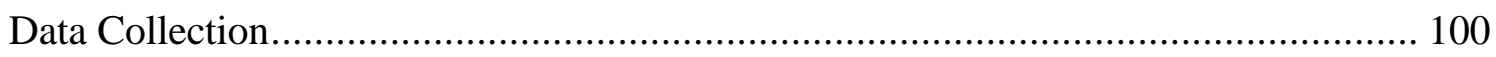

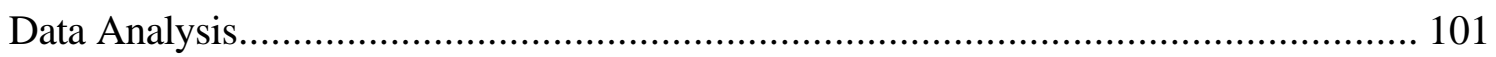

Chapter 4: Presentation and Analysis of the Data........................................................ 104

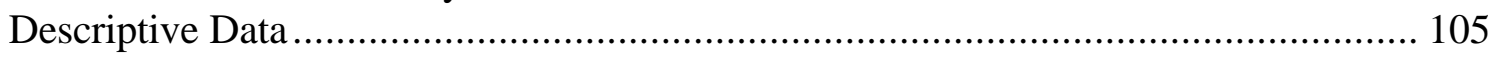

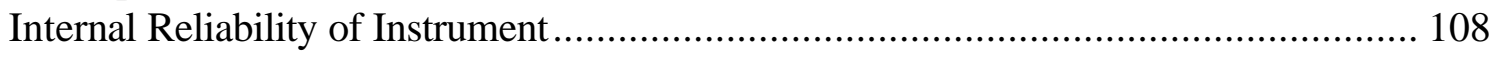

Major Findings:

Research Question 1.................................................................. 109

Research Question 2.................................................................. 113

Research Question 3................................................................ 115

Research Question 4........................................................................ 123

Research Question 5......................................................................... 125

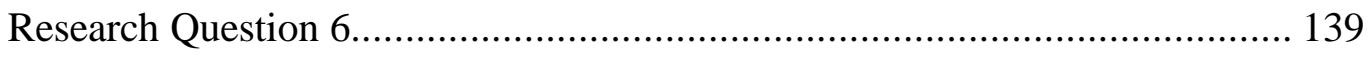

Research Question 7........................................................................... 154

Research Question 8...................................................................... 168

Research Question 9....................................................................... 170

Research Question 10................................................................. 173

Research Question 11........................................................................ 176

Research Question 12................................................................ 178

Research Question 13............................................................. 180

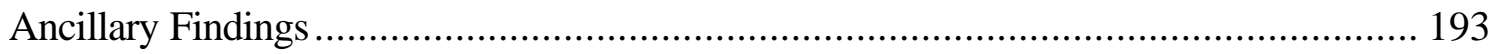

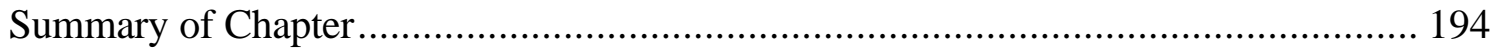

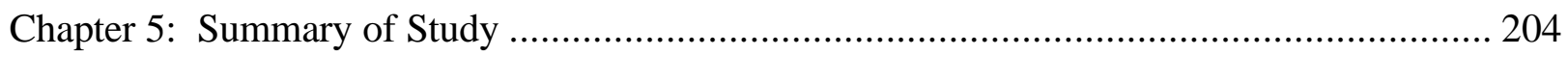

Purpose of the Study ................................................................................... 204

Summary of Procedures ...................................................................................... 206

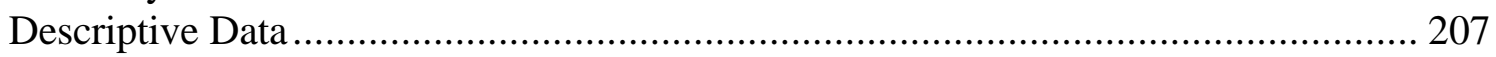

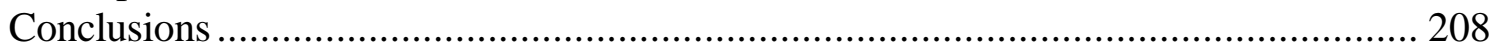

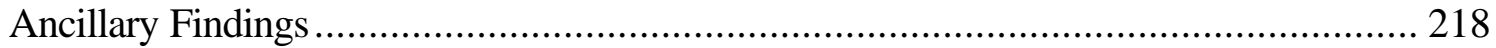

Discussion ......................................................................................... 219

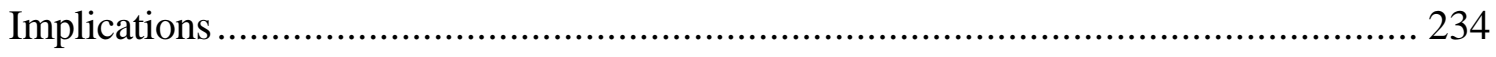

Recommendations for Further Research ................................................. 235

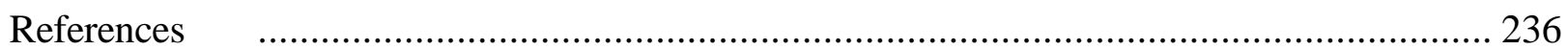


Appendices

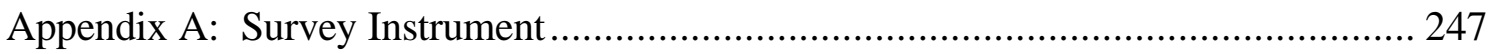

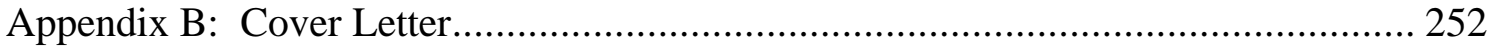

Appendix C: Information Request from RESA VI............................................ 254

Appendix D: Information Request from Brenda Williams ..................................... 256 
List of Tables

$\underline{\text { Table }}$

1 Descriptive Data on West Virginia Building-Level Administrator

Computer Usage Survey 2000: Responses by RESA Region

2 Numeric Frequency of Computer Usage Reported on the West

Virginia Building-Level Administrator Computer Usage Survey

2000 Form

3 Percentage Frequency of Computer Usage Reported on the

West Virginia Building-Level Administrator Computer Usage

Survey 2000 Form

4 Relationship Between Frequency of Computer Usage by Building-

Level Public School Administrators in West Virginia and Home

Personal Computer

5 Relationship Between Frequency of Computer Usage by Building-

Level Public School Administrators in West Virginia and

Administrators Reporting No Previous Usage of Computer

Operating Systems or Platforms

6 Relationship Between Frequency of Computer Usage by Building-

Level Public School Administrators in West Virginia and

Administrators Reporting Previous Usage of DOS

$7 \quad$ Relationship Between Frequency of Computer Usage by Building-

Level Public School Administrators in West Virginia and

Administrators Reporting Previous Usage of Windows

8 Relationship Between Frequency of Computer Usage by Building-

Level Public School Administrators in West Virginia and

Administrators Reporting Previous Usage of Macintosh/Apple

9 Relationship Between Frequency of Computer Usage by Building-

Level Public School Administrators in West Virginia and Years of

Usage of Personal Computer.

10 Relationship Between Frequency of Computer Usage by Building-

Level Public School Administrators in West Virginia and

Administrators Reporting No Previous Usage of Computer

Applications at Home

11 Relationship Between Frequency of Computer Usage by Building-

Level Public School Administrators in West Virginia and Previous

Usage of Word Processing Software at Home.

12 Relationship Between Frequency of Computer Usage by Building-

Level Public School Administrators in West Virginia and Previous

Usage of Desktop Publishing Software at Home 
13 Relationship Between Frequency of Computer Usage by BuildingLevel Public School Administrators in West Virginia and Previous Usage of Internet Browsing Software at Home

14 Relationship Between Frequency of Computer Usage by BuildingLevel Public School Administrators in West Virginia and Previous Usage of Database Software at Home

15 Relationship Between Frequency of Computer Usage by BuildingLevel Public School Administrators in West Virginia and Previous Usage of Electronic Spreadsheet Software at Home.

16 Relationship Between Frequency of Computer Usage by BuildingLevel Public School Administrators in West Virginia and Previous Usage of E-Mail Software at Home

17 Relationship Between Frequency of Computer Usage by BuildingLevel Public School Administrators in West Virginia and No

Previous Computer Training Received

18 Relationship Between Frequency of Computer Usage by BuildingLevel Public School Administrators in West Virginia and Previous Computer Training Through Required University/College Courses

19 Relationship Between Frequency of Computer Usage by BuildingLevel Public School Administrators in West Virginia and Previous Computer Training Through Elective University/College Courses

20 Relationship Between Frequency of Computer Usage by BuildingLevel Public School Administrators in West Virginia and Previous Computer Training Through Community College Courses

21 Relationship Between Frequency of Computer Usage by BuildingLevel Public School Administrators in West Virginia and Previous Computer Training Through Inservice Courses ....

22 Relationship Between Frequency of Computer Usage by BuildingLevel Public School Administrators in West Virginia and Previous Computer Training Through Self Teaching

23 Relationship Between Frequency of Computer Usage by BuildingLevel Public School Administrators in West Virginia and Previous Computer Training Through Peer Coaching....

24 Relationship Between Frequency of Computer Usage by BuildingLevel Public School Administrators in West Virginia and No Previous Computer Application Training in the Last Year....

25 Relationship Between Frequency of Computer Usage by BuildingLevel Public School Administrators in West Virginia and Word Processing Training Received Within the Last Year....

26 Relationship Between Frequency of Computer Usage by BuildingLevel Public School Administrators in West Virginia and Desktop Publishing Training Received Within the Last Year..... 
27 Relationship Between Frequency of Computer Usage by BuildingLevel Public School Administrators in West Virginia and Internet Browser Training Received Within the Last Year.

28 Relationship Between Frequency of Computer Usage by BuildingLevel Public School Administrators in West Virginia and Database Training Received Within the Last Year.

29 Relationship Between Frequency of Computer Usage by BuildingLevel Public School Administrators in West Virginia and Electronic Spreadsheet Training Received Within the Last Year.

30 Relationship Between Frequency of Computer Usage by BuildingLevel Public School Administrators in West Virginia and Electronic Mail Training Within the Last Year

31 Relationship Between Frequency of Computer Usage by BuildingLevel Public School Administrators in West Virginia and the

Amount of Computer Training Received Within the Last Year.

32 Relationship Between Frequency of Computer Usage by Building-

Level Public School Administrators in West Virginia and

Perceptions and Attitudes Toward Technology ....

33 Relationship Between Frequency of Computer Usage by Building-

Level Public School Administrators in West Virginia and

Individual Leadership Outcome of Extra Effort

34 Relationship Between Frequency of Computer Usage by Building-

Level Public School Administrators in West Virginia and

Individual Leadership Outcome of Effectiveness

35 Relationship Between Frequency of Computer Usage by Building-

Level Public School Administrators in West Virginia and

Individual Leadership Outcome of Satisfaction.

36 Demographic Characteristics Which Predict the Usage of

Database Software for the Management Function of

Organizing Information

37 Demographic Characteristics Which Predict the Usage of Word

Processing Software for the Management Function of

Communicating.

38 Demographic Characteristics Which Predict the Usage of E-Mail

Software for the Management Function of Communicating

39 Demographic Characteristics Which Predict the Usage of

Presentation Software for the Management Function of

Making Presentations

40 Demographic Characteristics Which Predict the Usage of Desktop

Publishing Software for the Management Function of Making

Presentations 
41 Demographic Characteristics Which Predict the Usage of Electronic Spreadsheet Software for the Management Function

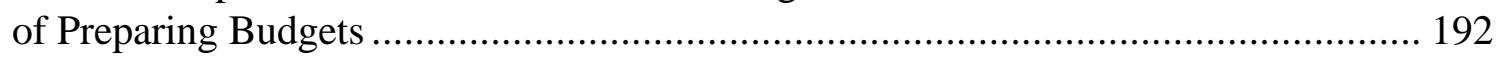




\section{CHAPTER 1}

\section{Introduction}

In recent years, one of the tools which has been used successfully in the management of any business is the computer. Since our schools are some of the largest businesses in the state, it seems only natural that the managers in this Abusiness@hould be effectively and efficiently using the computer as a management tool. This study focused on the frequency of West Virginia public school building-level administrators =usage of computers and related software to perform specific management tasks. Additionally, this study examined the relationships between computer usage by building-level administrators in West Virginia schools and certain aspects of general computer use, computer training received, perceptions and attitudes toward technology, various leadership outcomes, and demographic characteristics.

\section{Management}

Current management texts define management according to four managerial functions. These functions are planning, organizing and staffing, leading, and controlling (DuBrin, 2000; Robbins \& Coulter, 1999; Williams, 2000). This categorization is more narrow or compressed than the functions set out by Gulick and Urwick in 1937. According to Gulick and Urwick (1937), there are seven administrative functions or principles. These functions are planning, organizing, staffing, directing, coordinating, reporting, and budgeting. Gulick and Urwick (1937) further believed that once an administrative principle was found, it logically should work in any kind of administrative institution, from government bureaucracies to schools and universities. While management today is thought of as primarily a business-related activity, various levels of school personnel operate under the same principles. Henri Fayol, a French 
manager-engineer, fathered the first theory of administration through his study of the management process (Wren, 1972). Fayol is given credit for creating a universality of management. The categories of management set out by Fayol were planning, organization, command, coordination, and control (Wren, 1972). Fayol work stressed the importance of management in all undertakings--large or small, industrial, commercial, political, religious, or any other.

Today, growing numbers of principals are attempting to focus their energies on two major, interrelated efforts: implementing a systematic school improvement process and developing their own leadership and management skills (Mojkowski, 1986). Each of these efforts has the potential of being affected by and through computer usage. Given the foregoing scenario, a strong case can be made on both fronts at once. Blending school effectiveness and leadership with management development into a program for revitalization can be accomplished while using technology to help get it done (Mojkowski, 1986).

While managers primarily look at internal resources, goals, opportunities, and threats, the external environment must also be considered. The general external environment is comprised of economic conditions, political conditions, social conditions, global conditions, and technological conditions. In terms of these five components, the most rapid changes during the past quartercentury have probably occurred in technology (Robbins \& Coulter, 1999).

\section{Principalship Roles and Tasks}

For school administrators the most difficult part of building a bridge to the $21^{\text {st }}$ century is building it with microchips (Crouse, 1997). Education is just one of many institutions where the potential of the personal computer has been touted since its inception. Moreover, the principal is 
obviously a key person in the implementation of technology into the everyday operation of a school. Although the principal does not need to become the local expert in technology, he or she does need to provide consistent and positive leadership in this area. Leadership begins with being a role model (Brennan, 1997).

According to Byers (1991), most principals approach microcomputers in one of three ways: as adventurers, pragmatists, or recalcitrants. The adventurers have probably been using microcomputers in their offices to perform administrative tasks for several years. The pragmatists take a while to recognize the benefits and are now beginning to use microcomputers in their offices. As for the recalcitrants, they want nothing to do with them.

Technology costs in non-school organizations usually are justified by the value technology provides to the overall work of the organization (Rhodes, 1997). Put another way, most organizations believe that the more value that is added by a tool, the less the tool is perceived as costly. Further, value is added as the technology helps support more effective relationships, enabling new organizational structures to be created and sustained. These values seldom have been factored into school technology costs.

The value added to the building-level administrator can be seen specifically in four applications of technology (Wall, 1994). These four applications of technology are organizing information with tools such as database software, communicating via e-mail and word processing, using graphics or multimedia software to make presentations more powerful and visually attractive, and using budget-related software to plan and track spending. All of these applications can be performed through any of the major software productivity suites available today, such as Microsoft Office 2000, Corel Office 2000, and Lotus Millennium. In addition, 
many administrators say laptop computers are becoming the hardware of choice for these applications (Byers, 1991; Wall, 1994).

The earlier generations of microcomputers were appropriate only for instructional use, primarily because of their small capacity for the storage of data. But most microcomputers or personal computers (PCs) now available equal the storage capacity of many older, full-size computers. In addition, they are easier to use and more affordable than ever before. Thus, PCs are now available to assist in performing administrative tasks for principals.

According to a 1987 article by Crawford, there were several problems to be overcome when principals considered computerizing some of their office tasks. These problems were identified as computer phobia--which is now termed cyberphobia or technophobia (Bates, 2000; Drury, 1995; Filipczak, 1994)--initial cost, computer literacy, and security.

When asked about technology, one modern-day principal of Machon Elementary School in Swampscott, Massachusetts, Sherry Mattheisen, had the following to say:

I often think of Emma Jane Machon, a woman who started teaching at the Essex Street School, near Boston, in 1880. Miss Machon doubled as the school principal from 1901 to 1903 . Her $\$ 350$-a-year job included stoking the fire and cleaning the one-room school. In 1905, her obituary noted that Machon died in the harness while teaching a class of 48 second-graders. Indications are that she was worked to death (Wall, 1994, p. 48).

While Mattheisen was only half joking when she said she had turned to technology in an attempt to avoid a similar fate, Mattheisen ₹ productivity arsenal included database software, electronic mail, computer bulletin boards, desktop publishing, graphics presentation software, two 
Macintosh computers (one for home, and one for office), a laptop computer, and a cellular telephone for her car. Principals now have a broad selection of technology weapons with which to arm themselves.

To date, there is a paucity of literature which quantifies the usage of computer applications by school building administrators. It appears that there may be an assumption that since computers are visible in school administrative offices and software is purchased for administrative functions that school building administrators are using these tools (Benson, 1996). The four primary categories of technology usage discussed earlier and presented by Wall (1994) are broad enough to encompass the planning, organizing and staffing, leading, and controlling functions of school administrators. Further, these categories of computer usage were arrived at through a survey Wall (1994) conducted on practicing building-level school administrators in Georgia. While the literature does not support one best set of categories in a Tayloristic fashion, it does suggest that these four categories are sufficient for labeling current technology applications by school administrators.

\section{History of Computers}

All of the early computers are called first-generation computers (Clark \& White, 1986). First-generation computers used vacuum tubes for data processing, were very large in size, were very slow by today standards, and required constant maintenance (Campbell-Kelly \& Aspray, 1996). Second-generation computers were first available in the 1950s (Clark \& White, 1986). Improvements in technology brought lower prices to the market. These new computers used transistors rather than vacuum tubes for information processing (Campbell-Kelly \& Aspray, 1996). Third-generation computers brought the use of very small electronic circuits called 
integrated circuits (Clark \& White, 1986). These electronic circuits replaced the transistors of the previous generation for the processing of information. Fourth-generation computers use very large scale integration, which means that an extremely large number of electronic components can be crammed into each integrated circuit chip (Campbell-Kelly \& Aspray, 1996; Clark \& White, 1986).

In the mid-1960s, data processing mainframe computers for business had become well established (Campbell-Kelly \& Aspray, 1996). However, computers of this time often filled an entire room. By 1970 it was possible to buy a minicomputer with the power of a 1960 s mainframe for around \$20,000 (Campbell-Kelly \& Aspray, 1996; Clark \& White, 1986). The evolution of the computer has meant that the newer models are both smaller and faster than those available before. This holds true for the computers of today. It is now possible for an executive to have the power of the 1960s mainframe machine setting on his/her desk at a fraction of the 1960s mainframe cost. Advanced technology, competitive pricing, and available software have made the computer an important administrative tool for information management.

\section{Organizing Information}

Information is useful when it is accurate. To be accurate, information must be reliable and valid. School administrators and teachers are increasingly relying on sophisticated technology systems to provide support and service in completing their daily tasks in schools. Principals can use database software to keep a variety of records and lists. This trove of information includes address books, attendance records, inventories, records of students $=$ linic visits and medications, locker combinations, parking permits, and automobile license plates (Wall, 1994). 
Historically, school districts have been responsible for establishing and maintaining information reporting. Today, the concern is how to make records more accessible for assisting in decision-making (Splittgerber \& Stirzaker, 1984). Much of the information needed at the building level is similar to that required at the district level. Thus, a systematic method for reporting data which encompasses all needs would increase the efficiency of a school district, if it can be made more accessible for educational planning, programming, budgeting, and evaluation. It is imperative to generate reports that reflect actual needs and indicate what is the best utilization of available resources (Splittgerber \& Stirzaker, 1984).

One principal cited using a database program to keep behavior management files. When a student was sent to the office for discipline, he/she would sit in front of the computer with the principal to update the behavior file. Together, the student and principal would enter the offense, record the cause of the misbehavior, and write ways it could be avoided in the future. This record from the database would then be printed out for a parent or guardian signature (Wall, 1994).

Furthermore, all managers, to some degree, have informational roles: receiving, collecting, and disseminating information (Robbins \& Coulter, 1999). Managers also act as conduits of information to organizational members. This is the disseminator role. Database management software can be utilized to make these tasks operate more effectively and efficiently.

Database software is used to manage data that can be organized into lists of related information (Beskeen, Friedrichsen, Reding, \& Swanson, 2000). Before inexpensive microcomputers, small businesses and organizations used manual paper systems, such as index 
cards, to keep records. Using an electronic database also allows an individual to create on-screen data entry forms, which make managing a database easier, more accurate, and more efficient than using index cards. While the paperless office may never become reality, better usage of filing space can be made by using electronic storage media. Database programs allow for the organization of information into usable formats which can be utilized to communicate to people inside and outside of a particular business or institution.

\section{Communicating}

Technology, and more specifically information technology, has radically changed the way organizational members communicate (Robbins \& Coulter, 1999). Information technology has significantly improved a manager ability to monitor individual or team performance, and it has allowed employees to have more complete information to make faster decisions. The primary development in information technology which seems to have had the most impact on organizational communication is a networked computer system. Organizational members can communicate with each other and tap into information whether they are down the hall, across town, or halfway across the world.

Electronic mail, or e-mail, is the instantaneous transmission of written messages on computers that are linked together. Messages wait at the receiver computer and are read at the receiver convenience. Electronic mail is fast and cheap and can be used to send the same message to numerous people at the same time. E-mail is a quick and convenient way for organizational members to share information and communicate.

Communication is defined as the process of exchanging information by the use of words, letters, symbols, or nonverbal behavior (DuBrin, 2000). While electronic mail is one form of 
communication available to managers and leaders today, the written form of communication can be made more effective through the use of technology as well. Office productivity software normally comes with a word processing package, an electronic spreadsheet package, a database package, and presentation software. All of these software tools can be used in the communication process. However, word processing software is the primary tool available in office productivity packages for written communication. Word processing software allows an individual to create messages, both formal and informal, for others to read. The spell-checking and thesaurus tools available in most word processing software today assist the manager in creating more effective messages. Furthermore, a leader can import database files to prepare reports intended to communicate statistics, averages, or totals to others. Where numbers are involved, some leaders are now utilizing the advanced features of word processing software to create charts, graphs, and other visual aids in order to communicate the right message. Visual aids of this nature are especially helpful in showing relationships between or among several items. Finally, managers and leaders can even import presentation files and clipart from electronic presentation programs to create printed presentation material that is both interesting and informative.

Sometimes messages are poorly communicated simply because they are delivered using the wrong communication medium (Williams, 2000). There are two general kinds of communication media: oral and written communication. Oral communication includes face-toface and group meetings, as well as telephone calls or other ways, such as videoconferencing. On the other hand, written communication includes letters, e-mail, memos, charts, graphs, and 
reports. Written communication is not well suited to ambiguous or emotionally laden topics, which are better delivered through oral communication (Robbins \& Coulter, 1999).

The additional value of the computer for management purposes can be seen in the organizing and staffing functions, especially in its use in teacher evaluations. Byers (1991) wrote an article about the benefits he received by using a notebook-size computer for completing teacher evaluations. Byers first became impressed with the speed, neatness, and flexibility that word processing brought to memos, letters, and newsletters. Further, it was this impression that moved Byers to the next level. Instead of entering his scrawled notes from teacher observations into the computer, he decided to electronically record them on the spot by using a laptop.

While laptops are not necessary for building-level administrators, they do have several advantages to their use. This machine takes up little space and can be stored in a desk drawer or even on the corner of a principal cluttered desk. Further, the battery backup feature of laptops allows administrators to use "waiting" situations more productively. Byers (1991) discussed how a laptop could be used at airports, in the doctor office, and even in a shopping mall while waiting for a family member to return. By using a laptop on location, the principal ₹staffing functions are made more efficient by decreasing the amount of time it takes to communicate teacher evaluations.

In 1971, Engel, a professor at Iowa State University, insisted that the usual concept of the administrative processesBplanning, organizing, staffing, coordinating or directing, reviewing or evaluating, and budgeting or allocating resourcesBstill applies to the realm of education. However, he submitted that the ways of doing and thinking in carrying out these roles must take 
on new dimensions. Almost three decades ago, this forward-thinking individual saw new tools becoming available to relieve the burdens of administration. Engel believed that new hardware and software had the potential to solve, at least in part, many of the problems of education in the realms of instruction and administration.

\section{Making Presentations}

More administrators are finding that a personal computer, graphic presentation software, and a projection device make a powerful combination for getting information across to an audienceBbe it school board members, fellow administrators, or members of the public. Presentation software allows administrators to use graphics to add punch to their presentations, especially when numbers are involved.

Programs, such as Microsoft PowerPoint, transform ideas into professional, compelling presentations (Beskeen et al., 2000). With this software, administrators can create slides to use as an electronic slide show, as 35-mm slides, and as transparency masters to display on an overhead projector.

Today, much of workplace communication, including group decision making, takes place in meetings. When conducted poorly, meetings can represent a substantial productivity drain (DuBrin, 2000). Meetings are more productive when an agenda is planned and followed carefully, prepared beforehand, and shared with participants (Montgomery \& Murphy, 2001). The same holds true for any type of information that is disseminated. By using an electronic format, a building-level administrator can present information in an organized manner. By telling the audience what you will be telling them, then telling them, and then telling them what you told them, you can be sure that more of the information presented will stay with the audience 
longer. The venue of electronic presentation provides a way in which to do this without appearing too repetitive or condescending to the audience.

Building-level administrators are confronted with many opportunities for making presentations. During the course of an administrator tenure, he/she will more than likely have the chance to speak to groups of parents, community members, board members, professional staff, and classified staff. When deciding on the right channel to convey a message, administrators need to know that one available channel may be only an armslength away.

\section{Preparing Budgets}

A budget is a numerical plan for allocating resources to specific activities (Robbins \& Coulter, 1999). Managers typically prepare budgets for revenues, expenses, and large capital expenditures such as machinery and equipment. It is not unusual, though, for budgets to be used for improving time, space, and the use of material resources. These latter types of budgets substitute non-dollar numbers for dollar amounts. Such items as person-hours, capacity utilization, or units of production can be budgeted for daily, weekly, or monthly activities.

Budgets are so popular today because they are applicable to a wide variety of organizations and units within an organization. Monetary budgets are a useful tool for directing activities in such diverse departments as production and marketing research or at various levels in an organization, such as a county board office or an individual school. Budgets are one planning device that most managers, regardless of organizational level, help formulate.

Technology can be a valuable tool for budget preparation and implementation, especially as part of a site-based management strategy. A specialized electronic budgeting software or general electronic spreadsheet application can be used for performing this function. Once a budget is 
approved, this same software can be used in the controlling function of management by allowing the school administrator to track encumbrances and expenditures.

The tasks of budgeting and financial accounting often involve a rows-and-columns table of numbers. These tasks can be performed more efficiently with an electronic spreadsheet or the spreadsheet part of an integrated system. Most problems usually solved with a calculator, pencil, and a sheet of paper can be solved more efficiently with this type of software. Applying the design of the task to the spreadsheet will require a little learning, but the time savings and improved efficiency of the result will be well worth it (Crawford, 1987).

$$
\text { Independent Variables }
$$

\section{General Computer Usage Variables}

The general computer usage category, for the purposes of this study, included the independent variables of whether the administrator had a computer in his/her home, what types of computers had been previously used, the number of years the administrator had used a personal computer, as well as the types of applications previously used at home. Some of these variables had been examined in earlier studies on computer usage of public school administrators.

In a 1996 study by Benson, a computer usage survey was given to building-level administrators of the Washoe County School District in Nevada. Benson found that 78 percent of the survey respondents indicated that they had a computer in their home. Additionally, 75 percent of the school building administrators indicated that they had previously used both word processing and database/spreadsheet applications. When comparing the variable of having a home computer to the level of use of word processing applications, a positive correlation was 
found to exist. Results of this study further illustrated a correlation between the years of use of a personal computer to the use of word processing, database, and desktop publishing applications. Variables Concerning Computer Training Received

Experts say there is a link between administrators' ability to make informed technology decisions and their personal use of technology (Trotter, 1997). An increasing number of administrators are becoming technologically literate, but the percentage is still small. More than a decade ago, great attention began being given by professors of educational administration to the impact of personal computing technology on the educational administration knowledge base. In a survey of over eighty educational administration programs, Spuck and Bozeman (1988) found that a computing course was required by 20 percent to 30 percent of the institutions at the master $₹$ degree, doctoral degree, and mid-management/principal certificate levels. At that time, Spuck and Bozeman characterized administrative computing as ill-defined and lacking a practical or research-based body of knowledge, and the respondents lacked consensus on what constituted appropriate content of computer courses. The 1994 study by Wall of principals in Georgia does provide implications for training today. Since Wall was able to determine categories for administrative computer usage, areas for possible training can be derived.

Ideally, students €omputer knowledge and skills should be assessed upon their entry into a graduate educational administration program. The assessment results would be used to place students into one of three groups (House, 1989). The first group would be comprised of computer novices; the second group would contain students who had little anxiety about computer learning and minimal keyboarding skills; and the remaining students would be able to demonstrate competency in the use of applications software. Since this type of technology 
training represents the ideal situation, many practicing administrators still need computer software training centered around the tasks and roles they perform.

Basic technology skills will remain essential for administrators who want to assume a technology leadership role (Bozeman, Raucher, \& Spuck, 1991). Administrators should learn their skills in context, with applications learned in the role they will be employed in the school (Ritchie \& Rodriquez, 1996). Administrators with limited technology experience often need support to deal with new technologies. Hands-on practice time, a low-risk environment, individualized instruction or small group projects, and instruction based on a variety of learning styles should be offered whenever possible.

One way to accomplish the training needs of principals today is through fellow administrators who are using technology effectively (Donatucci, 1995). Although some of the training may take place in a group setting, the most significant aspect of training should take place administrator to administrator in a real school setting with a technology savvy principal working with a less technology oriented administrator. In this setting one can see the on-going spontaneous use of technology by an experienced practitioner. Further, the administrator must also take the responsibility for his/her own technology development.

The advantages of having technology-competent administrators are many. Not only will they be more productive and efficient, but they will also be better able to recognize the technology needs of the staff and students (Donatucci, 1995). It is difficult for principals to provide support for technology initiatives without appreciating the impact that technology is having and will continue to have on the students they educate. 
Training for the practicing administrators of today can come in many forms. For example, principals may have either been required or elected to take a university or college technology course. Principals also have the opportunity in many areas to register for community college courses that teach computer applications. Less formal means of training can also be achieved through inservice programs, peer coaching situations, or self-teaching approaches.

In 1993 the state of Indiana instituted the annual Principals=Technology Leadership Training program. At these conferences, principals were given four days of professional staff development which included instructional sessions on computers and an introduction to a variety of software programs and computer hardware (Rockman \& Sloan, 1993). Over the course of this venture, a network was established, comprised of principals interested in technology. Subgroups were also formed which were self-selected and within that network. These subgroups included building-level administrators looking for solutions to particular problems and principals who were looking for cutting edge ideas. This training plan was developed by the Indiana Department of Education to offer collegial learning that permitted principals the freedom to take risks, to get questions answered, and to gather important information.

Perceptions and Attitudes

Though few want to admit it, technophobia is rampant in American society (Hanna, RossGanguly, \& Katz, 1994). A 1994 technology article by Filipczak stated that 55 percent of all Americans are technophobic to some degree, meaning that they resist using technology in their daily lives. Moreover, one-fourth of the adults surveyed had never used a computer, set the timer on their VCRs, or programmed stations on their car radios. Even for those who do occasionally use computers, their technology comfort level is narrow indeed (Filipczak, 1994). Many 
individuals know how to use one or two items of technology, but go blank when it comes to learning others or to advancing skills, as in learning a new piece of software. So, if technophobia affects the majority of adults, or at least the majority of those who have come to technology since adulthood, why should administrators in school districts be any different (Hanna et al., 1994). The only difference may in fact be that many school administrators are very uncomfortable admitting their mystification at technology.

James A. Bates (2000), professor of business information systems at DeVry Institute in North Brunswick, New Jersey, talks a great deal in his courses about cyberphobia. Cyberphobia is simply a fear of computers. According to Bates, the only cure for this Adisease@s computer competency. Discerning the perceptions and attitudes of building-level administrators toward computers would be an excellent starting point for developing a prescriptive program to cure this ailment in West Virginia. One way to reveal these perceptions would be through a series of questions which referred to such items as how useful the administrator feels that computers can be as well as a rating of their perceived importance in educational administration.

\section{Three Individual Leadership Outcomes}

The Multifactor Leadership Questionnaire (MLQ) measures three categories of leadership factors (Bass \& Avolio, 1994). These categories include transformational leadership, transactional leadership, and non-transactional leadership. The MLQ also measures three outcomes of leadership which are extra effort, effectiveness, and satisfaction. The Multifactor Leadership Questionnaire can be given to the leader himself/herself or to individuals who are working in a position which falls under the leader chain of command. While the specific 
leadership style employed by a building-level administrator may not be specifically tied to computer usage, the outcomes of his/her leadership may be.

First of all, extra effort is defined by Bass and Avolio (1994) as getting others to do more than they expected to do, heightening others=flesire to succeed, and increasing others =willingness to try harder. Effectiveness, while meaning many things to many people, is defined by Bass and Avolio as the success of an individual in meeting others job-related needs, representing their group to higher authority, meeting organizational requirements, and leading a group that is itself effective. Finally, satisfaction examines whether or not the methods of leadership being used are satisfying and whether or not the individual is working with others in a satisfactory way. This study examined each principal sindividual perception of the outcomes of his/her leadership and the relationships that existed between the frequency of computer usage.

The reliability of the questionnaire items has been tested. One test examined the factor loadings of indicators on latent variables (Avolio, Bass \& Jung, 1995). Fornell and Larcker (1981) suggest that factor loadings should exceed .70, since this implies that less than half of the indicators $=$ variance is due to error. This .70 minimum requirement is also more stringent than some criteria required in traditional factor analytic methods (Avolio et al., 1995). Each composite scale has also been tested by performing a variable composite scale reliability computation, which is a measure of internal consistency similar to Cronbach $₹$ alpha. Fornell and Larcker (1981) recommend using a reliability cut-off of .70. It should also be noted that the MLQ has been utilized for measuring leadership constructs since 1985 (Avolio et al., 1995). 


\section{Demographic Data}

A 1996 study by Benson in Washoe County School District in Nevada examined the relationship that certain demographic variables have with the frequency of computer usage. Benson discovered some interesting results. The demographic items on Benson (1996) survey included age, gender, years of administrative experience, current school assignment, position, and school enrollment. Benson found that the more experienced administrators were less likely to use personal productivity applications. It was also revealed that school administrators used word processing applications for administrative purposes more frequently if they had at least one of the following characteristics present: a computer in the home, previous computer experience, were female, younger, or had fewer years of administrative experience. Since the population of this study was confined to one school district, it seems appropriate to determine if these same relationships hold true for a larger population.

West Virginia is divided into eight Regional Educational Service Agencies or RESAs (West Virginia Department of Education, 2000). These agencies are responsible for the West Virginia Education Information System (WVEIS) in their eight respective service area. WVEIS was created by the West Virginia Legislature in August 1990 (West Virginia Department of Education, 2000). WVEIS is a management information system for school and administrative record keeping and processing. School applications supported by WVEIS and each Regional Educational Service Agency include student record maintenance, course scheduling, attendance accounting, and grading. Additional applications are developed for special needs as they arise. As a regional agency, each of the RESAs in the past has also served as a center for computer and software training. Hence, the building-level administrator location, in terms of a specific RESA 
service area, may have some relationship with the frequency of computer usage engaged in by each school principal.

\section{Statement of the Problem}

In their argument for reinventing Education, Lou Gerstner and his colleagues in a school reform effort claim that nothing matters more for the future of U.S. schools than finding great principals to lead them (Gerstner, Semerad, Doyle, \& Johnston, 1994). The role of the school principal is increasingly being cited as the keystone of educational reform. It is not, however, the solitary, authoritative role of times past, but that of a dynamic change agent within an interactive system (Kaufman, 1997).

The principalship requires individuals who are flexible and credible, who inspire and respect others, and who can provide useful learning opportunities for teachers as well as students in schools. It is a position that requires school administrators to re-examine themselves and their organizations as society rethinks the important business of teaching and learning (Kaufman, 1997).

The purpose of this study was to determine the frequency with which building-level administrators, principals, in West Virginia use office productivity software to complete their management tasks of organizing information, communicating, making presentations, and preparing budgets. Further, this study examined the relationships between specific computer usage by building-level administrators and the independent variables in the category of general computer usage, the category of computer training received, perceptions and attitudes of computer usage, three different individual leadership outcomes, and demographic data. By gaining a better understanding of the general computer usage of building-level administrators, 
effective training programs can be designed to enhance the leadership roles of the school

principal. Administrators, supervisors, directors, and program coordinators at the West Virginia

Department of Education will be able to use the information found through this study to assist

administrators in becoming more effective leaders within their respective schools. More effective

leaders will lead to more effective schools. Further, the technologically literate principal will be

better equipped to take on a more active role in the technological advancements at his/her

respective school.

\section{Research Questions}

This study was designed to answer the following research questions:

Q1. What is the current frequency of specific computer applications usage by building-level administrators in West Virginia for the management function of organizing information, communicating, making presentations, and preparing budgets?

Q2. What is the relationship, if any, between the frequency of specific computer applications usage by building-level administrators in West Virginia and these building-level administrators' having a computer in their home?

Q3. What is the relationship, if any, between the frequency of specific computer applications usage by building-level administrators in West Virginia and the building-level administrators' usage of previous software platforms/operating systems?

Q4. What is the relationship, if any, between the frequency of specific computer applications usage by building-level administrators in West Virginia and the number of years these building-level administrators have used a personal computer?

Q5. What is the relationship, if any, between the frequency of specific computer applications usage by building-level administrators in West Virginia and the building-level administrators' previous usage of application software at home?

Q6. What is the relationship, if any, between the frequency of specific computer applications usage by building-level administrators in West Virginia and the types of computer training received by theses administrators?

Q7. What is the relationship, if any, between the frequency of specific computer applications 
usage by building-level administrators in West Virginia and the specific computer applications for which these administrators have received training within the last year?

Q8. What is the relationship, if any, between the frequency of specific computer applications usage by building-level administrators in West Virginia and the amount of computer training received by these administrators within the last year?

Q9. What is the relationship, if any, between the frequency of specific computer applications usage by building-level administrators in West Virginia and the perceptions and attitudes of these administrators toward technology?

Q10. What is the relationship, if any, between the frequency of specific computer applications usage by building-level administrators in West Virginia and the perception of the individual leadership outcome of extra effort expressed by these administrators?

Q11. What is the relationship, if any, between the frequency of specific computer applications usage by building-level administrators in West Virginia and the perception of the individual leadership outcome of effectiveness expressed by these administrators?

Q12. What is the relationship, if any, between the frequency of specific computer applications usage by building-level administrators in West Virginia and the perception of the individual leadership outcome of satisfaction expressed by these administrators?

Q13. What demographic characteristics are predictors for the frequency of specific computer applications usage by building-level administrators in West Virginia for the management functions of organizing information, communicating, making presentations, and preparing budgets?

\section{Operational Definitions}

Building-Level Administrator BResponse to survey question indicating elementary, middle/junior high, high school, or vocational school principalship in West Virginia.

Specific Computer Applications Usage BResponses to survey questions about the frequency of usage of office productivity software in performing the management tasks of organizing information, communicating, making presentations, and preparing budgets by West Virginia principals.

General Computer Use B Responses to four survey questions, each representing independent variables, which determine if the West Virginia principal has a computer in his/her home, the types of computers previously used by the West Virginia principal, the number of years of personal computer use by the West Virginia principal, and the types of software previously used at home by the West Virginia principal. 
Computer Training BResponses to three survey questions, each representing independent variables about the types of computer training received, the specific computer application training received within the last year, and the amount of computer training received within the last year by each West Virginia building-level administrator.

Perceptions and Attitudes Toward Technology B Responses to nine Likert-type survey questions by each West Virginia building-level administrator indicating attitudes toward computer usage and technology.

Individual Leadership Outcomes -- Responses to nine Likert-type survey questions by each West Virginia building-level administrator concerning extra effort, effectiveness, and satisfaction.

Extra Effort B Average of three responses by a building-level administrator in West Virginia on a leadership questionnaire to three statements concerning extra effort as an individual outcome of leadership.

Effectiveness B Average of four responses by a building-level administrator in West Virginia on a leadership questionnaire to four statements concerning effectiveness as an individual outcome of leadership.

Satisfaction B Average of two responses by a building-level administrator in West Virginia on a leadership questionnaire to two statements concerning satisfaction as an individual outcome of leadership.

Demographic Characteristics BResponses to twelve survey questions by each West Virginia building-level administrator concerning gender, age, ethnicity, education level, previous teaching experience, years of administrative experience, current school assignment, years at present site, approximate student enrollment at present site, number of professional staff at present site, number of classified staff at current site, and Regional Educational Service Agency (RESA) location.

Significance of the Study

Management processes of planning, organizing, directing, and motivating are vital to schools and industries alike. In fact, new demands are being placed upon school principals as a consequence of the expanding research on effective schools and the reports from national commissions which point to educational management as an important key to successful schools (Miller, 1983). The growing research base on effective schools highlights the principal as the key 
to success (Brennan, 1997; Miller, 1983; Rockman \& Sloan, 1993). As a result, more attention is being paid to the development of a wider variety of training approaches for education administrators (Donatucci, 1995; Miller, 1983).

Much of a manager's job is devoted to planning and organizing. If principals could see how much of the tedium of these tasks could be relieved through technology, a greater desire to make use of the computer as a management tool might be created. In planning purchases, scheduling, organizing budgets, and retrieving specific student information, principals could utilize technology applications to make better use of their time. When time is allocated more efficiently, principals will be permitted to spend more time in the roles and functions which provide greater personal satisfaction and institution-wide benefits. Both spreadsheet applications and database programs would allow a principal to computerize much of the routine planning and organizing required by a building-level administrator.

The time-saving features of technology would further allow the principal to devote more time to human-relations activities. While planning and organizing are important, the roles of directing and motivating others are also paramount. The use of technology, while not directly helpful in human-relations matters, can free up time to allow the principal to give personal attention to these areas. Hersey and Blanchard believe that individuals always need a certain amount of both task direction and relationship intervention in performing their job functions (Northouse, 1997). An effective manager is able to assess these needs and make a commitment to their fulfillment. This further implies that a manager must make the most of time resources so that human relation skills can be optimized. Technology, when used effectively, can free up this scarce resource. 
This study determined the frequency with which building-level administrators in West Virginia used office productivity software to complete their management tasks. Furthermore, through examining the relationships of leadership variables with the specific computer applications usage by building-level administrators in West Virginia, training opportunities could be prescribed which could increase the effectiveness of school principals. Many principals today do not fully understand the usage of all of the components of software packages and database systems (Donatucci, 1995). This fact means that those principals who lack knowledge and skills in office productivity software are not being as effective as they could be. One answer to this problem would involve training by fellow administrators who are using technology effectively (Donatucci, 1995). To develop administrators who are comfortable and innovative with technology, more effective training is needed (Dede, 1997; Kaufman, 1997). While part of this training could be in a group setting, a significant amount should take place administrator to administrator in a real school setting with a technology savvy principal working with a less technology oriented administrator (Donatucci, 1995). In a setting such as this, the principal with less technology orientation could see the on-going, spontaneous use of technology by an experienced practitioner. The information gleaned from this study could be used to prioritize building-level administrator training needs at the state or regional level. By highlighting areas of strength and weakness in administrative uses of technology, the West Virginia Department of Education and Regional Educational Service Agencies (RESAs) would be better able to serve the 
technology training needs of building-level administrators. The identification of variables which have a strong correlation to specific computer applications usage would make training efforts such as peer coaching more viable by allowing these agencies to correctly pair administrators in training activities. By allowing school administrators to become more effective leaders through greater technology usage, the West Virginia Department of Education and local RESAs would be indirectly impacting the effectiveness of West Virginia schools.

As administrators participate in staff development activities related to technology, they should anticipate increased independence in performing administrative tasks, more cooperative work with building computer committees, better communication with district technology coordinators, and more satisfaction with the efficiency of school operations. As informed advocates of computer usage and more effective managers of computer-literate students and teachers, administrators can expect an additional benefit--increased credibility with their school faculties (Hancock, 1990).

Rees (1987) conducted a study using a questionnaire asking Ontario secondary school principals to investigate the ways in which educational administrators, as planners, can use the computer. As a part of this study, Rees also examined the reasons administrators were not using computers. The most common reason given for not using computers was a lack of human, fiscal, capital, time, information, and expertise resources. There is, however, a paucity of research on variables associated with computer usage by building-level administrators.

Furthermore, West Virginia Regional Educational Service Agencies will be able to work in conjunction with the West Virginia Department of Education to offer the appropriate computer training to practicing administrators. By being able to find variables that relate to the frequency 
of computer usage, the training and staff development needs of building-level administrators can be better met through prioritization of need. Further, a more efficient allocation of available staff development funds and resources for leader training can be achieved.

\section{Limitations and Assumptions}

This study sought to determine the frequency of specific computer usage applications by building-level administrators and the relationships between specific computer applications usage by building-level administrators in West Virginia and the variables within the category of general computer usage, variables within the category of computer training, perceptions and attitudes toward technology, three individual leadership outcomes, and certain demographic data. In order for the results of this research to be generalizable, the researcher attempted to eliminate the reactive or interaction effect of testing and the interaction effects of selection biases and the experimental variable by choosing to survey all principals in West Virginia (Campbell \& Stanley, 1963). Kerlinger (1964) believes that a good rule for research is to use as large a sample as possible. While controls have been utilized for external validity to the extent possible by the researcher, Campbell and Stanley (1963) point out that the question of external validity is never completely answerable. Every attempt was made to systematically and empirically test the relationships under study as scientifically as possible (Kerlinger, 1964).

This study assumed that the building-level administrators in West Virginia responding to the survey instrument answered honestly to the questions posed. Further, it was assumed that the directions for completing the survey instrument were understood by the respondents. 
Summary

The advantages of having technology-competent administrators are many (Donatucci, 1995). Not only will they be more productive and efficient, but they will also be better able to recognize the technology needs of the staff and students (Lauda, 1994). Furthermore, it is difficult for principals to provide support for technology initiatives without appreciating the impact that technology is having and will continue to have on the students we educate (Clark \& Denton, 1998; Dede, 1997; Thomas \& Knezek, 1991). While this study did not directly impact the frequency of specific computer application usage by building-level administrators in West Virginia public schools, it did make useful information available to agencies responsible for building-level administrator staff development.

This study examined the frequency of specific computer application usage by buildinglevel, public school administrators in performing the management tasks of organizing information, communicating, making presentations, and preparing budgets. Relationships to frequency of computer usage were examined for independent variables in the category of general computer use, independent variables in the category of computer training, perceptions and attitudes toward technology, three individual leadership outcomes, and demographic data. The relationships discovered can be utilized by state and regional agencies or training centers in making the most effective use of staff development dollars.

Given the foregoing, as well as the fact that similar studies have been done in the recent past at different locations in the United States (Benson, 1996; Rockman \& Sloan, 1993; Witten et al., 1990), a current picture of computer usage by building-level administrators in West Virginia needed to be drawn. Aside from examining relationships between specific computer application 
usage with selected variables, a portrait of computer usage for completing management roles by building-level administrators in West Virginia was produced. 


\title{
CHAPTER 2
}

\author{
Review of the Literature \\ Building-Level Administrators and Computers
}

\section{Management}

Managers influence all phases of modern organizations (Certo, 2000). Plant managers run manufacturing operations that produce the clothes we wear, the food we eat, and the automobiles we drive. Sales managers maintain a sales force that markets goods. Personnel managers provide organizations with a competent and productive workforce. Our society could neither exist as we know it today nor improve without a steady stream of managers to guide its organizations. Peter Drucker (1969) emphasized this point when he said that effective management is probably the main resource of developed countries and the most needed resource of developing ones. In short, all societies need good managers.

Managers can have the most remarkable effects on organizations. International Business Machines (IBM) floundered through much of the 1980s and early 1990s, losing market share, seeing costs rise, and watching its stock price dwindle from almost $\$ 180$ per share to barely $\$ 50$. Within three years, new chairman Louis Gerstner revamped the company ₹roduct line, dramatically lowered costs, changed the company culture, and oversaw a rise in the firm stock price from $\$ 50$ back to almost $\$ 180$ again (Dessler, 1999). Managerial effects like these do not happen just at giant corporations. Rather, managerial effects take place in any organization where people are formally assigned roles and must work together to achieve stated goals. Thus, 
managers in school systems, such as principals, can influence the effectiveness of their individual schools.

All organizations are ran by managers. A manager is someone who plans, organizes, leads, and controls the people and the work of the organization in such a way that the organization achieves its goals. The four basic functions of planning, organizing, leading, and controlling are known as the management process (Dessler, 1999; Mintzberg, 1975). Planning is setting goals and deciding on courses of action, developing rules and procedures, developing plans, and forecasting. Organizing entails identifying jobs to be done, hiring people to do them, establishing departments, delegating or pushing authority to subordinates, establishing a chain of command, and coordinating the work of the manager subordinates. Leading means influencing other people to get the job done, maintaining morale, molding company culture, and managing conflicts and communication. Controlling is setting standards, comparing actual performance with these standards, and then taking corrective actions as required.

The roles the manager plays in carrying out the four basic processes of management are many. First of all, managers must spend part of their time performing some duties of a ceremonial nature. For example, a sales manager might take an important client to lunch. This type of role is referred to as the figurehead role (Dessler, 1999). Further, every manager must also function as a leader, motivating and encouraging his or her employees. This role is termed the leader role. Managers also spend a great deal of time in contact with people outside their own departments, especially acting as the liaison between their departments and other people within and outside the organization. This managerial role is termed the liaison role. The manager is also often the spokesperson for his or her organization. For example, the supervisor 
may have to keep the plant manager informed about the flow of work through the shop, or the president may make a speech to lobby the local county commissioners for permission to build a new plant on some unused land. This role is the spokesperson role. Finally, managers spend much time negotiating. A first-line supervisor might have to negotiate a settlement to a grievance with the union representative. This role is categorized as the negotiator role.

Today managers face many challenges on top of the daily pressures of supervising a business, organization, or department (Montgomery \& Murphy, 2001; Rue \& Byars, 1992). The workplace keeps changing. Computer technology, mixed with Internet technology, is fueling two trends that already are changing today business environmentBglobalization and mergers (Montgomery \& Murphy, 2001). Globalization is a part of the educational process in today school systems. Students in classrooms in the United States can link to another classroom on the other side of the globe. As for mergers, many school systems have gone to consolidation as a way to enjoy the benefits of economies of scale.

Management has also been defined as the process of coordinating and integrating work activities so that they are completed efficiently and effectively with and through other people (Robbins \& Coulter, 1999). Through management organizational work activities are completed efficiently and effectively. Efficiency is a vital part of management. It refers to the relationship between inputs and outputs (Certo, 2000; Robbins \& Coulter, 1999; Williams, 2000). If an individual can get more output from the given inputs, he/she has increased efficiency. Management is also concerned with completing activities so that organizational goals are attained. This is managerial effectiveness (Certo, 2000; Robbins \& Coulter, 1999; Williams, 2000). Efficiency and effectiveness are related. Management is concerned not only with getting 
activities completed and meeting organizational goals but also with doing so as efficiently as possible. However, it is easier to be effective if one ignores efficiency.

Managers need three basic skills or competencies: technical, human, and conceptual (Rue \& Byars, 1992; Robbins \& Coulter, 1999). Technical skills include knowledge of and proficiency in a certain specialized field, such as engineering, computers, finance, or manufacturing. The ability to work well with other people, both individuals and in a group, is a human skill. Managers must also have the ability to think and to conceptualize about abstract situations. These abilities are conceptual skills.

People in all walks of life have come to recognize the important role that good management plays in society. The study of management provides the body of knowledge that will help individuals to be more effective leaders. The study of management can also give an individual a great deal of insight into the way bosses behave and into the internal activities of organizations.

In current management texts, the study of management is dissected into two distinct areas: the old concept of management and the new concept of management (DuBrin, 2000). The old manager thought of himself/herself as manager or boss whereas the new manager thinks of himself/herself as sponsor, team leader, or internal consultant (DuBrin, 2000; Williams, 2000). The old manager is characterized as following the chain of command, working within a set organizational structure, making most decisions alone, hoarding information, mastering only one discipline, and demanding long hours (Certo, 2000; Dessler, 1999). The new manager deals with anyone necessary to get the job done, changes organizational structures in response to market changes, invites others to join in decision making, shares information, tries to master a broad 
array of managerial discipline, and demands results (Certo, 2000; DuBrin, 2000; Williams, 2000).

Management is the force that makes things happen. It pulls together resources to get important objectives accomplished.

Principalship Roles and Tasks

The role of the school principal is increasingly being cited as the keystone of educational reform (Kaufman, 1997). It is not, however, the solitary, authoritative role of times past, but that of a dynamic change agent within an interactive system. The principalship requires individuals who are flexible and credible, who inspire and respect others, and who can provide useful learning opportunities for teachers as well as students in schools. It is a position that requires school administrators to re-examine themselves and their organizations as society rethinks the important business of teaching and learning.

Leadership is moving people to action and keeping that action moving (Fileto \& Hoopes, 1997). Leadership requires the understanding that motion means chaos, but that even chaos involves intrinsic patterns that administrators can use to create order. Implementing change is probably one of the most difficult tasks of a school administrator. Organizing chaos/change into order seems impossible at times for a single administrator. It follows then that educational leaders need to create fractal cycles of change, patterns that replicate themselves, from the top of the organization down to the classroom. Principals must also consider the functions they are managing: planning, organizing and staffing, leading, and controlling. Leaders need to be identified throughout the organization who will filter the change cycle into the classroom via their managerial functions. The first step in implementing any change in the school setting is to 
identify areas of interest among school staff members. Listening is key in this step. Second, once one has identified which staff members are the initiators of ideas or concerns and serve as leaders within the school he/she must stimulate their areas of interest further. Finally, the administrator can use individual interests to form working committees to look for solutions to problems or to capitalize on available opportunities. The principal must use his/her organizing and staffing expertise to make these steps work effectively. It is the role of the administrator to initiate the win-win cycle of shared leadership in which others are empowered to mold the chaos around them into a manageable order. This pattern of leadership can also replicate itself in the classroom, as students learn how to identify supporters for issues and areas in need of reform and learn to stimulate interests into action. This pattern would also strengthen the principal frole as instructional leader since his/her actions would filter down into individual classrooms.

If technology is to be integrated into the school curriculum, the meaning of educational leadership and the role of the school principal within a technological paradigm must be redefined, especially in terms of the managerial functions of the principal which included planning, organizing and staffing, leading, and controlling (Bennett, 1996). Today students will have to compete in a complex global economy. The private sector demands a technologically literate, skilled work force to remain competitive in the world marketplace. Principals are among those who have elected to take a leadership role in educational reform measures that will lead to more effective schools. Principals cannot succeed, however, by using management and leadership strategies that do not support the integration of information technology into classroom and administrative practices. Today administrators must be knowledgeable users of technology themselves and effective managers of technology in their schools. A principal must at least be 
well-versed in technological terminology to lead a school in the computer/information technology arena. Unfortunately, studies have shown that the majority of principals have not had firsthand experience using technology in the classroom nor was technology training part of their teacher or administrator program. As a result, many find themselves facing technology challenges for which they are not prepared.

An intensive body of research suggests that principals=lecision making and actions fall into five essential categories (Bennett, 1996). These categories include defining and communicating a mission, managing curriculum and instruction, training and evaluating teachers, monitoring student progress, and promoting an effective instructional climate. An essential sixth category, managing technology, should be included to define these broad levels of organization. All six of these categories fall within the power of a principal in planning, organizing and staffing, leading, and controlling. In order to provide leadership in any area, be it staffing or technology, an administrator must possess a good knowledge base in order to be effective.

Teachers and administrators use computer and information technologies to improve their roles in the educational process (Kosakowski, 1998). Teachers and administrators use computer tools in their controlling functions to streamline record keeping and administrative tasks, thereby helping to free up time for instruction or professional development which are staffing issues.

Decreased isolation by using e-mail and the Internet to communicate with colleagues, parents, and the outside world is another benefit of technology to teachers and administrators. Also, technology increases professional development activities by allowing distance education courses, accessing educational research, and accessing classroom materials such as lesson plans. 
There are several factors which have been observed in successful, technology-rich schools (Kosakowski, 1998). These include evidence of a detailed technology plan, teacher training and continuing education, support from administration, support from the community, and support from government. These factors suggest that to succeed, technology, like any educational tool, cannot exist in isolation but must be made an integral part of the entire instructional process and must be incorporated into the managerial roles of the educational leader or administrator. To be effective, technology cannot exist in a vacuum but must become part of the whole educational environment.

Experts say there is a link between administrators $\Rightarrow$ ability to make informed technology decisions and their personal use of technology (Trotter, 1997). Craig Richards, a professor in the graduate program for school administrators at Teachers College, Columbia University in New York City, believes that only 5 percent of principals nationwide are fluent in the basics of word processing, spreadsheets, and presentation software. Richards believes that principals on average are 50 years old. This means that there is a generation of people who are actually barriers to the infusion of technology in school systems and are afraid of it themselves. To boost administrators $=$ skills, some districts in Missouri have required administrators to attend computer survival courses. Technology is now available to connect people in different ways and align them to a purpose and support them in a way that is sustainable. Such connections include everything from telephones and e-mail to central databases that store the accumulated expertise of school staff. New technological capabilities will require administrators to adopt new ways of managing. Trotter (1997) points out that one cannot simply sew a piece of new cloth onto an old garment. Effective schools have strong leadership in that their principal is instrumental in setting 
the tone of the school, helping decide on instructional strategies, and organizing and distributing the schools $=$ esources through planning, organizing and staffing, leading, and controlling (Edmonds, 1979).

Streatfield and Thompson reported on a 1983 survey which was conducted in England and Wales by the Education Management Information Exchange (EMIE). The Society of Education Officers Industry Committee (SEOIC) of England and Wales, following this study, examined the widespread administrative use of computers and related technology in Local Education Authorities (LEA₹). In England and Wales, the importance of information in the management of any service is widely recognized, and the application of information technology to educational administration is an issue that has been of concern to the Society of Education Officers for some years. The results of the survey showed that 80 percent of the LEAs reported that computers were being used for administrative purposes in schools. This sort of activity was less often found in metropolitan boroughs (66 percent) than in non-metropolitan counties ( 86 percent). However, less than 10 percent had formal plans for the use of administrative technology. Streatfield and Thompson pointed out that it was disturbing that such a new administrative tool was being introduced more or less haphazardly in many LEAs without administrators utilizing their planning functions and responsibilities. Similar findings were reported in a study of Kentucky school administrators in 1990 (Witten et al.). The administrative applications that were most frequently reported as being tied to microcomputer use were school timetabling or option blocks, school curriculum analysis, school roll information, pupil projections, and school examination results. The overall trends from this survey were apparent. LEAs, and particularly those in nonmetropolitan counties, were rapidly introducing computer 
based technology to support their basic administration at a time when staff and resources were severely restricted. Attention has already been drawn to the shift away from exclusive emphasis on financial administration systems and to the growing interest in better people records, as well as in the potential scope of computer-based systems as an aid to management decision making which is at the end result of managerial functions and duties.

The development of high performance computing and communications is creating new media, such as the World Wide Web and virtual realities (Dede, 1997). In turn, these new media enable new types of messages and experiences. For example, interpersonal interactions in immersive, synthetic environments lead to the formation of virtual communities. The innovative kinds of pedagogy empowered by these emerging media, messages, and experiences are driving a transformation of traditional teaching and leading by telling to an alternative paradigm called distributed learning. Emerging forms of distributed communication and learning are empowering the reconceptualization of K-12 education mission, process, and content. This new paradigm is based both on shifts in what learners as individuals need to be prepared for the future and on additional capabilities information technology is adding to the pedagogical repertoire of teachers and administrators. Information technology can make school administration and management more effective, freeing time and resources to enhance student learning. Beyond these gains in efficiency, major changes in current organizational practices, like block scheduling, are necessary to attain the full benefits of technology-enhanced learning. Administrators must master not only how to use information technology to make existing organizational practices more efficient, but also how to create and sustain innovative institutional processes that support new models of teaching. This is part of the administrator controlling 
function in that the leader must budget time, money, staffing, and other precious resources in order to reach maximum potential. Further, administrators must develop mechanisms to evaluate the effectiveness of information technology in accomplishing instructional and administrative goals and must establish comparative guidelines for allocating resources to technology among competing priorities.

In 1994, a study was conducted in the state of California which investigated changes in technology use in this state special education programs between the late 1980s and mid-1990s (Lewis, 1997). Administrators of special education programs were one of the groups which took part in this study. In this 1994 study, replies were received from 149 administrators which represented a return rate of 51 percent. Results of this study suggest that computers and other technologies are more available today and used more often by administrators, teachers, and students in special education programs. One month after sending reminders to administrators to complete the survey, postcards were sent to these individuals so that non-respondents could indicate their reasons for not replying to this technology-based survey. The most common reason selected was $A$ don $¥$ have the time@ Only one administrator chose $A \mp n$ not interested in technology@ The results of this study indicated that 75 percent of administrators owned home computers. This number had increased from 40 percent in a similar study in 1987 . The 1994 study also showed that eighty percent of special education administrators had computers in their offices and that they spent an average of 7.8 hours per week on the computer. The reported number of hours per week had also increased from the similar study of 1987 by 4.4 hours. It was found that special education administrators used word processing programs most often and that the second most used program by this group was database software. 
Research has also been conducted into education administration training and certification programs. A questionnaire survey study was conducted by House in Ohio in 1989. Institutions offering degrees in education administration were surveyed (House, 1989). The results of this survey indicated ten primary assumptions that schools of educational leadership hold about technology:

1. Instructional applications is not considered part of the definition for administrative computer literacy.

2. Students will learn the computer skills needed to be effective on their own. Graduate students will enter educational administration programs with greater proficiency than the faculty.

3. Educational administration faculty members have sufficient expertise to integrate computer learning activities into their coursework.

4. Sufficient computing resources are available both in institutions of higher education and in school administrators $\Rightarrow$ ffices to support state-of-the-art training and practice.

5. Computer skills are computer skills. Administrators-in-training can learn generic computer skills somewhere besides the educational administration program and make the needed transfer of computer skills to administrative functions on their own.

6. It is legitimate to award graduate credit for a computing course of either or all of these degree levels: master₹, specialist₹, or doctoral. 
7. Acquisition of computer skills by administrators will improve their performance.

8. It is not necessary to require administration students to analyze the social and political aspects of computer use within the school.

9. Administrators will save time by using the computer.

10. Administrators need no special training to benefit by the greater flow of information produced by computer technology (p. 5).

Several recommendations were made with regard to the training of education administration students. Ideally, students $=$ computer knowledge and skills should be assessed upon their entry into the educational administration program. These assessment results should be used to place students into one of three groups. The first group would be comprised of computer novices, those with little or no computer knowledge or skills. The second group should contain students who have little anxiety about computer learning and minimal keyboarding skills. The remaining students should be able to demonstrate competency in the use of applications software, possibly through an independent study course. Overall, the results of this questionnaire survey report the need for a more formalized effort toward computer education in education administration programs.

Today, most administrators gain their technology experience through self-instruction, vendors, school personnel, consultants, or external courses (Ritchie, 1996). Basic technology skills will remain essential for administrators who want to assume a technology leadership role. Administrators with limited technology experience often need support to deal with new technologies. Hands-on practice time, a low-risk environment, individualized instruction or 
small group projects, and instruction based on a variety of learning styles should be offered whenever possible. Further, administrators should learn their skills in context, with applications learned in the role they will be employed in the school.

Administrators need to become productive in technology usage with emphasis on their roles as planner, organizer and staffer, leader, and controller. Activities may begin with administrative duties such as budgets, memoranda, and strategic plans, and advance to technology-related activities in which staff inservice training, technology plans, or technologybased grant applications are generated (Ritchie, 1996). Other technology skills and knowledge appropriate for administrators include an understanding of computer platforms or operating systems, the creation and use of a local or wide area network, Internet access and service providers, physical and electrical configuration of classrooms and labs, deployment of technology resources in a school, classroom software applications based on learning objectives, compatibility of software and computer systems, ergonomic concerns of lighting, furniture, and radiation, emerging technologies, and security for technologyBincluding physical theft, viruses, and network break-ins. Technology courses for education administration candidates should explore all of these topics. As administrators improve their technology skills and their conceptual knowledge of how technologies can restructure education, a final step to infusing these forces into the curriculum is for the administration to mobilize the educational community, especially through motivational skills.

School administrators and teachers are increasingly relying on sophisticated technology systems to provide support and service in completing their daily tasks in schools (Clark \& Denton, 1998). A multitude of tasks associated with operating a school has been affected 
dramatically over the past few years as computer and telecommunications technologies have been integrated into the school sinstructional and administrative functions. The Texas Education Agency, in a 1996 report, developed guidelines to be used in the state long-range technology plan. The Texas Education Agency (TEA) said that between 1997 and 2010, schools should integrate planning for technology into all classroom, campus, and district planning. The TEA also said that technology must be integrated into instructional management and administration.

As for the staffing function, school administrators realize the importance of effective staff development programs in enhancing the professional knowledge and skills of personnel to improve classroom instruction (Clark \& Denton, 1998). To effectively implement a staff development program for the school, the principal is responsible for establishing planning committees, discussing the resources and facilities available, recruiting faculty and staff to participate, and reviewing plans and arrangements. Research indicates that effectiveness of staff development programs increases when principals maintain a high profile during training, when the principal involves the faculty in program planning and evaluating post-training performance, and when the principal encourages and arranges for school faculty to serve as trainers and leaders.

\section{History of Computers}

In the Victorian period, the word Acomputer@meant an occupation, one who computes, a calculator or reckoner, or more specifically a person employed to make calculations (CampbellKelly \& Aspray, 1996). This Victorian definition held true into the early twentieth century when the term data processing came into being (Adams, 1982). In manual data processing, the brain, the hands, and simple tools are used to process data. From prehistoric times to the present, 
humans have been involved in the processing of data. The electronic computer of today can be said to combine the roles of the human computer and the human clerk (Campbell-Kelly \& Aspray, 1996).

In 1617, a mathematician from Scotland, named John Napier, invented calculating rods to help people multiply large numbers (Education Service Center Region 20 [ESCR20], 1986). These rods were called Napier Bones and were originally made from bone or ivory. The rods did not actually do the multiplication, but by moving the rods around and reading rows of numbers, a person could compute the product of two large numbers quickly and easily.

The first digital computer used in business was put into place in 1954 (Clark \& White, 1986). Although the first computer was slow compared to today computer, it did make computations automatically and rapidly. While computers and electronic devices were around prior to 1954, they were not practical for an average business or organization to use, both in size and in cost.

While the first computer for practical applications did not appear until 1954, Howard Aiken, in 1944, developed a calculator called the Mark I (Clark \& White, 1986). This device obtained data from punched cards and then made calculations with the aid of mechanical devices. While the Mark I was regarded by some as the first successful computer, it was not an electronic computer since it was mechanically operated.

Dr. John V. Atanasoff, another early pioneer in technology, is given credit for developing the ideas upon which the first electronic computers were based (Clark \& White, 1986). Atanasoff ideas were utilized by Dr. John W. Mauchly and J. Presper Eckert in building and developing a computer for the U.S. Army. This computer was called the Electronic Numerical 
Integrator and Calculator (ENIAC). The ENIAC was invented in 1946 and required thousands of vacuum tubes to operate. Because of the ENIAC size and cost, it was not practical for most organizations as a computation or data compiling tool. It used to be said that a digital watch of the 1970s had approximately the same power as the ENIAC (Campbell-Kelly \& Aspray, 1996).

In 1949, Dr. John von Neumann built the Electronic Delay Storage Automatic Calculator (EDSAC) (Clark \& White, 1986). This electronic computer was the first to use the storedprogram concept. Another computer built at this same time was the Electronic Discrete Variable Automatic Computer (EDVAC). This computer was developed after the EDSAC but also made use of the stored-program concept.

The ENIAC, EDSAC, and EDVAC were primarily used as experimental military machines (Clark \& White, 1986). Following the invention of the ENIAC, Remington Rand bought Eckert and Mauchly company and their latest computer, the UNIVAC I. The first of these computers was sold to the U.S. Census Bureau in 1951. In 1952, CBS television decided to use the UNIVAC computer to predict the outcome of the 1952 presidential election between Eisenhower and Stevenson (ESCR20, 1986). On the night of the election, UNIVAC indicated that Eisenhower would carry 43 states (438 electoral votes) and Stevenson only 5 states (93 electoral votes). However, because most people had predicted this would be a close election, the UNIVAC programmers thought they had made a mistake and did not release UNIVAC prediction. The final election tally was 442 electoral votes for Eisenhower, and 89 for StevensonBonly a few votes off UNIVAC $₹$ prediction.

In 1954, General Electric became the first business to use a computer when they purchased the UNIVAC I (Clark \& White, 1986). This was really the beginning of the era in 
which computers would start being produced for business use because companies like IBM realized that they had to try to stay ahead of competitors in this new market.

All of the early computers are called first-generation computers (Clark \& White, 1986). First generation computers used vacuum tubes for data processing, were very large in size, were very slow by today standards, and required constant maintenance (Campbell-Kelly \& Aspray, 1996). Second-generation computers were first available in the 1950s (Clark \& White, 1986). Improvements in technology brought lower prices to the market. These new computers used transistors rather than vacuum tubes for information processing (Campbell-Kelly \& Aspray, 1996). Third-generation computers brought the use of very small electronic circuits called integrated circuits (Clark \& White, 1986). These electronic circuits replaced the transistors of the previous generation for the processing of information. Fourth-generation computers used very large scale integration (VLSI), which meant that an extremely large number of electronic components could be condensed into each integrated circuit chip (Clark \& White, 1986; Campbell-Kelly \& Aspray, 1996).

By the mid-1960s, data-processing computers for business and commercial use had become well established (Campbell-Kelly \& Aspray, 1996). Commercial computer installation usually means a large, centralized computer manufactured by International Business Machines (IBM) or one of its six competitors. Today, however, when most people think of computing, they think of the personal computer on their desks.

By 1970, it was possible to buy for around $\$ 20,000$ a minicomputer with the power of a 1965 mainframe that had cost ten times as much (Campbell-Kelly \& Aspray, 1996). While 
mainframe computers often filled an entire room, the minicomputer was much smaller because of the introduction of integrated-circuit technology.

The microprocessor was the technology that enabled the onset of the personal computer or PC as it is commonly known today (Campbell-Kelly \& Aspray, 1996). The microprocessor was developed between 1969 and 1971 . While there were several companies inventing this technology, Intel is often looked upon as the most important. In January 1975 the first microprocessor-based computer, the Altair 8800, was announced on the front cover of Popular Electronics. This computer was primarily thought of as a hobbyist machine. The price of this computer was low enough that it could realistically be purchased by an individual. In January of 1980 more computers were built than children were born (ESCR20, 1986). By 1983, there were as many computers in the world as people.

Between 1975 and 1977, the computer was transformed from a hobby machine to a consumer product (Campbell-Kelly \& Aspray, 1996). However, new computer manufacturing firms fell almost as quickly as they rose, and only a few survived beyond the mid-1980s. Apple Computer was the rare exception because it made it into the Fortune 500 and achieved long-term global success. In 1977 Apple, Commodore Business Machines, and Tandy were the three primary vendors of personal computers.

If there can be said to be one moment in time when the personal computer arrived in the public consciousness, then it was the West Coast Computer Faire in April 1977 (Campbell-Kelly \& Aspray, 1996). At this faire, the Apple II and the Commodore PET were launched into the consumer market. While these computers, along with Tandy $₹$ TRS80, were being advertised as machines that would enable the consumer to organize, index, and store data on household 
finance, income taxes, recipes, biorhythms, balance checking account, and even control the home environment, no software was yet available for these functions.

The market of packaged software was developed between 1978 and 1980 with computer games being considered the first of the available offerings (Campbell-Kelly \& Aspray, 1996). The second market for packaged software was for educational programs. Schools and colleges were the first organizations to buy personal computers on a large scale and they required software as an aid in teaching various disciplines. The third market for packaged software was for the business sector. Three generic business applications enabled the personal computer to become an effective business machine: the spreadsheet, the word processor, and the database. The personal computing concept involved applying the processing capabilities of a microcomputer to the processing needs of the individual, and this was done through software (Mandell, 1979).

In education, the computer controls the learning situation in what is known as computerassisted instruction (CAI) (Mandell, 1979). CAI work can be drill work, exercises, remedial or enrichment material, tests, or simply dialogue between the computer and the student. Computers assist in administrative tasks such as student scheduling, counseling, and grade reporting. Using them to score tests is now a fairly routine application, especially in schools with large classes .

Wiring computer stations into a local area network (LAN) is another technological area which has had many benefits for administrators and managers (Mandell, 1979). Computer network users no longer have to worry about backing up filesBsomething few PC owners learned to do faithfully anywayBand they could now exchange files and messages with one another using electronic mail. Also, there was one unanticipated, but very important, thing that users connected to a LAN got in returnBaccess to the Internet. While the LAN is a network that 
connects computers in a limited geographic area, such as a school computer laboratory, business office, or group of adjacent buildings, a wide area network (WAN) is a network that covers a large geographical area, such as one that connects the district offices of a statewide school system or the offices of a national corporation (Shelly, Cashman, Gunter \& Gunter, 1999). Most business chains, corporations, and education systems today are connected to both LANs and WANs through ethernet wiring and communication links established through a local service provider.

The Internet is a worldwide collection of networks that link together millions of businesses, governments, educational institutions, and individuals using modems, telephone lines, and other communications devices and media (Shelly \& Cashman, 1982). The Internet is composed of INTERconnected NETworks (Shelly, Cashman \& Walker, 1997). The Internet has its roots in a networking project of the U.S. Department of Defense Advanced Research Projects Agency (ARPA) (Shelly \& Cashman, 1982). ARPA goal was to build a network that would allow scientists at different locations to share information and collaborate on military and scientific projects that could function even if part of the network were disabled or destroyed by a disaster such as a nuclear war. The ARPANET became functional in 1969 and has since grown from 4 host machines to more than 35 million host computers worldwide. Since 1988, the Internet has doubled in size, and it continues to grow explosively each year.

The transition from an agricultural era to the business and industrial era in the United States was based on low technology and know-how and took place over a long period of time (Groff, 1993). As the U.S. emerged during the business and industrial era, the vocational track was added to the academic track. A general track was added to accommodate students whose 
needs were not met in either the academic or vocational tracks. Major expansion occurred in the 1940s and 1950s in all sectors of the economy, particularly manufacturing and services. Rapid advances in science and technology yielded global competition and modernization at an accelerating rate. Establishments that survived, modernized with new technology in the 1960s and early 1970s. During the late 1970s and the early 1980s, it became apparent that modernization of industrial era establishments was necessary but insufficient. The manufacturing sector establishments that survived modernized several times with contemporary technology and then began to restructure. More important, however, establishments began to recognize the centrality of human resources development committed to total quality and benchmarking standards.

Education in general has lagged behind business and industry in use of computers (Singer \& Phelps, 1982). But since the advent of microcomputers, education has begun to respond to the computer revolution. To reveal the growth of computer usage in education, Singer and Phelps graphed the number and type of computer articles listed in the Education Index for the years 1950, 1960, 1970, and 1980. Only one article occurred in 1960; this article pertained to computer literacy. By 1970, a dramatic change had occurred: 11 articles focused on computer literacy, 118 on computer-assisted instruction, 1 on testing, and 1 on computer-managed instruction. Articles on computer literacy and computer assisted instruction increased in 1980, but the greatest gain was in testing and computer managed instruction (Singer \& Phelps, 1982).

The earlier generations of computers were appropriate only for instructional use, primarily because of their small capacity for the storage of data (Crawford, 1985a). However, microcomputers are now available which equal or surpass the storage capacity of many older, 
full-size computers. In addition, these computers are easier to use and more affordable than ever before. Because of this fact, microcomputers are now available to assist in performing administrative tasks for principals.

Crawford (1985a; 1987) points out that there are three basic steps to follow in deciding which microcomputer to purchase for administrative purposes. The first step is to decide which administrative functions involve tasks that should be computerized and in what order of priority. The school administrator must also identify the microcomputer software that best computerize these tasks (Crawford, 1985a). Finally, the administrator must select the hardware that runs the selected software. Crawford also points out the barriers which exist to getting computers into the administrative functions of school management. Among these are computer phobia, initial hardware cost, level of computer literacy, and security concerns. The selection of a computer for administrative use should receive as much consideration as the selection of a new member of the administrative team.

Crawford (1985a; 1987) has identified four situations which would generally justify the use of a computer, provided that the task to be performed is of high enough priority to computerize at all. These are:

1. When massive amounts of data are processed through well-defined operations.

2. When processing is highly repetitive.

3. When speed of processing is of importance.

4. When the tasks to be performed are not practicable by manual means. (Crawford, 1985a, p. 72) 
The first function of management is planning. Crawford (1985b) points out that within the business field a considerable selection for this function of school administration exists (Crawford, 1985b; Crawford, 1987). Electronic spreadsheets provide a framework for financial, student, and staff projections if an administrator will take the time to learn how to use them. Much of the school administrator time is spent in scheduling and organizing. Scheduling software is available that performs tasks from student locator to full-scale, variable-length-period scheduling of both staff and students (Crawford, 1985b).

All administrators must deal with staff/personnel records to varying degrees. For this administrative task in education, the computer performs the function of a data management system with certification data, skills inventory, inservice education activities, educational training, and personal data (Crawford, 1985b; Crawford, 1987). The school administrator must understand that microcomputers do not solve problems for them; rather they perform tasks (Crawford, 1987).

Crawford (1985b) believes that when looking for the correct software to automate tasks, one should first consider software with general applicability rather than software specifically applicable to the tasks of school administration. General applications software is of three basic types: data management systems, electronic spreadsheet systems, and word processing systems. The newer software also comes with a graphics or presentations module. Having access to software with general applicability will help to ensure that data can be shared among software modules and among other individuals.

Word processing is the writing of new text or the recalling of a previously written text from memory, editing it, and producing it in a final form on paper (Crawford, 1985b). The 
automation of the word processing task with computer software has eliminated the need for messy correction tools and has decreased the amount of time it takes to communicate via printed media. The simplest word processing system allows an individual to type text, correct typographical errors, store the document as it appears on the display, and then automatically print it out in its correct format. Other special functions available with most word processing software of today includes searching, deleting, and replacing text; spell checking; grammar checking; thesaurus tools; and simple desktop publishing functions.

A database is the computer equivalent of a filing cabinet full of information (Crawford, 1985b). One can create a database and store within it any kind of information that may need to be retrieved. The information retrieved can be used to refresh a person $₹$ memory or to generate reports. A good database management system will provide the capability of generating needed reports without programming. The accessibility to different parts of each record stored in a database by people with different needs is an advantage of this software use. Database management software should eliminate the replication of data storage within any organization.

An electronic spreadsheet system handles the kind of data and information that one would normally put in a table with rows and columns and their respective headings (Crawford, 1985b). Most problems that can be solved with a calculator, a pencil, and a sheet of paper could be solved with an electronic spreadsheet system on a microcomputer. The electronic spreadsheet is a matrix of columns and rows, the intersections of which define positions called cells into which one can enter a number, an alphabetic title, or a formula to be calculated. An electronic spreadsheet can be made to look exactly like a school monthly budget or expenditure report. The power of the electronic spreadsheet comes in analyzing situations to see what the outcome 
might be if one of the variables were to change. In an electronic spreadsheet program, an individual can set up what-if situations to help in managerial decision making.

While general applicability software is widely available, vendors do offer specialized software for athletics, attendance accounting, budgeting, financial accounting, food service, grade analysis and reporting, guidance, instructional management, inventory and property records, scheduling, and staff/personnel records (Crawford, 1985a). When general applicability software cannot meet the needs of an individual, one should look to specialized software which can perform these management or administrative tasks. The familiarization of the school administrator with the general applicability software will make the move into specialized software much easier.

School executives are turning to technology to help them get their jobs done (Wall, 1994). For example, Mattheisen is the modern-day principal of Machon Elementary School in Swampscott, Massachusetts. Her productivity arsenal includes database software, electronic mail, computer bulletin boards, desktop publishing, graphics presentation software, two Macintosh computers (one for home, one for the office), a laptop computer, and a cellular telephone for her car. Matthiesen is only one of thousands of school executives who in the past decade have adopted the same word processing, database, spreadsheet, e-mail, presentation, and budget tools used by their counterparts in business. Matthiesen says that she does not think on paper anymore; she says that she thinks on the computer.

The case of Matthiesen (Wall, 1994) is only one of many similar one found across the country. In 1993, there were approximately 435,000 personal computers being used for administrative work. This number represented about 10 percent of all the computers being used 
in K-12 education. Furthermore, tool software was the largest category of non-instructional software K-12 schools planned to purchase during the 1992-93 school year. This all added up to growth in the use of technology productivity tools. Tool software typically includes word processing, spreadsheet, and database programs.

Wall (1994) believes that the new generation of administrators feel more comfortable using technology in the office because many of them used it in the classroom as teachers. According to Wall, school administrators say four applications of technology are growing rapidly. These are organizing information with tools such as database software, communicating with email and bulletin boards, using graphics or multimedia software to make presentations more powerful and visually attractive, and using budget software to plan and track spending, especially as part of a site-based management strategy.

Technology has been moving rapidly into all levels of administrative practice (Cooper, 1989). Business functions, student accounting, and major central office activities have been among the major uses of computers in the schools and still account for much of school districts= core computer use. Today, however, with the wide acceptance of microcomputers and ease of access to mainframe computers, many principals can use a wide array of computer applications to facilitate daily administrative functions. At the same time, other schools lag far behind the technology curve in making optimum use of computers for administrative use. Some schools, while possessing the components for computer use, have only a few people actually using the technology. Few schools are truly using the full potential of computer technology to increase administrative efficiency and to enhance the educational process. 
Further, concern for children well-being is so strong in the school culture today that it makes it almost impossible to have a more total perspective in which the relationships among all technology users can be seen and their interdependence understood (Rhodes, 1997). A few years ago, vendors and many in the educational technology community viewed information technology through a narrow lens. They artificially classified technology first as educational and then within that category as either instructional or administrative. What was missing were the organizational uses. The AASA believes that a growing recognition that the unique nature of system leadership requires connecting tools and processes that could link present actions and results more directly to future visions. These technologies, such as intranets, and processes, such as quality management, could create a sustainable core for the missing infrastructure between visions and actions.

Within a cultural perspective, resource scarcity forces either/or decisions between providing direct services for children or building a continuing capacity within the school system to provide these direct services (Rhodes, 1997). In making that decision, direct services always will win because children are at the center of everyone value system. Expenditures of significant resources for building or reinforcing the infrastructure of knowledge, skills, and capacities that could support the improvement of direct teaching and learning services has not been acceptableBeither by a public that sees it as bureaucracy-building, or by many educators with fundamental commitments to keep children first.

Technology costs in non-school organizations usually are justified by the value technology provides to the overall work of the organization (Rhodes, 1997). Put another way, most organizations believe that the more value that is added by a tool, the less the tool is 
perceived as costly. Value is added in school systems because technology helps support more effective relationships and enables new organizational structures to be created and sustained.

Fortunately, the world outside of schools has provided a significant body of theory and practice focused on bridging internal connectivity gaps as part of daily work (Rhodes, 1997). In the midst of national fascination with the Internet information superhighway, the organizational world discovered that access to all the information one could ever want was not the critical issue. What was needed was knowledge. This knowledge has to be created internally and will become to be known outwardly as the transformed way of conducting business. Building knowledge is the name of the game, and today processes and technologies can break through the isolation that has limited the schools =apacities to improve and grow.

\section{Organizing Information}

Information such as address books; inventories of furniture, textbooks, professional books, and audiovisual equipment; records of students $=$ linic visits and medications; class attendance; birthdays; and yearbook sales are among the information being organized by principals (Wall, 1994). Some principals report that it is easier to leave the PC on all day and check for the information than it is to reach into a drawer for a file. Matthiesen, an elementary principal in Massachusetts, says that every time a student is sent to the office for discipline the student must sit at the computer, double-click the mouse, and pull up their behavior file from the hard drive. Then, she and the student begin updating the discipline file by entering the offense, the cause of the misbehavior, and ways it can be avoided in the future.

Historically, school districts, rather than individual schools, have been responsible for establishing and maintaining information reporting. Today, the concern is how to make records 
more accessible for assisting in decision making (Splittgerber \& Stirzaker, 1984). Much of the information needed at the building-level is similar to that required at the district level. Thus, a systematic method for reporting data which encompasses all needs would increase the efficiency of a school district, if it can be made more accessible for educational planning, programming, budgeting, and evaluation. Furthermore, it is imperative to generate reports that reflect actual needs and indicate what is the best utilization of available resources.

Public school districts, as well as individual schools, should have the capacity to do forecasting in order to better anticipate types of unexpected events that might occur, such as increases or decreases in economic activity, enrollment shifts, and program emphases (Splittgerber \& Stirzaker, 1984). Having access to databases and communication tools would allow buildinglevel administrators to forecast their own individual situations. This would be especially true of an elementary school with a Kindergarten and/or pre-school program. Birth records and age distribution information would be necessary in forecasting projected enrollment which has a direct impact on personnel.

\section{Communicating}

Administrators and teachers alike are increasingly using bulletin boards and e-mail for communication within a school, between central office and schools, and beyond the district (Wall, 1994). Principals can send notices of committee meetings or notes of praise via e-mail. Even if a principal is gone for several days, he/she can connect to the Internet through a hotel phone line and communicate with school staff. In some schools, all staff members send and receive electronic mail as the primary means of communication. This includes teachers, secretaries, and custodians. 
Education is such an isolated profession. In the past, principals have had little contact with other principals in the day-to-day operations of the school. Now, principals can communicate with each other via electronic mail. When a principal faces a new problem, he/she can contact counterparts at other schools to see if this problem has arisen and find out the manner in which it was dealt with at that location (Wall, 1994).

Since the vast majority of conflict situations arise from a breakdown in the communication process, where one individual misunderstands something generated by another, the crucial challenge for leaders lies in avoiding misunderstandings (Lamb, B., Rhinehart, M., \& Still, J., 1996). Leaders must remember, when formulating all sorts of correspondence, that when a sender forms a message and channels this information to a receiver, communication breakdowns occur either through mistakenly encoding and decoding information or through language barriers and cultural differences. Further, leaders must be conscious that written communication lacks the non-verbal cues used in oral communication to refine and interpret the meaning of the message. When the written word is decoded in a way different from its intent, the breakdown often results in an emotional response, conflict, and wasted time. Administrators should consider the intended audience to further define the need for written communication. Finally, writers must pay close attention to the voice they adopt to prevent misinterpretations of the tone of the correspondence. An administrator must remember that the words he/she select and the order of presentation create the voice in the correspondence. The words used in written communication and the order of presentation become what the audience hears through vocal inflection, facial expressions, and body gestures since these cannot be purely observed. 
Making Presentations

More and more school administrators are finding that a personal computer, graphic presentation software, and a projection device make a powerful combination for getting information across to an audience (Wall, 1994). School administrators must often communicate with school board members, fellow administrators, and members of the public. Some school administrators have even begun digitizing images of their schools to use in these presentations. They do this by way of image scanning devices and digital cameras. Some principals believe that the visual imagery created with presentation software makes their presentations more powerful.

An electronic presentation consists of a series of slides (Grauer \& Barber, 1999). The various slides contain different elements, such as text, clip art, and word art, yet the presentation has a consistent look with respect to its overall design and color scheme. Usually, the person designing the presentation supplies the text and supporting elements and the overall formatting is left to the capabilities of the program used. Most of today software allows the inclusion of sounds, music, and video files. If the designer of the presentation has to make a presentation where a computer and projector are not present, the presentation may be printed out for the audience $₹$ use and a copy of the presentation can be supplied on a standard 32 inch high density diskette. Since the software takes care of the formatting of such presentations, the designing and completion of an electronic presentation are made fairly simple.

\section{Preparing Budgets}

Technology also can be a valuable tool for budget preparation and implementation, especially as part of a site-based management strategy (Wall, 1994). Budget preparation programs allow administrators to prepare budgets without ever using paper. A principal can 
access the budget program, change figures, and enter data until everything looks right. Then, once the school board has approved the budget, its implementation is made easier since it can be tracked electronically. A principal can access balances and move funds between accounts.

A spreadsheet is the computerized equivalent of an accountant ledger (Grauer \& Barber, 1999). As with the ledger, it consists of a grid of rows and columns that enables an individual to organize date in a readily understandable format. The greatest feature of a spreadsheet is that after an entry is changed, the spreadsheet will automaticallyBalmost instantlyBrecompute all of the formulas. With a calculator and bottle of correction fluid or a good eraser, the same changes could also be made to the ledger. However, imagine a ledger with hundreds of entries and the time that would be required to make the necessary changes to the ledger by hand. The same spreadsheet will be recomputed by the computer. Also, given the correct input, the computer will not make mistakes. Herein lies the advantage of a spreadsheetBthe ability to make changes, and to have the computer carry out the recalculation faster and more accurately than could be accomplished manually.

\section{Laptop Computers}

If technology-using principals and administrators have a favorite piece of hardware, it is the laptop computer (Wall, 1994). A laptop allows an administrator to be much more productive. Some laptops slip into a docking station at the administrator desk to become a desktop computer, with connections to a large color monitor, full-size keyboard, printers, and file servers. Laptops allow principals to record teacher observations in the classroom rather than waiting to get back to the office to fill out the appropriate forms. With a laptop computer, administrators can work everywhere and anywhere. Travel away from the office can be made more productive, 
especially since laptops can be used while in route on commercial carriers such as airlines and railways.

Administrators are becoming impressed with the speed, neatness, and flexibility that word processing brings to memos, letters, newsletters, and evaluation narratives (Byers, 1991). Instead of entering scrawled notes from teacher observations into the computer, the building-level administrator can electronically record them on the spot. The note-book size unit is very effective for most tasks, including word processing, graphics, forms, databases, directories, and class lists.

There are several advantages to having a laptop computer. First, the machine takes up little space and can be stored in a desk drawer or even on the corner of a principal cluttered desk (Byers, 1991). Another advantage that laptops have over standard units is a battery backup. The laptop battery pack also comes in handy in travel situations. While others try to read or nap on an airplane, the principal can use this time to tap out thank-you notes, proposals, requests, and other communication items. Actually, laptops can help an administrator use time effectively in any waiting situation. The most useful feature of the laptop is its transportability. A school administrator can take the laptop to a classroom, record teacher observations, return to his/her office, edit the evaluation, and print it in final form. Laptop computers are not yet standard equipment in schools. However, the remarkable capability and versatility of these miniature units deserves attention.

$\underline{\text { Needs Assessment }}$

One means of determining the best utilization of computer technology is to develop a comprehensive district-wide needs assessment (Splittgerber \& Stirzaker, 1984). This needs 
assessment would ask what types of administrative information and instructional management needs existed. The needs assessment would also address the scope of computer technology that would be required. This would be represented by an actual number and dollar figure. The needs assessment would help to determine whether or not there was a justification for spending a certain amount of money to gain computer technology equipment and software. The district would also have to consider whether it was going to buy independent microcomputers, interfacing microcomputers tied to a central location, or a central computer with terminals. It is also necessary to determine early the amount of money available to implement computer technology. The resulting set of specifications should become the basis for establishing priorities to purchase computer technology.

The reason that most school offices are still operating roughly the same as they did in the late 1800 s is that few school systems want to bite the bullet and provide all their schools with the microcomputers they need to bring their administrative functions into the $20^{\text {th }}$ century (Frankel, 1987). What school systems often do not realize is how little money truly basic equipment costs. For instance, if one were to open any computer magazine he would find at least 20 sources willing to sell IBM-PC clones along with a letter-quality printer for right approximately $\$ 1,000$. Further, there is nothing that says one has to pay for the whole system at once. Many local leasing operations will finance these purchases over three years. Often, a standard funding cut clause is written into the contract that says if the school board does not appropriate sufficient money to make the payments in future years, then the hardware can be returned at no penalty. In some cases, judiciously placed phone calls or notices in the PTA newsletter may yield a used computer, and the donor a tax write-off worth more than the machine would yield on the open 
market. School systems need to look to their business world counterparts to see that the additional productivity computer systems offer is well worth the cost.

It is about time school administrators became models for computer use rather than tentative proponents (Hancock, 1990). Just as teachers need computer skills to perform their job tasks more effectively, so do school administrators. And just as staff development activities enable teachers to acquire useful computer skills, similar activities provide administrators with the tools and competencies they need to do their jobs more efficiently.

Hancock (1990) says that to become effective computer users, school administrators need at least five basic competencies. First, they should use computers for personal productivity by learning the basic operations of word processing, database, and spreadsheet software. As they become comfortable with these packages, they can issue their own correspondence, create and manipulate name and address lists, and develop and analyze rudimentary budget information. Their competence in these functions leads to autonomy in basic administrative tasks, freeing more time to interact with students, teachers, and parents. Second, Hancock says that administrators should be aware of the many administrative tasks microcomputer can simplify. Third, building administrators should learn to determine appropriate computer applications for their schools. To make these decisions, administrators must understand thoroughly the software applications and the conditions that will affect their success in a particular school. These administrators will further need to assess the costs and benefits for potential electronic applications. Fourth, administrators should be informed enough to select the most appropriate hardware and software to meet their schools fleeds. Administrators must learn to be discriminating consumers as well as skilled computer users. Finally, school leaders should be 
able to develop thorough plans to implement hardware and software features. As an informed advocate of computer use and more effective managers of computer-literate students and teachers, administrators can expect an additional benefitBincreased credibility with their school faculties.

It is recognized that in some quarters the managerial ability of educational administrators trained and experienced in the traditional ways is being questioned (Engel, 1971). One way to become informed is to follow the activities and results of the AASA Commission on Administrative Technology. This special AASA commission has as its objectives to investigate recent developments in administrative technology, determine the feasibility of adapting what has proved to be successful in other fields to school administration, plan and prepare publications on new developments in administrative technology that hold promise of being of help to school administrators, and design vehicles for the dissemination of new insights into administrative technology. Each concerned administrator can strive to remain alert to techniques used by industry, government, and higher education. These are the agencies whose activities and experience will eventually be of greatest influence in bringing about changes in public school practices.

The development of high performance computing and communications is creating new media, such as the World Wide Web and virtual realities which can also be of use to school administrators (Dede, 1995). In turn, these new media enable new types of messages and experiences. For example, interpersonal interactions in immersive, synthetic environments lead to the formation of virtual communities. The global marketplace and the communications and entertainment industries are driving the rapid evolution of high performance computing and 
communications. Regional, national, and global information infrastructures are developing that enhance individuals $\Rightarrow$ abilities to sense and act and learn across barriers of distance and time. Within two decades, the process of building these physical and technical infrastructures will be complete. Many people are still reeling from the first impact of high performance computing and communications, shifting from the challenge of not getting enough information to the new challenge of surviving too much information.

\section{Barriers to Change}

Economic and technical barriers to change, while significant, are not the primary problems (Dede, 1995). By shifting how current resources are allocated, educational institutions can deploy and utilize powerful technologies. According to the 1995 Congressional joint hearing with the Committee on Science and the Committee on Economic and Educational Opportunities, one strategy that must be undertaken is to help groups with sometimes opposing goals (e.g., school administrators, teachers =ınions) to work together toward technology-based educational innovation as a win-win situation. A major barrier to educational change is that, despite the rich lessons learned in many diverse school-based technology projects, no systematic mechanism exists for sharing ideas or providing information on issues as basic as how to design and implement viable projects, what technology and financial options are available, and how to overcome common problems and barriers. All information technologies are more like clothesBto get a benefit, you must make them a part of your personal space, tailored to your needs.

The principal is obviously a key person in the implementation of technology into the everyday operation of a school (Brennan, 1997). Although the principal does not need to become the local expert in technology, he or she does need to provide consistent and positive leadership 
in this area. Leadership begins with being a role model. This means the principal should be a regular user of technology. Whether sending the staff an administrative bulletin on a local area network or using a presentation software program to communicate a point to the school board, the principal must be willing to use the technology at hand. Administrative programs typically are used by office personnel to perform specific tasks of the school office. In addition to general productivity software, these may include financial software or specialized database programs.

The principals who will succeed in transforming schools will be those whose leadership corrals disparate individual interests into a collective movement towards a common vision, and who elevate human performance in the process (Stone, 1992). This type of effective leadership results in followers having respect, trust, and confidence in the leader. The followers also identify with the leaders and the leader vision. Leaders who demonstrate intellectual stimulation support innovative and creative ideas, especially in relation to the followers developing themselves. The transformational picture of the principalship also reflects school reform rhetoric which calls for a new breed of principals who can initiate and advance the changes required for schools to move into the $21^{\text {st }}$ century. These leaders will be able to effect the culture of their schools.

Father Theodore Hesburgh had this to say about vision: AThe very essence of leadership is you have to have a vision. It got to be a vision you articulate clearly and forcefully on every occasion. You can $¥$ blow an uncertain trumpet@Groff, 1993, p. 14). Leadership consists of the processes of intuition, analysis, visioning, communicating and action plan development and implementation. Leadership occurs at the self, team, organizational, community, and societal levels. This matrix becomes the centerpiece for which all learning activity contributes 
increments of growth. The competencies and skills to be developed are conceptual, interactive, and technicalBdirected at applications and outcomes.

\section{Technological Competencies}

Indiana is one state that has begun working upon the competencies of its school administrators. The Principals=Technology Leadership Training Program (PTLT), a collaborative venture of the Center for School Improvement and Performance and the Indiana Principals Leadership Academy, was established in 1990 by the Indiana Department of Education (Rockman \& Sloan, 1993). Each year principals are given four days of professional staff development which includes instructional sessions on computers and an introduction to a variety of software programs and computer hardware. It has, by all reports, served them exceedingly well. In conversations with more than a third of the first two years zlumnae, evaluators heard over and over again that the PTLT program was one of the most personally rewarding and professionally productive programs principals had ever attended. Principals commended a design that took into account the daily pressures under which they work, and agreed that they must be given release time, away from those constant demands, to explore advances in technology. Principals, superintendents, and also technology coordinators saw wisdom in the decision to target principals for the training. Principals must have a solid base of knowledge to draw on, whether they are setting budgets and standards for their schools, implementing system-wide technology plans, or just trying to keep pace with staff and students. All agreed that it was no small accomplishment to train principals whose experience ranged from barely being able to turn a computer on to developing administrative software. By offering something to please everyone, the team made novices comfortable without boring the experts. In many cases, they 
turned computer illiterates into proponents of technology. Principals got hands-on experience. They were allowed to be users and learners.

Principals, as learners, were insecure, frustrated, and lost without creative, reassuring, solid instruction (Rockman \& Sloan, 1993). All those interviewed stressed the importance of continuing PTLT to inform those principals who had not yet had the opportunity and to update the alumnae and keep them aware of innovations in school technology. For principals and superintendents, it has become an agent of change. It has provided a focus for issues not necessarily related to technologyBrelationships among school personnel, equity in school funding, and shared decision-making in school systems. PTLT ties principals into a collegial network that enables them to share information, concerns, talents, and successes. All of these ideas become part of the discussion among participants at PTLT workshops.

In its first three years of operation, the PTLT program has served more than 400 Indiana principals (Rockman \& Sloan, 1993). Principals who do not go to something like this do not know what is going on. Principals are given four days of professional staff development, beginning with a two-day instructional session on computers, with everyone trying to learn the components of Microsoft Works at a minimum. They are introduced to a variety of software programs and computer hardware in a context of collegiality, discussing the utility of each item with others in similar circumstances. Training is also given in the use of digital cameras, scanners, video systems, and portable computers. Software might include instructional programs for all levels of schooling, administrative packages, and specialized school programs. Furthermore, the training program is distributed over the course of a school year so principals have the chance to go back to their schools to practice what they have learned, undertake visits to 
schools that might serve as models for emulation, and learn more of what they want and need to learn.

Leadership and Technology

Views of school leadership are changing largely because of current restructuring initiatives and the demands of the 90s (Liontos, 1993). Advocates for school reform also usually advocate altering power relationships. The problem has been that education leaders have tended to think of leadership as the capacity to take charge and get things done. This view keeps leaders from focusing on the importance of teamwork and comprehensive school improvement. Perhaps it is time to stop thinking of leadership as aggressive action and more as a way of thinkingBabout ourselves, our jobs, and the nature of the educational process. Today sleaders involve staff in collaborative goal setting, reduce teacher isolation, use bureaucratic mechanisms to support cultural changes, share leadership with others by delegating power, and actively communicate the school s norms and beliefs. This would indicate that the principal must influence the culture of a school positively toward technology usage and integration. This heightening of awareness requires a leader with vision, self confidence, and inner strength to argue successfully for what he sees is right or good, not for what is popular or is acceptable according to the established wisdom of the time (Turan \& Sny, 1996). The shifts and major changes which have been shaping the 1980s and 1990s are as follows: from industrial society to information society; from forced technology to high tech/high touch; from national economy to world economy; from short-term to long-term; from centralization to decentralization; from institutional help to self-help; from representative democracy to participatory democracy; from hierarchies to networking; and from 
either/or to multiple choice. These trends have not stopped. These changes have become part of the daily life of organizations and people.

Organizational culture is a pattern of basic assumptions, invented, discovered, or developed by a given group that is the result of coping with problems of external adaption and internal integration that has worked over time, well enough to become valid and therefore taught to the members as the correct way to perceive, think, and feel in relation to these problems (Evans, 1996b). Dealing with technology in any organization, and especially educational institutions, requires coping with problems of adaptation and integration. It is the skilled leader who can lead the technology movement and help others buy into its effectiveness.

Leadership that is proactive in its problem-solving orientation and that values creativity at all organizational levels is essential for increasing its readiness to cope with new changes and opportunities (Evans, 1996b). Currently, there are numerous challenges to our school principals due to the changing education environment, the trends of educational reforms, and the pursuit of multiple school functions in the new century (Cheng, 1997). During the 1980s and 1990s, the society and the education environment have changed very quickly: educational goals became more complex and uncertain; educational tasks became more difficult and demanding; expectations from the public became higher; input quality of students and teachers became more diverse; school accountability to the public became heavier than any time before. All these inevitably became challenges to the leadership of school principals as they pursue school effectiveness and education quality in such a rapidly changing environment. Administrators need to realize that they are part of a service organization, and that to be effective they must serve their constituency well. 
Because of a redefinition of the principalship, principals themselves are faced with a need for new job knowledge and skills, including technology skills (Johnson \& Snyder, 1990). If principals are expected to perform new tasks and accomplish different kinds of performance results from that for which they were trained, their development in a new set of knowledge and skills must become a district priority. If we expect principals to lead effective schools, society owes it to them to provide the necessary knowledge, skills, and support for their success.

Leadership has become more than someone or a processBmore than only exterior change (Slack, 1990). Leadership has become a guide on the path and not a controller of vision. Leadership is then open to many definitions and the gender becomes the guided in a truly emancipatory way.

Part of being an effective leader involves developing a strong school culture (Leithwood, 1992). The culture of a school is based partially around the behavior on the part of the leader that reinforces beliefs, norms and values concerning the primacy of service to students, continuous professional learning, and collaborative problem solving. The principal that actually utilizes technology and seeks professional training in this area does much to improve the culture of the school and is happily keeping abreast of changing trends and new technologies. When principals encourage forms of staff development which acknowledge what can be learned from one immediate colleagues, school culture is strengthened. This usually involves stressing the expertise available within the school.

Leadership does not exist in a vacuum (Pejza, 1994). One has to have a group of people before one can have leadership. One cannot have a leader without followers, or followers without a leader. People tend to think of followers as passive individuals who are not involved 
in decision making. These individuals view followers as sheep, going wherever the shepherd leads them. But in this new view of leadership, a follower is an active participant, not just a spectator. Each member of a group contributes to the goals of the group. The influence which each exerts on the group is part of leadership. One person may eventually be recognized as the leader in a particular situation, but in reality, various members of the community contribute to the process of moving the organization forward. The designation as leader is only a temporary designation. Leadership is shared and transferred between leaders and followers. Leaders and followers become interchangeable. Leadership is change. Without change there is no leadership. Leadership is the antithesis of the status quo. There has to be a change if the vitality and quality of life of the school is to blossom.

Expectations for schools emerging within the foreseeable future demand a different order of response than has been required to most previous reform initiatives (Leithwood, 1993). To meet the needs of a post-bureaucratic era that Leithwood felt was emerging for the year 2000, a new form of leadership would have to be examined. Leithwood surveyed 2,547 teachers and principals in 272 British Columbia elementary schools to gather data. Leithwood first year research indicated that leadership is helpful in building commitment to the kind of restructuring proposed by the new British Columbia educational program which involved a greater reliance on computers and technology for assisting student learning and for increasing administrative effectiveness. This new type of leadership would have to offer a vision of what could be and give a sense of purpose and meaning to those who would share that vision. Leadership for the $21^{\text {st }}$ century must build commitment, enthusiasm, and excitement. It must also create a hope in the future and a belief that the world is knowable, understandable, and manageable. Further, 
Leithwood found that school goals, school culture, and policies and organization were the inschool processes that had the most effect on school restructuring, including a commitment to a greater reliance on computer technology in classrooms and in administrative offices in order to achieve higher levels of quality.

A quality learning environment, whether it is a classroom, a staff meeting, or a citizen advisory group meeting will occur when: each person is acknowledged, included and valued just as he/she is; each person results or accomplishments are recognized; and each person feels like the environment supports his/her autonomy and uniqueness as well as membership in the group or community culture (Sayers, 1978). Culture is sometimes defined as a pattern of basic assumptionsBinvented, discovered or developed by a given group as it learns to cope with its problems of external adaptation and internal integrationBthat has worked well enough to be considered valid and, therefore, to be taught to new members as the correct way to perceive, think and feel in relation to those problems (Ortiz, 1986). The creation of culture requires changes in four different areas: activities, relational patterns, attitudes, and reconceptualization or redefinition of organizational functions. Important changes in institutional attention, structure, and reward do not happen overnight (Ewell, 1985). Gains come about as the result of steady and consistent reform rather than spectacular, short-term actions.

\section{Technology Training and Technophobia}

Rees (1987) conducted a study in 1986 for the purpose of researching activity that was carried out on a sample of Ontario secondary school principals to investigate the ways in which educational administrators, as planners, can use the computer. By means of a questionnaire, data were obtained to describe the current situation, the state-of-the-art, and also to identify a future 
and preferred state of computer usage by Ontario educational practitioners. One in three, or 205, of the secondary school principals was randomly selected to represent each school board in Ontario for inclusion in this study. Each principal, by name, was sent a covering letter explaining the purpose of the research accompanied by a three-page questionnaire in May 1986. The questionnaire was divided into three main sections: one, background information on their own use of computers; two, information on school scheduling procedures; and three, questions on types of information needed by educational administrators that could then be part of the management information system.

Rees (1987) stated that educators are experiencing the negative aspects of stress. This distress of educators is largely attributed to an insufficient amount of time available to accomplish the tasks with which they are charged. Rees is convinced that computer technology will save more than 50 percent of the administrator time and that the administrator will be able to accomplish more tasks in the same time available. By using computer technology, the manager can spend more time in the role of leader, dealing with people and not only paperwork.

Computer training should be applications-based since the computer is supposed to be a tool (Rees, 1987). The time-consuming, routine, and ritualistic tasks which consume the administrator $₹$ day as well as the more sophisticated tasks like resource allocation could be handled by appropriate software. It is believed that such application-based computer training should foster higher cognitive skills by encouraging the generalizing of these skills and fostering a positive attitude towards change and self-improvement. The overall results of this earlier study indicated that a variety of systems were in operation, but the standalone Personal Computers 
(PCs) were clearly in the majority, with a range of functions, and predominantly that of word processing.

School principals must understand the importance of technology for improving school management as well as its implications for improved instruction (MacNeil \& Delafield, 1998). The transformation from industrial age schools into information age schools will not happen without active leadership by the school principal. If schools are to take full advantage of the educational opportunities available through media centers, principals must be knowledgeable concerning their vast potential.

Lifelong learning is a new name for an old idea--human beings with the potential to learn from the day of birth to the day of death (Hanna et al., 1994). With the accelerating transformation fueled by technology, learning can no longer stop with diplomas accepted and certificates earned. It must be carried forward in organized training centers, at our offices, and in the privacy of our homes. In school districts with growing technology resources, it is the adults, from teachers to administrators to secretaries, who need to learn more about technology. Hanna states that administrators need training to become bona-fide computer users.

Fifty-five percent of all Americans are technophobic to some degree (Hanna et al., 1994). Furthermore, one quarter of the adults surveyed had never used a computer, set the timer on their VCRs or programmed stations on their car radios. The frightening fact is that these statistics were gathered in 1994. Even for those who do occasionally use computers, their technology comfort level is narrow indeed. Many know how to use one or two items of technology, but go blank when it comes to learning others or to advancing skills, as in learning a new piece of software. So, if technophobia affects the majority of adults, why should administrators in school 
districts be any different. The only difference may be that many school administrators are very uncomfortable admitting their mystification at technology. Further, too many education business managers have not yet become proficient at using word processing programs, databases, spreadsheet applications, or their own accounting software. Following are reasons provided by school administrators for not being proficient in computer use:

1. My assistant is a computer whiz. I rely on her/him to take care of all computerrelated issues. I am an administrator, not a data input clerk.

2. I have intended to learn to use computers for years, but you have no idea how pressured my schedule is. With the demands of my job, I cannot find the time.

3. The technology keeps changing so fast. Once it settles down, I \# learn it. But I don want to have to re-learn it in six months.

4. When is someone going to write software that meets all my complex needs but is easy for my staff and me to learn?

5. I am planning to take a course on computers ... next year. That is soon enough (Hanna et al., 1994, p. 6).

While there is some kernel of truth in each of these reasons, all can be seen as statements by professionals in denial about their technophobia. It can be unnerving for professionals to admit their techno-ignorance to their staffs, their computer and software vendors, and their superintendents and boards. It is even hard to admit it to themselves. When administrators limit themselves to what they already know about their needs, they are limiting themselves to increasing productivity only by doing more of the same. Once administrators accept that using 
computers confidently, efficiently, and creatively is not a one-shot deal, but an ongoing, lifelong, learning process, they will have taken the first step toward overcoming technophobia and integrating technology with their way of life.

Linking Technology and Leadership

Technology is often cited as a cause for a more impersonal world (MacNeil \& Harmon, 1998). Technology has created speed and efficiency at the cost of personal encounters. Society has been inundated with recorded messages that instruct individuals to press a number to get a certain place, person, or menu. The world is increasingly becoming more impersonal as people become more technologically advanced. MacNeil and Harmon point out that the impersonal side of communication can be avoided in the use of technology if thoughts are planned carefully before going into an e-mail message. The words and phrases a person chooses can tell the receiving party much about the sender. Also, MacNeil and Harmon believe that this is only a temporary problem as the design of see-you-see-me systems are becoming both popular and affordable. For the meantime, these authors indicate that school administrators must remain conscientious about putting the personal touch to a cold, somewhat impersonal mode of communication such as email.

Growing numbers of principals are attempting to focus their energies on two major, interrelated efforts: implementing a systematic school improvement process and developing their own leadership and management skills (Mojkowski, 1986). Principals are looking for levers and switches that will help them form a coherent vision and select appropriate means to actualize it. On the other hand, they must be problem solvers, crisis managers, and resolvers of conflicts. Skeptical of yet another bromide for their already tempestuous situation, some principals derive 
little comfort from technology z promise but view it as just one more innovation to implement. New technology should be a significant impetus and support for accomplishing school improvement and for revitalizing the way principals think about their own work. Mojkowski says that principals need to rethink the very essence of what they do in schools. His thesis is conditioned not on the technology but on principals $\approx$ bilities and commitment to reconceptualize and reshape their roles. Principals must look first at their own needs and those of their schools and then, based on this examination, to technology existing and emerging capabilities. The decisions principals make now about using technology are critical to their growth as leaders and managers and to the improvement of schools.

Some principals are turning to technology, particularly the computer and its ability to automate many of their information processing tasks (Mojkowski, 1986). They are recognizing that information is at the core of both school improvement and effective leadership and management. Despite pockets of innovation, it is still commonplace to leave the computer lab where students are learning computer tool skills and to pass the principal office where the typewriter and three-by-five cards are much in evidence. A strong case can be made for working on both fronts at onceBblending school effectiveness, leadership, and management development into a program for revitalization; and using technology to help get it done.

Principals, more than any other group of educational professionals, will need to use technology appropriately to help bring about the revitalization of education (Mojkowski, 1986). If schools are to become learning organizations, the principal will need to show the way. School effectiveness through leadership will not just happen because technology is used. It will take deliberateness, persistence, and patience to achieve the reconceptualization and revitalization that 
is needed. If principals can move with technology and see it as a tool rather than an appendage, they will encounter substantial opportunities for effective and productive leadership and management. Without such a perspective, principals will fail to realize not only technology potential, but they will fail to realize their own.

Sharman and Cothern (1986) tell principals to take note that if they are not using a computer in their school administrative office, then they are making their jobs harder than they have to be. Although the invasion of computers into the classroom is already well-publicized, computers in administration offices are not as widely discussed. In a survey of Virginia 1,125 elementary school principals, only one-third of those responding said that they used a computer for administrative purposes in 1986. Seventy-four percent of principals using computers reported that they have cut the time spent on office chores by as much as 30 percent. Reduced paperwork was reported by 79 percent of respondents. Of the two-thirds who did not use office computers, 58 percent said that they recognized the need for the machines. Sharman and Cothern point to the lack of funds and poor training opportunities as the reasons for the delay in bringing computers into the office.

Further, computer lessons should be geared to a hands-on, easy-paced approach that emphasizes the practicalBwhat principals need to know to do their jobs (Sharman \& Cothern, 1986). While training programs are now popping up in almost every communityBto meet the demand from business and home usersBSharman and Cothern predict principals will find the problem of training increasingly less troublesome. Sharman and Cothern further believe that principals will not have much choice about using computers in the future. They believe that most 
principals will accept them because they will recognize the potential for increasing productivity and for freeing time to provide the leadership needed in the school environment.

Isherwood (1985) believes that principals should have keyboarding skills, understand word processing, how to construct and report from a database, how to use a spreadsheet to solve financial problems, how to create reports and link them with mail-merge packages, how to create and maintain files on a disk, how to use hardware available in their district, and how to use specific applications programs in use in their schools. Educators preparing themselves for the principalship should have access to training that will assure they have these skills. Principals without these skills should be pursuing them now. Isherwood (p. 6) believes that the APrince@ can work interactively with the school database, generate reports from that database with a few key strokes, print report cards from the database, analyze questions about teacher grading practices, print mailing lists for teachers or groups of teachers, schedule the school from the school office, merge database reports with word processing documents, answer parent questions about student progress or attendance, analyze student attendance over a span of years, reschedule the entire school in mid-year, and analyze teacher attendance patterns. In contrast, the APauper@s left to paper files, hand updating, printing report cards and attendance records on a cyclical basis, and maintaining multiple files for secretaries, counselors, and administrators (p. 7). Based upon a review of administrative applications that lend themselves to computer treatment in schools conducted by a group of principals in a recent course, the following list includes the knowledge and skills that principals should possess: software, word processing, database, spreadsheet, and integrated software. In addition, principals should have knowledge of current school applications, including school scheduling, grade reporting, medical files, transcripts, test 
scoring, inventory, attendance accounting, honor roll, registration, staff attendance, test analysis, and budget fiscal statements. These applications may be derived from the school database, or they may operate from specific software packages.

\section{Computer Invasion in Education}

Because of recent advances in computer technology, the invasion of computers into the school system is a non-debatable fact (Marshall, 1982). For a person concerned with educational administration there is the further reality that the invasion has had, and will continue to have, implications for the practice of educational administration. It has been suggested that information is a basic requirement for good decision-making. What has been seen in the past decade of computer usage, however, is a shift from the question of availability to the question of selection. The amount of permutated and computated information that a computer can spew out to the aspiring decision-maker is almost infinite. School administrators must have the skills to formulate the right questions to get the right answers. The computer term Agarbage-in, garbageout@s most applicable to the information search (p. 7). Marshall studies indicated that microcomputers could handle 80 percent of school management functions in 1982. What was previously a time-sharing function because of centralized computers can now take place inside the school administrator office. As a final point, Marshall says that ignorance of computers will eventually render people as functionally illiterate as ignorance of reading, writing, and arithmetic does today. This point was reiterated by Vacca (1983).

With the microcomputer, the strides in knowledge must become incorporated into the educational scene (Vacca, 1983). If educational technology does not keep pace with the general proliferation of technology advances in our society, we could easily find ourselves in a situation 
analogous to that of the Ancient MarinerBsurrounded by something we need but are unable to utilize. This knowledge advancement must include computer literacy. As far as implementation of technology into school systems, Vacca believes that support must begin and continue at the top with the administrator. Recent research has shown that administrative support is one factor which makes a significant difference in the process of implementation. In schools where the administrator supported the use of computers, they were effectively implemented. Vacca says that research further shows that administrators who had a leadership style of high-task and highrelationship were more effective implementers. These administrators were both people- and task-oriented. Education must move into the information age and this is only possible by using the computer as a tool for the future.

For school administrators the most difficult part of building a bridge to the $21^{\text {st }}$ century is building it with microchips (Crouse, 1997). The personal computer revolution has been going on for the last 15-20 years and shows no signs of abating. In every area, information technology is continuing its rapid transformation of almost all human endeavors. Education is just one of many institutions where the potential of the personal computer has been touted since its inception. Throughout the revolution, education has been slow to embrace the rapid changes brought about by the computer age. Any administrator is wise to be prudent in an area where as soon as you decide to do something, it is on its way to obsolescence. Educational administrators are unsure about making technological decisions, and with good reason. Few administrators have either the expertise or the time to acquire the expertise to plan and implement decisions in this area, but the responsibility is still present be it in the instructional area or in the administrative arena. 
Throughout history new technologies have transformed society (Lauda, 1994). Today, those technologies involve collecting, storing, manipulating, and communicating information, and are limited only by our imagination. In 1985, there were fewer than 300,000 FAX machines in the United States. By 1990, there were five million. This phenomenon will be repeated over and over with the development of new innovations that will transform the transmission and use of information. Technological knowledge describes how the human-built world is designed and created and how people can use it to extend their potential.

\section{Technologically Competent Administrators}

The technology aware principal reads e-mail at the beginning of the work day (Donatucci, 1995). Messages may emanate from many sourcesBschool district bureaucracy, colleagues within and outside the school system, and from locations around the world. A colleague may send a student assessment file that contains text and photos, as well as a movie that demonstrates actual student performance. The principal could also use research articles downloaded from an Internet server. Since this information would most likely be on the school server, it could be accessed by the school staff as well as parents. School administrators need to use fully relational databases for accessing information concerning staff and students on a regular basis. However, many principals today do not understand the usage of all of the components of both software packages and database systems. One answer to this problem would involve training by fellow administrators who are using technology effectively. To develop administrators who are comfortable and innovative with technology, more effective training is needed. While part of this training could be in a group setting, a significant amount should take place administrator to administrator in a real school setting with a technology savvy principal working with a less 
technology-oriented administrator. In this setting, one would be able to see the on-going, spontaneous use of technology by an experienced practitioner. However, the individual administrator must also take the responsibility for his/her own technology development.

The advantages of having technology-competent administrators are many (Donatucci, 1995). Not only will they be more productive and efficient, but they will also be better able to recognize the technology needs of the staff and students. It is difficult for principals to provide support for technology initiatives without appreciating the impact that technology is having and will continue to have on the students they educate.

Reform strategies for upgrading educational administration call for a revised conception of the role of principal as leader and a different mechanism for recruiting and selecting principal candidates (Crow \& Glascock, 1995). Discussions of school reform deal with a variety of factors from organizational components to effects on students outcomes. Crow and Glascock point out that public schools are moving from traditional organizations to emerging entities that recognize lateral rather than vertical interaction of individuals as being the most effective. The school reform movement offers the opportunity to reshape leadership from a traditional, hierarchical style to one where the principal is a leader of leaders. The leader of today schools serves in a nonhierarchical leadership role. He/She solicits and encourages shared decision making, actively involves himself in the learning environment of the school, and does not isolate himself to a management role only.

School leaders of today face the challenge of combining human resources with emerging technologies to reshape our schools (Thomas \& Knezek, 1991). Experts suggest that there is no consensus of the definition of restructured schools. However, Thomas and Knezek found 
through extensive literature reviews that changes occurring in schools involved in restructuring efforts generally fall into five categories:

1. changes in the types of learning experiences provided for students;

2. changes in roles and responsibilities of teachers;

3. changes in the curriculum;

4. changes in organizational leadership and structure; and

5. changes in governance and funding. (p. 266).

Efficient and effective communication supported by system-wide networking form the backbone of effective school systems. The vision of technology as a support tool for productive education is shared across the system, with every professional employee having direct access to the network. Desktop publishing and presentation, forecasting of various aspects of the schooling enterprise, research and peer-assistance capabilities, and the linking of technology-supported instruction with computer-based management of instruction are valuable tools to teachers and administrators alike. Information management tools related to detailed record keeping, data analysis, and report generation provide important support as districts make their case that accomplishments in student performance deserve incentive bonuses of government funds. In the competitive scramble for private and public grant money, schools use information access to stay abreast of funding possibilities, and they use standard publication/presentation technology to prepare grant applications.

The study undertaken by Thomas and Knezek (1991) surveyed school administration, K12 personnel, teacher educators, and members of the educational professional community. While every state was surveyed, responses came only from 35 states. A number of respondents 
regarded the use of technology as absolutely essential in accomplishing the types of high instructional, curricular, and management goals required in schools. Respondents of this survey indicated that word processing, database usage, and access to information are several competencies requiring mastery in every administrative position. Thomas and Knezek pointed out that these competencies should constitute prerequisites for entry into programs leading to any administrative certification or degree.

Technophobia and Techno-Stress

Although we have entered the age of technology, we have not overcome the fear of technology (Stover, 1990). Even with all the new methods and tools now available to educators, a pervasive resistance to change continues to keep innovations from reaching the American classroom. Resistance to change is a natural human tendency. Teachers have a responsibility to tap into its power as a teaching tool. Administrators have a further responsibility to help teachers do this.

In recent years, one of the tools which has been used successfully in the effective management of any business is the computer (Witten et al., 1990). Since schools in Kentucky represent some of the largest businesses in that state, several researchers conducted a survey which focused on the status of the knowledge of secondary school principals regarding computers as well as the extent to which these principals use computers for administrative purposes in their schools. Administrative purchases of the latest technology have lagged behind the private sector counter parts in Kentucky for a variety of reasons. Primarily, school principals 
have adopted the posture that if it works, don fix it. Furthermore, in order to be a successful school administrator, there are other problems which must be overcome:

1. fear of computers or the problems a computer might cause;

2. initial cost of hardware and software;

3. lack of knowledge about what tasks can or cannot be performed by a computer; and

4. security of the methods needed to ensure limited access to data (p. 12).

Witten and other researchers surveyed all secondary principals in Kentucky and received 154 responses. Based on the research, it was found that a majority of secondary principals in the Commonwealth of Kentucky were not using computers to assist them in managing the school in which they work. These principals received little or no formal training in the use of computers. Beyond this, the school system in which they worked did not offer any type of training in the use of computers to help them manage their schools. In a majority of the school systems, there was no centralized computer coordinator to assist the administrators in learning how to use computers. There was also a very evident lack of planning and commitment to computer use in the administrative areas of Kentucky schools. Basically, the data collected led to several conclusions. Kentucky school administrators were in great need of training, preparation, and knowledge regarding the effective use of the computer as a management tool. There was a need to assist the principals in the recognition of the importance of the computer in good management as a personal productivity tool.

As definitions of leadership have emerged, the realities of principals=laily work life require a wide variety of complex tasks involving perpetual cognitive shifts (Hipp, 1997). It is in 
these shifts that principals model what they believe and value and inspire others to achieve excellence by providing meaning and challenge. In contexts where goals are shared and attained, feelings of success occur for students and staff alike. Through their example, principals facilitate teaching and learning through their everyday behavior, and again, convey a sense of certainty that teachers can make a difference.

Smith and Lischin (1986) believe that increased global interdependence will be the dominant feature of the $21^{\text {st }}$ century. This increased relatedness among the world $₹$ culture and nations will require close inter-cultural linkages which are often fragile and full of hazards. If the $21^{\text {st }}$ century is to experience a greater sense of planetary community, rather than increased tensions and conflict, nations will need culturally fluent global leaders. These leaders will work internationally in academic, corporate, government or other settings. According to Smith and Lischin, the culturally fluent leadership is like a pyramid which is built in eight levels. These levels are: understanding self, understanding another cultural reality, guiding concepts, holistic perspective, empathy and communication abilities, technical/professional skills, process skills, and leadership abilities. The sixth level in the development of culturally fluent leadership is the technical and professional knowledge and skills which are traditionally learned in schooling and further updated through continued education and talking with others in one technical fields. Smith and Lischin believe that their pyramid offers a developmental agenda for the different knowledge and skill areas in which the culturally fluent leader must become proficient.

According to Carnine, Miller, and Woodward (1984), there are a few common application programs used by administrators. Word processing is undoubtedly the most popular application program for microcomputers and administrators, but with such popularity comes an extraordinary 
range in pricesBfrom $\$ 50$ to $\$ 500$ Band options. Some programs can be learned in an hour; others require extensive training. A second common application for administrators is the electronic spreadsheet. Like word processing packages, they vary greatly in price. Electronic spreadsheets are good tools for calculating budgets, supply usage, and enrollments, as well as for examining what-if situations. Integrated packages are now available which combine an electronic spreadsheet, a word processor, a database manager, and other applications into one piece of software. Aside from the common applications available, administrators can look to specialty software for attendance, scheduling, and individualized education plan management. The administrator must always determine if the software being considered is going to increase productivity by reducing the amount of time previously taken to do the job manually. With word processing packages, the answer is quite clear. However, some attendance software can actually increase the amount of time taken to determine presences and absences.

New demands are being placed upon school principals as a consequence of the expanding research on effective schools and the reports from national commissions which point to educational management as an important key to successful schools (Miller, 1983). In fact, the growing research base on effective schools highlights the principal as the key to success. The National Commission on Excellence in Education specifically mentions the active leadership role necessary for school principals. As a result, more attention is being paid to the development of a wider variety of training approaches for educational administrators. Management processes of planning, organizing, directing, and motivating are vital to schools and industries alike. 


\section{$\underline{\text { Summary of Earlier Studies }}$}

In 1990, a study was conducted in the state of Kentucky by Witten, Richardson, and Prickett to determine the status of computer use by secondary principals. Data were derived from responses of 154 principals to a statewide survey. Findings in this study indicated that a majority of the principals were uninformed and poorly trained to use computers in the management of their schools. The result of this lack of information and training revealed a situation where computers were, at best, being used haphazardly and inefficiently. There was also a very evident lack of planning and commitment to computer use. Moreover, only 20.78 percent of the respondents had ever received any type of computer training. The results of this study were generalizable only to secondary school principals in Kentucky. No effort was made in this study to include elementary, middle, or junior high school building administrators.

A 1996 study by Benson addressed the problem of the quantification of computer application usage by school building administrators for administrative functions and identification of possible factors related to computer usage by building administrators. Benson chose only to examine building-level administrators in the Washoe County School District, in Reno, Nevada. The population used by Benson in her study consisted of 112 administrators who were attending a district-level staff and training meeting. The Benson study found that 80.4 percent of county building-level administrators used word processing software at least once weekly. However, this study showed a smaller group of building-level administrators using database or spreadsheet software, 42.5 percent and 20.9 percent respectively. Furthermore, 34.5 percent of these administrators used some type of desktop publishing software at least once weekly. Benson found that administrators used word processing applications for administrative 
purposes more frequently if they had at least one of the following characteristics present: a computer in the home, previous computer experience, were female, younger, or had fewer years of administrative experience. However, Benson noted that her small population size made the generalizability of her data limited. 


\section{CHAPTER 3}

\section{Methodology}

The purpose of this study was to determine the frequency with which building-level administrators (principals) in West Virginia public schools used office productivity software to complete their management tasks of organizing information, communicating, making presentations, and preparing budgets. This study also examined variables within the category of general computer usage, variables within the category of computer training, perceptions and attitudes of computer usage, three individual leadership outcomes, and demographic data of the building-level administrators in West Virginia public schools. In addition, the level of use of computer applications in administrative functions by school building administrators was then compared to the variables within general computer usage, variables within computer training, perceptions and attitudes of computer usage, and three individual leadership outcomes to determine any statistically significant relationships. This study also examined demographic characteristics to determine predictors for computer usage of specific software applications. This study was patterned after a 1996 (Benson) study conducted in the Washoe County School District in Reno, Nevada. The Benson study only examined these relationships within one school district of a state whereas the current study examines the entire population of a state. An additional section, Individual Leadership Outcomes, was added to this study as a way of examining another aspect which Benson felt needed to be included in future studies. Benson felt that the impact of the acceptance and use of computer applications might have a relationship with the effectiveness of administrative leadership. Effectiveness of administrative leadership was measured by 
Utilizing part of the Multifactor Leadership Questionnaire Form 5x-Short which looked at the individual leadership outcomes of extra effort, effectiveness, and satisfaction.

Population and Sample

The population consisted of 826 building-level administrators in West Virginia public schools. Of this population, 496 were administrators in elementary schools; 135 were administrators in middle or junior high schools; 121 were administrators in senior high schools; 34 were administrators in vocational/technical centers; 5 were administrators in intermediate schools; 6 were administrators in comprehensive, K-12 schools; 17 were administrators in combined elementary/middle schools; 11 were administrators in alternative schools; and 1 was an administrator in a combined junior/senior high school. This population represented all public schools in each of West Virginia eight Regional Education Service Agency (RESA) districts. Each of the eight RESA districts had from 64 to 156 public schools. All 55 counties in West Virginia were members of one of the eight RESA districts. The population was partitioned into two categories: educational level of the facility managed by the administrator and RESA location in which the administrator functioned. Only primary building-level administrators, principals, were examined in the course of this study. The researcher determined that the minimal level of response for examination of data was 50 percent plus 1 .

The subjects in this study were all 826 public school, building-level administrators in all of West Virginia feight RESA districts. A West Virginia Building-Level Computer Usage Survey 2000 form was mailed to all public school building-level administrators in the state of West Virginia with return postage marked. Five hundred three usable survey forms were returned. This number represented the sample for this study. 
Usable results were defined as West Virginia Building-Level Administrator Computer Usage Survey 2000 forms which were returned in the two-week period specified in the coverletter accompanying the mailed survey form. No random sampling selection process was utilized in that all building-level administrators in the public schools of West Virginia were given the opportunity to complete a computer usage survey form. This sample size was chosen in order to strengthen the reliability of the data gleaned from this research process. One limitation to this approach was that the researcher realized that the return rate would be below 100 percent for the West Virginia Building-Level Administrator Computer Usage Survey 2000 form since there was no requirement that administrators complete this form.

Instrumentation

The West Virginia Building-Level Administrator Computer Usage Survey 2000 instrument was comprised of two parts. The first part of this instrument was adapted from a 1996 (Benson) study conducted in Washoe County School District in Reno, Nevada. The items omitted on the 2000 version of this form included all those questions pertaining specifically to the student accounting software utilized by the Washoe County School District. These items were omitted because administrators in West Virginia use the West Virginia Education Information System (WVEIS) for student accounting functions. A review of WVEIS goes beyond the purview of this study and was therefore not examined.

The first part of this evaluation instrument was comprised of five sections. Section 1 asked the building-level administrator to rate his/her frequency of computer usage of database software for organizing information, word processing and e-mail software for communicating, presentation software and desktop publishing software for making presentations, and electronic 
spreadsheet software for preparing budgets. The second section of this survey instrument asked the administrator to answer four questions about general computer use. Each of these four questions were treated as separate independent variables. Section 3 asked the building-level administrator three questions about the amount and types of computer training received during the last year. Each of these three items were treated as separate independent variables. The fourth section asked nine questions which rated the administrators=perceptions and attitudes toward computer usage in the administrative arena. Demographics were requested in Section 6 and included previous teaching experience and school size information for evaluative purposes. Sections 1, 2, 3, 4, and 6 of the West Virginia Building-Level Administrator Computer Usage Survey 2000 form were adapted from the survey form used by Benson in her 1996 study. Prior to the usage of this instrument by Benson (1996), the survey instrument was read by a panel of experts to review content validity. The Cronbach Alpha in the Statistical Package for the Social Sciences (SPSS) was used to test the reliability of the survey instrument. The Cronbach Alpha procedure, run on the non-demographic items of the survey instrument to determine internal consistency, produced a score of .78 for those items on the Benson instrument. The Cronbach Alpha procedure was utilized to determine the relationship of all items to all other items on this survey instrument and to the survey instrument as a whole (Gay, 1992). The West Virginia Building-Level Administrator Computer Usage Survey 2000 form was read by a panel of experts in West Virginia to establish validity. The Chronback Alpha in the Statistical Package for the Social Sciences (SPSS) Version 10.0 was used for the West Virginia Building-Level Administrator Computer Usage Survey 2000. The results of this analysis produced a score of .78 
which was the same as for the Benson survey instrument. However, the Chronbach Alpha was ran on all data in the West Virginia survey instrument, including the demographic data.

The second part of the West Virginia Building-Level Administrator Computer Usage Survey 2000 was made up of one section--Individual Leadership Outcomes. Section 5 was comprised of 9 questions which measured the respondents $=$ perception of his/her efforts in leading a group. These nine questions were taken from the Multifactor Leadership Questionnaire (MLQ) Form 5x-Short. The portion of the MLQ represented by these nine items measured how often the rater perceived his/her efforts in motivating others to be successful, how effective the rater perceived himself/herself at different levels of the organization, and how satisfied the rater was with his/her methods of working with others (Bass \& Avolio, 1994). Bass and Avolio termed these items extra effort, effectiveness, and satisfaction, respectively. The reliability of questionnaire items for these constructs was assessed by examining the factor loadings of indicators on latent variables, computing a variable composite scale reliability which is a measure of internal consistency similar to Cronbach Alpha, and by examining the average variance extracted by the construct variables from indicators. All three of these constructs exceeded the criterion cut-off of .50 in terms of average variance extracted by the construct variables from indicators. Composite scale reliability indices indicated that all constructs met the minimum cutoff requirement of .70 . Eight of the nine items exceeded criterion for factor loading. The one item that did not was retained, given that the overall scales met or exceeded the cut-offs for reliability of .70 (Bass \& Avolio, 1994). The MLQ has been used for at least 10 years. From 1990 to 1995 , the MLQ was used in approximately 100 theses and doctoral dissertations. 
Of the nine questions taken from the MLQ, three represented the construct extra effort; four represented the construct effectiveness; and two represented the construct satisfaction. These nine items represented 100 percent of the items from the MLQ measuring these three constructs of leadership outcomes. These items were items 37 through 45 of the Multifactor Leadership Questionnaire Form 5x-Short form. These items made up Section 5BIndividual Leadership OutcomesBof the West Virginia Building-Level Administrator Computer Usage Survey 2000 instrument. These items were presented in the same order as the MLQ 5x-Short form. Items 18, 21, 24, and 26 measured the construct effectiveness. Items 19 and 22 measured the construct satisfaction. Items 20, 23, and 25 measured the construct extra effort. More specifically, extra effort determined the frequency with which an administrator was able to get others to do more than they expected to do, the frequency with which the administrator was able to heighten others=lesire to succeed, and the frequency with which the administrator was able to increase others $=$ willingness to try harder. The construct effectiveness examined the frequency with which the administrator saw himself/herself as being effective in meeting others job-related needs, effective in representing their group to higher authority, effective in meeting organizational requirements, and effective in leading a group that was itself effective. Finally, the construct satisfaction determined the frequency with which the administrator saw himself/herself using methods of leadership that were satisfying and working with others in satisfactory ways. The MLQ measured the outcomes of leadership by these three aforementioned constructs.

All of the items on the West Virginia Building-Level Administrator Computer Usage Survey 2000 were of a forced-choice answer type. Section 1BSpecific Computer Applications UsedBasked the respondent to identify the frequency of usage of personal productivity 
applications for administrative tasks by having the respondent choose from a range of responses which included daily, often, weekly, rarely, and never. Section 4BPerceptions and AttitudesBsimilarly asked the respondent to answer using a Likert-type scale with responses including strongly agree, agree, uncertain/undecided, disagree, and strongly disagree. Section 5BIndividual Leadership OutcomesBhad the respondent choose from a range of frequency options including not at all, once in a while, sometimes, fairly often, and frequently if not always. Section 2BGeneral Computer Use, Section 3BComputer Training Received, and Section 6BDemographic Data were multiple choice questions which, in specified instances, allowed the respondent to choose more than one choice. In order to maximize the response rate for this survey instrument and to minimize qualitative data collection, no open-ended questions requiring written responses were asked.

\section{$\underline{\text { Data Collection }}$}

In the Fall of 2000, the West Virginia Building-Level Administrator Computer Usage Survey 2000 form was mailed to all 826 building administrators in West Virginia sublic schools. This survey (Appendix A) was accompanied by a cover letter from the researcher (Appendix B). The names and addresses for the public schools in West Virginia were taken from the 1999-2000 Education Directory through the West Virginia Department of Education web site. These names and addresses were keyed into a database file to allow for easy creation of address labels for the mailing envelopes. Bright colors were chosen for the envelopes to help increase the likelihood that the surveys would be returned in a timely manner. The survey form had been 
fashioned into a brochure-style format. This brochure, constructed from an 11" X 14" sheet of 24-pound paper, was sent with the required address and postage for return mailing. Each administrator was required to pull an adhesive tab over the open fold to secure the instrument for return to the researcher. The format of this survey instrument was kept as simple as possible in order to obtain the highest response rate possible.

Upon receiving this survey instrument in the mail, each respondent had two weeks from the date of mailing to return this instrument. The survey was designed to take each administrator approximately 10 minutes to complete. Since this survey was conducted anonymously, the researcher had no way of establishing which administrators responded to the survey instrument. Reminder postcards were mailed to all building-level administrators in West Virginia one week after the initial survey mailing date in an attempt to increase the response rate for this study. The turnaround time for this survey was kept to a minimum due to the ease of this instrument completion. All items on the instrument could have been answered with a check mark or an $\mathrm{X}$ in the appropriate printed box.

\section{$\underline{\text { Data Analysis }}$}

The data from the West Virginia Building-Level Administrator Computer Usage Survey 2000 were entered on the Statistical Package for the Social Sciences (SPSS) 8.0 software. The data analysis followed a nonparametric statistical design since the data was in ordinal form. The analyses included the Mann-Whitney U test, which measured the amount of association or difference between two variables, such as the amount of computer use by school building administrators and having a home personal computer. The Spearman Rho test was utilized to determine the relationship between variables. Finally, a stepwise forward multiple linear 
regression analysis was conducted on the demographic data to determine demographic characteristics which were predictors of computer usage in each of the software applications under study. The results of these analyses have been reported in Chapter 4 .

This research design would be classified by Campbell and Stanley (1963) as a one-shot case study. This research design contained the process of comparison, of recording differences or of contrast. Campbell and Stanley assert that securing scientific evidence involves making at least one comparison. Much of the research in education today conforms to a design in which a single group is studied only once. While the one-shot case study lacks some of the controls ensured in more detailed research designs, it appeared to be the most practical design to answer the research questions stated earlier in this study.

In conclusion, Section 1BSpecific Computer Applications Used of the West Virginia Building-Level Administrator Computer Usage Survey 2000 form identified the frequency with which each administrator used personal productivity software for specified administrative tasks. This section set forth the dependent variables for this study. Section 2BGeneral Computer Use, Section 3BComputer Training Received, Section 4BPerceptions and Attitudes, and Section 6BDemographic Data included questions adapted from the 1996 Benson study of one school district in Nevada. Section 5BIndividual Leadership Outcomes--included questions related to the individual leadership outcomes of extra efforts, effectiveness, and satisfaction and thus included nine items from the Multifactor Leadership Questionnaire Form 5x-Short to measure the frequency of perceived positive leader behaviors identified under these three individual leadership constructs. The data analyses followed a nonparametric design utilizing the Mann-Whitney U test and the Spearman Rho test to determine the relationships between the independent and dependent 
variables. A stepwise forward multiple linear regression analysis was conducted on the demographic data to determine demographic characteristics which were predictors of computer usage of specific software applications. Post hoc analyses were included as appropriate based on the results of the aforementioned data analyses. 


\section{CHAPTER 4}

\section{Presentation and Analysis of the Data}

This chapter presents and discusses analyses of the data collected from 503 West Virginia public school principals on the West Virginia Building-Level Administrator Computer Usage Survey 2000 form. The survey instrument (Appendix A) and cover letter (Appendix B) were mailed to 824 public school principals on October 24, 2000. A postcard reminder was mailed to all participants on October 31, 2000, in order to obtain a higher response rate. From this mailing, 503 usable surveys were mailed to the researcher. Of the original 824 enveloped mailed, five were returned because schools had either consolidated or closed since the time of the publication of addresses of public schools in West Virginia by the West Virginia Department of Education. Two additional surveys were received by the researcher but were not usable because they were damaged through the United States Postal Service mail system. The response rate obtained was 61.2 percent. This percentage exceeded the researcher's minimum acceptable level of 50 percent plus one. The purpose of this study was to determine the frequency with which building-level administrators, principals, in West Virginia public schools use office productivity software to complete their management tasks of organizing information, communicating, making presentations, and preparing budgets.

The data were examined to determine if there were statistically significant relationships between the frequency of computer usage of office productivity software by building-level public school administrators in West Virginia and eleven independent variables. The first four independent variables came under the category of general computer use. These four variables were having a home personal computer, the types of computer platforms/operating systems 
previously used, the number of years of use of a personal computer, and the software applications previously used at home. The next three independent variables came under the category of computer training received. These three variables were the types of computer training received, the specific applications for which training was received within the last year, and the amount of computer training received within the last year. Perceptions and attitudes was an additional independent variables and was represented by one section of the survey which included nine statements which were to be answered on a Likert-type scale from strongly agree to strongly disagree. The three individual leadership outcomes of extra effort, effectiveness, and satisfaction were treated as separate independent variables. The data for these items came from Section 5 of the survey on individual leadership outcomes. These questions were also answered on a Likerttype scale from not at all to frequently, if not always. The frequency of specific computer application usage was also compared to demographic characteristics to determine demographic predictors for computer usage in each of the six software categories under study. A stepwise forward multiple linear regression analysis was conducted on these data. All data were analyzed using the Statistical Package for Social Sciences (SPSS) software for Windows, Version 10.0. The remainder of the chapter includes the following sections: (a) descriptive data, (b) internal reliability of instrument, (c) major findings, (d) ancillary findings, and (e) a summary of the chapter.

\section{Descriptive Data}

Eight hundred nineteen public school administrators received the West Virginia BuildingLevel Administrator Computer Usage Survey 2000 form. These forms were sent to all public school principals in the state of West Virginia. The addresses used for the mailing were the most 
recent available from the West Virginia Department of Education through their on-line directory service at http://wvde.state.wv.us/ed_directory as of October 1, 2000. Five hundred three usable surveys were received from this mailing. All Regional Education Service Agency (RESA) areas were represented. The response rate as a percentage of the total by RESA region ranged from 7.6 to 18.9 as indicated in Table 1. 
Table 1

Descriptive Data on West Virginia Building-Level Administrator Computer Usage Survey 2000

Responses by RESA Region

\begin{tabular}{lcc}
\hline & Number of Responses & Percent of Total \\
RESA Region & 55 & 10.9 \\
\hline I & 58 & 11.5 \\
II & 78 & 15.5 \\
III & 64 & 12.7 \\
IV & 54 & 10.7 \\
V & 38 & 7.6 \\
VI & 95 & 18.9 \\
VII & 61 & 12.1 \\
VIII & & \\
\hline
\end{tabular}




\section{Internal Reliability of Instrument}

Prior to use, the survey instrument was read by a panel of experts to review validity. The Chronbach Alpha in the Statistical Package for the Social Sciences (SPSS) was used to test the reliability of the survey instrument. The use of that test determined the relationship of all items to all other items of a test and to the test as a whole. The Cronbach Alpha procedure produced a score of .78 .

Because the survey instrument was given at one point in time, the effect of history upon the survey was controlled. Further, because this survey did not have a pretest/posttest components built into it, interference from maturation was limited. Since every building-level administrator in West Virginia was sent a survey, statistical regression and selection biases were all but eliminated.

All surveys were completed at the discretion of each individual administrator. All completed surveys were rated through statistical analyses after being entered into a statistical application on a computer. Since all surveys were scored, or entered, on an objective basis where numbers were assigned to each response, the interference of instrumentation was eliminated as a possible threat to internal validity. Because no post assessment was utilized, the possible dangers for internal validity due to testing, experimental mortality, and selection-maturation were controlled. 
Major Findings

\section{$\underline{\text { Research Question One }}$}

What is the current frequency of specific computer applications usage by buildinglevel administrators in West Virginia as it relates to the management functions of organizing information, communicating, making presentations, and preparing budgets?

The 503 usable survey responses indicated that 310 building-level administrators use database software for the management function of organizing information often if not daily. Those administrators reporting daily or often for utilizing word processing software for the management function of communicating numbered 401. Furthermore 338 administrators reported using e-mail software for the communication function either daily or often. The numbers using presentation software for making presentations, desktop publishing software for making presentations, and electronic spreadsheet software for preparing budgets were 75,107 , and 51, respectively, for the combined categories of daily and often. Further inspection of the data indicated that 422 respondents either rarely or never use electronic spreadsheet software for the management function of preparing budgets. Table 2 summarizes the numeric frequency of specific computer applications usage by building-level administrators in West Virginia public schools. 
Table 2

Numeric Frequency of Computer Usage Reported on the West Virginia Building-Level

Administrator Computer Usage Survey 2000 Form

Software Utilized

Daily Often Weekly Rarely Never

Usage of Database Software for

210

100

48

105

40

Organizing Information

Usage of Word Processing

303

98

35

46

21

Software for Communicating

Usage of E-Mail Software for

255

83

46

88

31

Communicating

Usage of Presentation Software

3

72

34

284

110

for Making Presentations

Usage of Desktop Publishing

15

92

64

208

124

Software for Making

Presentations

Usage of Electronic Spreadsheet

11

40

30

212

210 
In terms the percentage makeup of responses to various categories of the frequency of computer application usage for specific management functions, several observations should be made. The percentage of respondents indicating that they made daily or often usage of database software for organizing information was 61.6. Almost 80 percent of respondents indicated daily or often usage of word processing software for the management function of communicating. Further, 67.2 percent of survey respondents marked daily or often as an indication of their usage of e-mail software for the management function of communicating. The percentage of respondents who reported rarely or never using electronic spreadsheet software for preparing budgets was 83.8 . The percentage of responses by frequency of usage category for the six software types under study are summarized in Table 3. 
Table 3

Percentage Frequency of Computer Usage Reported on the West Virginia Building-Level

Administrator Computer Usage Survey 2000 Form

Software Utilized

Daily Often Weekly Rarely Never

Usage of Database Software for

41.7

19.9

9.5

20.9

8.0

Organizing Information

Usage of Word Processing

60.2

19.5

7.0

9.1

4.2

Software for Communicating

Usage of E-Mail Software for

50.7

16.5

9.1

17.5

6.2

Communicating

Usage of Presentation Software

6

14.3

6.8

56.5

21.9

for Making Presentations

Usage of Desktop Publishing

3.0

18.3

12.7

41.4

24.7

Software for Making

Presentations

Usage of Electronic Spreadsheet

2.2

8.0

6.0

42.1

41.7 


\section{$\underline{\text { Research Question Two }}$}

What is the relationship, if any, between the frequency of specific computer applications usage by building-level administrators in West Virginia and these buildinglevel administrators having a computer in their home?

The first question in Section 2, General Computer Use, of the West Virginia BuildingLevel Administrator Computer Usage Survey 2000 form asked whether or not the administrator had a personal computer at home. Spearman's Rho, the Pearson Chi-Square, and the MannWhitney $\mathrm{U}$ analyses all found levels of significance at the $\mathrm{p}<.01$ level as shown in Table 4. 
Table 4

Relationship Between Frequency of Computer Usage by Building-Level Public School

$\underline{\text { Administrators in West Virginia and Home Personal Computer }}$

\begin{tabular}{|c|c|c|c|}
\hline & $\begin{array}{c}\text { Spearman's } \\
\text { Rho } \\
\text { p }\end{array}$ & $\begin{array}{c}\text { Pearson Chi- } \\
\text { Square } \\
\text { p }\end{array}$ & $\begin{array}{c}\text { Mann- } \\
\text { Whitney } \\
\text { p }\end{array}$ \\
\hline $\begin{array}{l}\text { Usage of Database Software for Organizing } \\
\text { Information }\end{array}$ & $.006^{* *}$ & $.001 * *$ & $.006^{* *}$ \\
\hline $\begin{array}{l}\text { Usage of Word Processing Software for } \\
\text { Communicating }\end{array}$ & $.002 * *$ & $.000 * *$ & $.002 * *$ \\
\hline $\begin{array}{l}\text { Usage of E-Mail Software for } \\
\text { Communicating }\end{array}$ & $.000 * *$ & $.000 * *$ & $.000 * *$ \\
\hline $\begin{array}{l}\text { Usage of Presentation Software for Making } \\
\text { Presentations }\end{array}$ & $.000 * *$ & $.000 * *$ & $.000 * *$ \\
\hline $\begin{array}{l}\text { Usage of Desktop Publishing Software for } \\
\text { Making Presentations }\end{array}$ & $.000 * *$ & $.000 * *$ & $.000 * *$ \\
\hline $\begin{array}{l}\text { Usage of Electronic Spreadsheet Software for } \\
\text { Preparing Budgets }\end{array}$ & $.010 * *$ & $.001 * *$ & $.010 * *$ \\
\hline
\end{tabular}

$* * \mathrm{p}<.01$ 
Eighty-nine percent of survey respondents reported having a personal computer at home. Sixty-four percent of the respondents who reported having a home personal computer indicated that they used database software either daily or often and had a personal computer at home. Eighty-one percent of the respondents used word processing software either daily or often and had a personal computer at home. Further, 70 percent of respondents who reported having a personal computer at home indicated either daily or often usage frequencies for of e-mail

programs. As for presentation software, all respondents who marked daily usage of this software reported having a personal computer at home. Ninety-four percent of those administrators who marked often in the frequency of usage of presentation software had a personal computer at home. This same percentage was found for desktop publishing software. In the case of desktop publishing software, all respondents who marked daily usage of the software had a personal computer at home while 95.7 percent of those who marked often had a personal computer at home. Sixty-three percent of those individuals reporting no previous spreadsheet usage also reported no home computer.

\section{$\underline{\text { Research Question Three }}$}

What is the relationship, if any, between the frequency of specific computer applications usage by building-level administrators in West Virginia and the building-level administrators' usage of previous software platforms/operating systems?

No Previous Computer Operating Systems Used. Spearman's Rho yielded negative correlations for usage of database, word processing, e-mail, presentation, desktop publishing and spreadsheet software when this analysis was run for those administrators reporting no previous computer platform/operating system use. The levels of significance are reported in Table 5. 


\section{Table 5}

Relationship Between Frequency of Computer Usage by Building-Level Public School

Administrators in West Virginia and Administrators Reporting No Previous Usage of Computer

Operating Systems or Platforms

\begin{tabular}{|c|c|c|c|}
\hline & $\begin{array}{c}\text { Spearman's } \\
\text { Rho } \\
\text { p }\end{array}$ & $\begin{array}{c}\text { Pearson Chi- } \\
\text { Square } \\
\text { p }\end{array}$ & $\begin{array}{c}\text { Mann- } \\
\text { Whitney } \\
\text { p }\end{array}$ \\
\hline $\begin{array}{l}\text { Usage of Database Software for Organizing } \\
\text { Information }\end{array}$ & $.002 * *$ & $.000 * *$ & $.002 * *$ \\
\hline $\begin{array}{l}\text { Usage of Word Processing Software for } \\
\text { Communicating }\end{array}$ & $.000 * *$ & $.000 * *$ & $.000 * *$ \\
\hline $\begin{array}{l}\text { Usage of E-Mail Software for } \\
\text { Communicating }\end{array}$ & $.001 * *$ & $.000 * *$ & $.001 * *$ \\
\hline $\begin{array}{l}\text { Usage of Presentation Software for Making } \\
\text { Presentations }\end{array}$ & $.000 * *$ & $.000 * *$ & $.000 * *$ \\
\hline $\begin{array}{l}\text { Usage of Desktop Publishing Software for } \\
\text { Making Presentations }\end{array}$ & $.000 * *$ & $.002 * *$ & $.000 * *$ \\
\hline $\begin{array}{l}\text { Usage of Electronic Spreadsheet Software for } \\
\text { Preparing Budgets }\end{array}$ & $.013 *$ & .171 & $.013^{*}$ \\
\hline
\end{tabular}

$* \underline{p}<.05 . * * \underline{p}<.01$ 
There were ten administrators who reported no previous usage of a computer operating system. Of these ten, eight reported rarely or never using database software, eight reported rarely or never using word processing software, seven reported rarely or never using e-mail software, ten reported rarely or never using presentation software, ten reported rarely or never using desktop publishing software, and ten reported rarely or never using spreadsheet software.

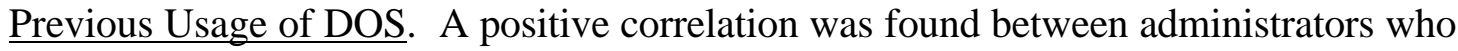
had previously used the disk operating system (DOS) software and usage of database, word processing, e-mail, and desktop publishing software. The levels of significance are reported in Table 6. 
Table 6

$\underline{\text { Relationship Between Frequency of Computer Usage by Building-Level Public School }}$

$\underline{\text { Administrators in West Virginia and Administrators Reporting Previous Usage of DOS }}$

\begin{tabular}{|c|c|c|c|}
\hline & $\begin{array}{c}\text { Spearman's } \\
\text { Rho } \\
\text { p }\end{array}$ & $\begin{array}{c}\text { Pearson Chi- } \\
\text { Square } \\
\text { p }\end{array}$ & $\begin{array}{c}\text { Mann- } \\
\text { Whitney } \\
\text { p }\end{array}$ \\
\hline $\begin{array}{l}\text { Usage of Database Software for Organizing } \\
\text { Information }\end{array}$ & $.020 *$ & $.031 *$ & $.021 *$ \\
\hline $\begin{array}{l}\text { Usage of Word Processing Software for } \\
\text { Communicating }\end{array}$ & $.008^{* *}$ & $.000 * *$ & $.008^{* *}$ \\
\hline $\begin{array}{l}\text { Usage of E-Mail Software for } \\
\text { Communicating }\end{array}$ & $.017 *$ & .081 & $.018^{*}$ \\
\hline $\begin{array}{l}\text { Usage of Presentation Software for Making } \\
\text { Presentations }\end{array}$ & .129 & .324 & .129 \\
\hline $\begin{array}{l}\text { Usage of Desktop Publishing Software for } \\
\text { Making Presentations }\end{array}$ & $.001 * *$ & $.003 * *$ & $.001 * *$ \\
\hline $\begin{array}{l}\text { Usage of Electronic Spreadsheet Software for } \\
\text { Preparing Budgets }\end{array}$ & .421 & .535 & .421 \\
\hline
\end{tabular}

$* \underline{p}<.05 . * * \underline{p}<.01$. 
Sixty-five percent of the administrators who reported previous usage of DOS used database software for organizing information daily or often. Eighty-three percent of the administrators who indicated previous usage of DOS utilized word processing software for communication daily or often. Sixty-nine percent of the administrators who reported previous usage of DOS indicated daily or often for the frequency of utilization of e-mail programs for communication. Twenty-six percent of the administrators who indicated previous usage of DOS reported daily or often levels of usage of desktop publishing software for making presentations.

Previous Use of Windows Operating System. A positive correlation was found between administrators who had previously used a version of Windows and the administrators' usage of office productivity software. The levels of significance in three different statistical calculations are presented in Table 7. 
Table 7

$\underline{\text { Relationship Between Frequency of Computer Usage by Building-Level Public School }}$

Administrators in West Virginia and Administrators Reporting Previous Usage of Windows

\begin{tabular}{|c|c|c|c|}
\hline & $\begin{array}{c}\text { Spearman's } \\
\text { Rho } \\
\text { p }\end{array}$ & $\begin{array}{c}\text { Pearson Chi- } \\
\text { Square } \\
\text { p }\end{array}$ & $\begin{array}{c}\text { Mann- } \\
\text { Whitney } \\
\text { p }\end{array}$ \\
\hline $\begin{array}{l}\text { Usage of Database Software for Organizing } \\
\text { Information }\end{array}$ & $.003 * *$ & $.000 * *$ & $.003 * *$ \\
\hline $\begin{array}{l}\text { Usage of Word Processing Software for } \\
\text { Communicating }\end{array}$ & $.000 * *$ & $.000 * *$ & $.000 * *$ \\
\hline $\begin{array}{l}\text { Usage of E-Mail Software for } \\
\text { Communicating }\end{array}$ & $.001 * *$ & $.000 * *$ & $.001 * *$ \\
\hline $\begin{array}{l}\text { Usage of Presentation Software for Making } \\
\text { Presentations }\end{array}$ & $.000 * *$ & $.000 * *$ & $.000 * *$ \\
\hline $\begin{array}{l}\text { Usage of Desktop Publishing Software for } \\
\text { Making Presentations }\end{array}$ & $.001 * *$ & $.002 * *$ & $.001 * *$ \\
\hline $\begin{array}{l}\text { Usage of Electronic Spreadsheet Software for } \\
\text { Preparing Budgets }\end{array}$ & $.014 *$ & .192 & $.014 *$ \\
\hline
\end{tabular}

$* \underline{p}<.05 . * * \underline{p}<.01$ 
Sixty-three percent of those administrators who reported previous usage of the Windows operating system indicated that they used database software for preparing budgets either daily or often. Eighty-one percent of the administrators who indicated previous usage of Windows reported using word processing either daily or often in the management task of communicating. Further, 68 percent of the administrators who reported previous usage of Windows indicated daily or often levels of usage for e-mail software in communicating. Fifteen percent of the administrators reporting previous usage of Windows indicated utilization of presentation software either daily or often. Of the administrators with previous Windows experience, 22 percent recorded daily or often for frequency of usage of desktop publishing software for making presentations. Finally, 10 percent of the administrators who reported previous usage of Windows indicated usage of electronic spreadsheet software either daily or often for preparing budgets.

Previous Usage of Macintosh/Apple Operating System Software. Statistically significant relationships were reported between an administrator's previous usage of Macintosh/Apple operating software and the use of word processing, e-mail, and desktop publishing software. The results of the statistical analyses performed on these data are shown in Table 8. 
Table 8

$\underline{\text { Relationship Between Frequency of Computer Usage by Building-Level Public School }}$

Administrators in West Virginia and Administrators Reporting Previous Usage of

Macintosh/Apple

$\begin{array}{ccc}\text { Spearman's } & \text { Pearson Chi- } & \text { Mann- } \\ \text { Rho } & \text { Square } & \text { Whitney } \\ \text { p } & \underline{p} & \underline{p}\end{array}$

Usage of Database Software for Organizing

.505

.929

.505

Information

Usage of Word Processing Software for

$.000 * *$

$.002 * *$

$.000 * *$

Communicating

Usage of E-Mail Software for

$.005 * *$

$.025^{*}$

$.005^{* *}$

Communicating

Usage of Presentation Software for Making

.401

.447

.400

Presentations

Usage of Desktop Publishing Software for

$.001^{* *}$

$.001 * *$

$.001 * *$

Making Presentations

Usage of Electronic Spreadsheet Software for

.558

.303

.558

Preparing Budgets

$* \mathrm{p}<.05 . * * \mathrm{p}<.01$ 
Eighty-nine percent of those administrators who had previously used Macintosh/Apple software reported daily or often usage of word processing software for communication. Seventyfour percent of those reporting previous usage of Macintosh/Apple software reported daily or often usage of e-mail programs for communication. Further, twenty-seven percent of administrators reporting previous usage of Macintosh/Apple software indicated daily or often usage of desktop publishing software.

\section{Research Question Four}

What is the relationship, if any, between the frequency of specific computer applications usage by building-level administrators in West Virginia and the number of years these building-level administrators have used a personal computer?

Spearman's Rho and the Pearson Chi-Square statistics were used to analyze data reported by West Virginia public school administrators related to the number of years these administrators had used the personal computer. The levels of significance reported on both tests were all at the $p$ $<.01$ level as shown in Table 9. 
Table 9

$\underline{\text { Relationship Between Frequency of Computer Usage by Building-Level Public School }}$

Administrators in West Virginia and Years of Usage of Personal Computer

$\begin{array}{cc}\text { Spearman's Rho } & \text { Pearson Chi-Square } \\ \underline{p} & \underline{p}\end{array}$

Usage of Database Software for Organizing

$.000 * * \quad .000 * *$

Information

Usage of Word Processing Software for

$.000 * * \quad .000 * *$

Communicating

Usage of E-Mail Software for

$.000 * * \quad .000 * *$

Communicating

Usage of Presentation Software for Making

$.000 * * \quad .000 * *$

Presentations

Usage of Desktop Publishing Software for

$.000 * * \quad .000 * *$

Making Presentations

Usage of Electronic Spreadsheet Software for

$.000 * *$

$.000 * *$

$* * \underline{p}<.01$ 
Forty-two percent of the administrators surveyed reported that they had used a personal computer for seven or more years and used database software daily or often to organize information. Fifty-three percent of the administrators surveyed reported that they had used a personal computer for seven or more years and used word processing software daily or often in the management function of communicating. For the category of e-mail, 44 percent of the administrators surveyed reported that they had used a personal computer for seven or more years and made daily or often usage of these programs for communication. Eleven percent of the administrators surveyed reported that they had used a personal computer for seven or more years and also made daily or often usage of presentation software. Seventeen percent of the administrators surveyed reported that they had used a personal computer for seven or more years and that they used desktop publishing software for presentations daily or often. In the area of spreadsheet usage for preparing budgets, seven percent of the administrators surveyed reported that they had used the personal computer for seven or more years and marked the daily or often frequency categories.

\section{$\underline{\text { Research Question Five }}$}

What is the relationship, if any, between the frequency of specific computer applications usage by building-level administrators in West Virginia and the building-level administrators' previous usage of the application software at home?

No Previous Software Usage. A negative correlation was found between the frequency of use of office productivity software on the job and no previous use of this software at home. The levels of significance reported were all at the $\mathrm{p}<.01$ level as shown in Table 10 . 
Table 10

Relationship Between Frequency of Computer Usage by Building-Level Public School

Administrators in West Virginia and Administrators Reporting No Previous Usage of Computer

Applications at Home

$\begin{array}{ccc}\text { Spearman's } & \text { Pearson Chi- } & \text { Mann- } \\ \text { Rho } & \text { Square } & \text { Whitney } \\ \text { p } & \underline{p} & \underline{p}\end{array}$

Usage of Database Software for Organizing

$.000 * * \quad .000 * * \quad .000 * *$

Information

Usage of Word Processing Software for

Communicating

Usage of E-Mail Software for

$\begin{array}{lll}.000 * * & .000 * * & .000 * *\end{array}$

Communicating

Usage of Presentation Software for Making

$.000^{* *}$

$.000 * *$

$.000 * *$

Presentations

Usage of Desktop Publishing Software for

$.000 * *$

$.000 * *$

$.000 * *$

Making Presentations

Usage of Electronic Spreadsheet Software for

$.001 * *$

$.000 * *$

$.001 * *$

Preparing Budgets

$* * \mathrm{p}<.01$ 
Nine percent of the administrators surveyed used database software with any level of frequency and had no previous home experience with office productivity software. This same percentage was also reported for word processing and e-mail utilization by these administrators. Five percent of the administrators surveyed used presentation software in performing their management function and reported no previous usage of office productivity software at home. This percentage was the same for desktop publishing. Only four percent of the administrators surveyed used spreadsheet software with any level of frequency in performing their management function of preparing budgets and reported no previous home usage of office productivity software.

Previous Home Usage of Word Processing Software. A positive correlation was shown to exist between the frequency of usage of office productivity software by public school administrators and previous usage of word processing software at home. The levels of significance on three statistical tests were all at the $\mathrm{p}<.01$ level and are shown in Table 11 . 
Table 11

Relationship Between Frequency of Computer Usage by Building-Level Public School

Administrators in West Virginia and Previous Usage of Word Processing Software at Home

\begin{tabular}{|c|c|c|c|}
\hline & $\begin{array}{c}\text { Spearman's } \\
\text { Rho } \\
\text { p }\end{array}$ & $\begin{array}{c}\text { Pearson Chi- } \\
\text { Square } \\
\text { p }\end{array}$ & $\begin{array}{c}\text { Mann- } \\
\text { Whitney } \\
\text { p }\end{array}$ \\
\hline $\begin{array}{l}\text { Usage of Database Software for Organizing } \\
\text { Information }\end{array}$ & $.000 * *$ & $.000 * *$ & $.000 * *$ \\
\hline $\begin{array}{l}\text { Usage of Word Processing Software for } \\
\text { Communicating }\end{array}$ & $.000 * *$ & $.000 * *$ & $.000 * *$ \\
\hline $\begin{array}{l}\text { Usage of E-Mail Software for } \\
\text { Communicating }\end{array}$ & $.000 * *$ & $.000 * *$ & $.000 * *$ \\
\hline $\begin{array}{l}\text { Usage of Presentation Software for Making } \\
\text { Presentations }\end{array}$ & $.000 * *$ & $.000 * *$ & $.000 * *$ \\
\hline $\begin{array}{l}\text { Usage of Desktop Publishing Software for } \\
\text { Making Presentations }\end{array}$ & $.000 * *$ & $.000 * *$ & $.000 * *$ \\
\hline $\begin{array}{l}\text { Usage of Electronic Spreadsheet Software for } \\
\text { Preparing Budgets }\end{array}$ & $.000 * *$ & $.000 * *$ & $.000 * *$ \\
\hline
\end{tabular}

$* * \underline{p}<.01$. 
Fifty-five percent, or 278 administrators, reported previous home usage of word processing software and either daily or often usage of database software in the management function of organizing information. Seventy-two percent, or 361 administrators, reported previous home usage of word processing software and either daily or often usage of word processing software in the management function of communicating. Fifty-nine percent, or 296 administrators, reported previous home usage of word processing software and either daily or often usage of e-mail programs in performing the management function of communicating. For making presentations, 75 administrators reported daily or often usage of presentation software. Of these 75 , only 4 had not previously used word processing software at home. One hundred seven administrators reported daily or often usage of desktop publishing software. Of the 107, only 3 had no previous experience with word processing programs at home. Fifty-one administrators reported usage of spreadsheet software in preparing budgets either daily or often. Of the 51, only 9 had no previous experience with word processing on a home computer.

\section{Previous Home Usage of Desktop Publishing Software. A positive correlation was} found between the frequency of use of office productivity software and previous usage of desktop publishing software at home. The levels of significance reported on three statistical calculations were all at the $\mathrm{p}<.01$ level as reported in Table 12 . 
Table 12

Relationship Between Frequency of Computer Usage by Building-Level Public School

Administrators in West Virginia and Previous Usage of Desktop Publishing Software at Home

\begin{tabular}{|c|c|c|c|}
\hline & $\begin{array}{c}\text { Spearman's } \\
\text { Rho } \\
\text { p }\end{array}$ & $\begin{array}{c}\text { Pearson Chi- } \\
\text { Square } \\
\text { p }\end{array}$ & $\begin{array}{c}\text { Mann- } \\
\text { Whitney } \\
\text { p }\end{array}$ \\
\hline $\begin{array}{l}\text { Usage of Database Software for Organizing } \\
\text { Information }\end{array}$ & $.000 * *$ & $.000 * *$ & $.000 * *$ \\
\hline $\begin{array}{l}\text { Usage of Word Processing Software for } \\
\text { Communicating }\end{array}$ & $.000 * *$ & $.000 * *$ & $.000 * *$ \\
\hline $\begin{array}{l}\text { Usage of E-Mail Software for } \\
\text { Communicating }\end{array}$ & $.000 * *$ & $.000 * *$ & $.000 * *$ \\
\hline $\begin{array}{l}\text { Usage of Presentation Software for Making } \\
\text { Presentations }\end{array}$ & $.000 * *$ & $.000 * *$ & $.000 * *$ \\
\hline $\begin{array}{l}\text { Usage of Desktop Publishing Software for } \\
\text { Making Presentations }\end{array}$ & $.000 * *$ & $.000 * *$ & $.000 * *$ \\
\hline $\begin{array}{l}\text { Usage of Electronic Spreadsheet Software for } \\
\text { Preparing Budgets }\end{array}$ & $.000 * *$ & $.000 * *$ & $.000 * *$ \\
\hline
\end{tabular}

$* * \mathrm{p}<.01$ 
Thirty-one percent of the administrators surveyed reported that they had previously used desktop publishing software at home and used database software daily or often at work for organizing information. Forty percent of the administrators surveyed reported that they had previously used desktop publishing software at home and used word processing software daily or often at work for communication. Thirty-five percent of those who had used desktop publishing software previously at home reported daily or often usage of e-mail software at work for communicating. Twenty percent of all the administrators surveyed reported that they had never used desktop publishing software at home and never used presentation software at work for making presentations. Twenty-three percent of all administrators surveyed reported that they had never used desktop publishing software at home and never used desktop publishing at work. Forty-nine percent of survey respondents reported that they never or rarely used spreadsheet software for preparing budgets and never used desktop publishing software previously at home. Previous Home Usage of Internet Browsing Software. A positive correlation was shown between the frequency of computer usage by building-level public school administrators in West Virginia and previous usage of Internet browsing software at home. Table 13 reports that the levels of significance on three different statistical calculations on these variables were all at $\mathrm{p}<$ .01. 
Table 13

Relationship Between Frequency of Computer Usage by Building-Level Public School

Administrators in West Virginia and Previous Usage of Internet Browsing Software at Home

\begin{tabular}{|c|c|c|c|}
\hline & $\begin{array}{c}\text { Spearman's } \\
\text { Rho } \\
\text { p }\end{array}$ & $\begin{array}{c}\text { Pearson Chi- } \\
\text { Square } \\
\text { p }\end{array}$ & $\begin{array}{c}\text { Mann- } \\
\text { Whitney } \\
\text { p }\end{array}$ \\
\hline $\begin{array}{l}\text { Usage of Database Software for Organizing } \\
\text { Information }\end{array}$ & $.000 * *$ & $.000 * *$ & $.000 * *$ \\
\hline $\begin{array}{l}\text { Usage of Word Processing Software for } \\
\text { Communicating }\end{array}$ & $.000 * *$ & $.000 * *$ & $.000 * *$ \\
\hline $\begin{array}{l}\text { Usage of E-Mail Software for } \\
\text { Communicating }\end{array}$ & $.000 * *$ & $.000 * *$ & $.000 * *$ \\
\hline $\begin{array}{l}\text { Usage of Presentation Software for Making } \\
\text { Presentations }\end{array}$ & $.000 * *$ & $.000 * *$ & $.000 * *$ \\
\hline $\begin{array}{l}\text { Usage of Desktop Publishing Software for } \\
\text { Making Presentations }\end{array}$ & $.000 * *$ & $.000 * *$ & $.000 * *$ \\
\hline $\begin{array}{l}\text { Usage of Electronic Spreadsheet Software for } \\
\text { Preparing Budgets }\end{array}$ & $.005 * *$ & $.003 * *$ & $.005 * *$ \\
\hline
\end{tabular}

$* * \underline{p}<.01$. 
Fifty-three percent of the administrators surveyed reported that they had previously used Internet browsing software at home and used database software at work for organizing information daily or often. Sixty-five percent of all survey respondents reported that they had previously used Internet browsing software at home and used word processing software at work for the management function of communicating. Fifty-six percent of all administrators surveyed reported that they used e-mail software daily or often at work for communicating and had previously used Internet browsing software at home. All of the survey respondents who indicated daily usage of presentation software at work reported previous usage of Internet browsing software at home. Sixty-four percent of the survey respondents reported some level of usage of desktop publishing software for creating presentations and had previously used Internet browsing software at home. Forty-nine percent of the survey respondents reported some level of spreadsheet usage for preparing budgets and previous home usage of Internet browsing software. Previous Home Usage of Database Software. A positive correlation was found between the frequency of computer usage by building-level public school administrators in West Virginia and previous usage of database software at home. The levels of significance on three statistical analyses are reported in Table 14. 
Table 14

Relationship Between Frequency of Computer Usage by Building-Level Public School

Administrators in West Virginia and Previous Usage of Database Software at Home

\begin{tabular}{|c|c|c|c|}
\hline & $\begin{array}{c}\text { Spearman's } \\
\text { Rho } \\
\text { p }\end{array}$ & $\begin{array}{c}\text { Pearson Chi- } \\
\text { Square } \\
\text { p }\end{array}$ & $\begin{array}{c}\text { Mann- } \\
\text { Whitney } \\
\text { p }\end{array}$ \\
\hline $\begin{array}{l}\text { Usage of Database Software for Organizing } \\
\text { Information }\end{array}$ & $.000 * *$ & $.000 * *$ & $.000 * *$ \\
\hline $\begin{array}{l}\text { Usage of Word Processing Software for } \\
\text { Communicating }\end{array}$ & $.000 * *$ & $.000 * *$ & $.000 * *$ \\
\hline $\begin{array}{l}\text { Usage of E-Mail Software for } \\
\text { Communicating }\end{array}$ & $.000 * *$ & $.000 * *$ & $.000 * *$ \\
\hline $\begin{array}{l}\text { Usage of Presentation Software for Making } \\
\text { Presentations }\end{array}$ & $.000 * *$ & $.000 * *$ & $.000 * *$ \\
\hline $\begin{array}{l}\text { Usage of Desktop Publishing Software for } \\
\text { Making Presentations }\end{array}$ & $.000 * *$ & $.000 * *$ & $.000 * *$ \\
\hline $\begin{array}{l}\text { Usage of Electronic Spreadsheet Software for } \\
\text { Preparing Budgets }\end{array}$ & $.000 * *$ & $.000 * *$ & $.000 * *$ \\
\hline
\end{tabular}

$* * \mathrm{p}<.01$ 
Forty-two percent of all administrators who reported any level of usage of database software at work for organizing information had previously used database software at home. There were 21 administrators who reported that they never used word processing for communicating at work. All 21 also reported no previous home usage of database software. Thirty-four percent of respondents reported that they used e-mail software at work daily or often and had previously used database software at home. Fifty-four percent of survey respondents reported that they rarely or never used presentation software at work and had never previously used database software at home. Forty-six percent of survey respondents reported that they rarely or never used desktop publishing software for creating presentations at work and had no previous experience with home usage of database software. Fifty-one percent of survey respondents reported that they rarely or never used spreadsheet software at work for preparing budgets and also reported no previous home usage of database software.

Previous Home Usage of Electronic Spreadsheet Software. A positive correlation was also found between the frequency of computer usage by building-level public school administrators in West Virginia and previous usage of electronic spreadsheet software at home. Table 15 reports the levels of significance from three different statistical analyses for all six categories of computer usage. 
Table 15

Relationship Between Frequency of Computer Usage by Building-Level Public School

Administrators in West Virginia and Previous Usage of Electronic Spreadsheet Software at Home

\begin{tabular}{|c|c|c|c|}
\hline & $\begin{array}{c}\text { Spearman's } \\
\text { Rho } \\
\text { p }\end{array}$ & $\begin{array}{c}\text { Pearson Chi- } \\
\text { Square } \\
\text { p }\end{array}$ & $\begin{array}{c}\text { Mann- } \\
\text { Whitney } \\
\text { p }\end{array}$ \\
\hline $\begin{array}{l}\text { Usage of Database Software for Organizing } \\
\text { Information }\end{array}$ & $.000 * *$ & $.000 * *$ & $.000 * *$ \\
\hline $\begin{array}{l}\text { Usage of Word Processing Software for } \\
\text { Communicating }\end{array}$ & $.000 * *$ & $.000 * *$ & $.000 * *$ \\
\hline $\begin{array}{l}\text { Usage of E-Mail Software for } \\
\text { Communicating }\end{array}$ & $.000 * *$ & $.000 * *$ & $.000 * *$ \\
\hline $\begin{array}{l}\text { Usage of Presentation Software for Making } \\
\text { Presentations }\end{array}$ & $.000 * *$ & $.000 * *$ & $.000 * *$ \\
\hline $\begin{array}{l}\text { Usage of Desktop Publishing Software for } \\
\text { Making Presentations }\end{array}$ & $.000 * *$ & $.000 * *$ & $.000 * *$ \\
\hline $\begin{array}{l}\text { Usage of Electronic Spreadsheet Software for } \\
\text { Preparing Budgets }\end{array}$ & $.000 * *$ & $.000 * *$ & $.000 * *$ \\
\hline
\end{tabular}

$* * \mathrm{p}<.01$ 
Twenty-six percent of the administrators responding to the survey reported that they used database software daily or often for organizing information at work and reported previous home usage of electronic spreadsheet software. Thirty-two percent of the administrators surveyed reported that they used word processing software daily or often and had previously used electronic spreadsheet software at home. Twenty-eight percent of the administrators surveyed reported that they used e-mail daily or often at work for communicating and that they had also previously used electronic spreadsheet software at home. One hundred administrators surveyed reported that they had never used presentation software at work for preparing presentations and also had no previous experience with electronic spreadsheet software at home. One hundred seven administrators surveyed reported that they had never used desktop publishing software at work for creating presentations and also reported no previous usage of electronic spreadsheet software at home. One hundred eight-two, or 36 percent, of the administrators surveyed reported no usage of spreadsheet software at work for preparing budgets and also had no experience with using spreadsheet software at home.

Previous Home Usage of E-Mail Software. A positive correlation was found between the frequency of computer usage by building-level public school administrators in West Virginia and previous usage of e-mail software at home. The results of three different statistical procedures are presented in Table 16. 
Table 16

Relationship Between Frequency of Computer Usage by Building-Level Public School

Administrators in West Virginia and Previous Usage of E-Mail Software at Home

\begin{tabular}{|c|c|c|c|}
\hline & $\begin{array}{c}\text { Spearman's } \\
\text { Rho } \\
\text { p }\end{array}$ & $\begin{array}{c}\text { Pearson Chi- } \\
\text { Square } \\
\text { p }\end{array}$ & $\begin{array}{c}\text { Mann- } \\
\text { Whitney } \\
\text { p }\end{array}$ \\
\hline $\begin{array}{l}\text { Usage of Database Software for Organizing } \\
\text { Information }\end{array}$ & $.000 * *$ & $.000 * *$ & $.000 * *$ \\
\hline $\begin{array}{l}\text { Usage of Word Processing Software for } \\
\text { Communicating }\end{array}$ & $.000 * *$ & $.000 * *$ & $.000 * *$ \\
\hline $\begin{array}{l}\text { Usage of E-Mail Software for } \\
\text { Communicating }\end{array}$ & $.000 * *$ & $.000 * *$ & $.000 * *$ \\
\hline $\begin{array}{l}\text { Usage of Presentation Software for Making } \\
\text { Presentations }\end{array}$ & $.000 * *$ & $.000 * *$ & $.000 * *$ \\
\hline $\begin{array}{l}\text { Usage of Desktop Publishing Software for } \\
\text { Making Presentations }\end{array}$ & $.000 * *$ & $.000 * *$ & $.000 * *$ \\
\hline $\begin{array}{l}\text { Usage of Electronic Spreadsheet Software for } \\
\text { Preparing Budgets }\end{array}$ & $.000 * *$ & $.000 * *$ & $.000 * *$ \\
\hline
\end{tabular}

$* * \mathrm{p}<.01$ 
Fifty-one percent of the administrators surveyed reported that they used database software daily or often at work for organizing information and had previously used e-mail software at home. Sixty-five percent of those surveyed reported that they used word processing software daily or often in performing their communication tasks and reported previous home usage of email software. Fifty-six percent of the administrators surveyed reported that they used e-mail software at work to communicate either daily or often and had previously used e-mail software at home. All survey respondents who reported daily usage of presentation software at work for creating presentations had previously used e-mail software at home. Further all survey respondents who reported daily usage of desktop publishing software at work for making presentations had previously used e-mail software at home. Eighty-two percent of all administrators indicating daily usage of spreadsheet software for preparing budgets had previously used e-mail software at home.

\section{$\underline{\text { Research Question Six }}$}

What is the relationship, if any, between the frequency of specific computer applications usage by building-level administrators in West Virginia and the types of computer training received by these administrators?

Three questions were asked on the West Virginia Building-Level Administrator Computer Usage Survey 2000 form which related to computer training. The first question asked administrators to identify the types of computer training they had previously received. The second question asked building-level administrators to identify the specific computer application areas in which they had received training within the last year. The final question on training asked how much training each administrator had received within the last year. 
Administrators Receiving No Type of Computer Training. The first survey question related to training asked administrators to identify the type(s) of computer training they had received. Negative correlations were found between the frequency of usage of database software for organizing information and no type of computer training received and between the frequency of usage of electronic spreadsheet software for preparing budgets and no type of computer training received. The results of three different statistical tests are presented in Table 17. 
Table 17

Relationship Between Frequency of Computer Usage by Building-Level Public School

$\underline{\text { Administrators in West Virginia and No Previous Computer Training Received }}$

\begin{tabular}{|c|c|c|c|}
\hline & $\begin{array}{c}\text { Spearman's } \\
\text { Rho } \\
\text { p }\end{array}$ & $\begin{array}{c}\text { Pearson Chi- } \\
\text { Square } \\
\text { p }\end{array}$ & $\begin{array}{c}\text { Mann- } \\
\text { Whitney } \\
\text { p }\end{array}$ \\
\hline $\begin{array}{l}\text { Usage of Database Software for Organizing } \\
\text { Information }\end{array}$ & $.002 * *$ & $.000 * *$ & $.002 * *$ \\
\hline $\begin{array}{l}\text { Usage of Word Processing Software for } \\
\text { Communicating }\end{array}$ & .120 & .290 & .120 \\
\hline $\begin{array}{l}\text { Usage of E-Mail Software for } \\
\text { Communicating }\end{array}$ & .851 & .935 & .851 \\
\hline $\begin{array}{l}\text { Usage of Presentation Software for Making } \\
\text { Presentations }\end{array}$ & .463 & .156 & .463 \\
\hline $\begin{array}{l}\text { Usage of Desktop Publishing Software for } \\
\text { Making Presentations }\end{array}$ & .065 & .423 & .065 \\
\hline $\begin{array}{l}\text { Usage of Electronic Spreadsheet Software for } \\
\text { Preparing Budgets }\end{array}$ & $.046^{*}$ & .402 & $.046^{*}$ \\
\hline
\end{tabular}

$* \underline{p}<.05 . * * \underline{p}<.01$ 
Only four administrators reported any level of database usage for organizing information and indicated receiving no type of computer training. Ninety-nine percent of the administrators who reported using database software daily indicated some type of computer training. All administrators who reported daily usage of electronic spreadsheet software for preparing budgets also indicated some previous type of computer training.

Required University/College Courses for Computer Training. A positive correlation was found to exist between the frequency of word processing software usage for the management function of communicating and administrators receiving computer training through required university/college courses. The results of two of three statistical procedures produced levels of significance of $p<.05$ as indicated in Table 18 . 
Table 18

Relationship Between Frequency of Computer Usage by Building-Level Public School

$\underline{\text { Administrators in West Virginia and Previous Computer Training Through Required }}$

$\underline{\text { University/College Course(s) }}$

$\begin{array}{ccc}\text { Spearman's } & \text { Pearson Chi- } & \text { Mann- } \\ \text { Rho } & \text { Square } & \text { Whitney } \\ \text { p } & \underline{p} & \underline{p}\end{array}$

Usage of Database Software for Organizing

.151

.102

.150

Information

Usage of Word Processing Software for

$.012 *$

.096

$.012 *$

Communicating

Usage of E-Mail Software for

.377

.790

.376

Communicating

Usage of Presentation Software for Making

.200

.290

.200

Presentations

Usage of Desktop Publishing Software for

.084

.258

.084

Making Presentations

Usage of Electronic Spreadsheet Software for

.598

.619

.598

Preparing Budgets

$* \underline{p}<.05$. 
Ninety-five percent of the administrators who indicated that they never used word processing for communicating also reported that they had never taken a required university/college course in computer applications. Seventy administrators, or 14 percent, reported that a required university/college course in computer training had been taken.

Elective University/College Courses for Computer Training. The relationship between the frequency of computer usage by building-level administrators and previous elective university/college courses in computer training was found to be significant in four of six software application categories. The results of the statistical analyses performed on these data are shown in Table 19. 
Table 19

Relationship Between Frequency of Computer Usage by Building-Level Public School

Administrators in West Virginia and Previous Computer Training Through Elective

$\underline{\text { University/College Course(s) }}$

$\begin{array}{ccc}\text { Spearman's } & \text { Pearson Chi- } & \text { Mann- } \\ \text { Rho } & \text { Square } & \text { Whitney } \\ \text { p } & \underline{p} & \underline{p}\end{array}$

Usage of Database Software for Organizing

.255

.077

.255

Information

Usage of Word Processing Software for

$.010 * *$

$.015^{*}$

$.010 * *$

Communicating

Usage of E-Mail Software for

$.027 *$

.217

$.027^{*}$

Communicating

Usage of Presentation Software for Making

$.013^{*}$

$.009 * *$

$.013 *$

Presentations

Usage of Desktop Publishing Software for

$.000 * *$

$.000 * *$

$.000 * *$

Making Presentations

Usage of Electronic Spreadsheet Software for

Preparing Budgets

$* \underline{p}<.05 . * * p<.01$. 
Ninety-one percent of the administrators who indicated that they had never used word processing software for communicating also reported that they had never taken an elective university/college course in computer training. Seventy-seven percent of the administrators who reported that they had never used e-mail software for communicating also indicated that they had never taken an elective university/college course in computer training. Eighty-six percent of the administrators who reported that they had never used presentation software on the job also reported that they had taken no elective university/college courses in computer applications. Twenty-three percent of the administrators reported some frequency of usage of desktop publishing software and the taking of an elective university/college computer training course. No significant relationships were found with the frequency of either database usage or electronic spreadsheet usage.

Community College Courses for Computer Training. A positive correlation was found between the frequency of usage of word processing software for communicating and computer training via community college courses. A positive correlation was also found between the frequency of usage of electronic spreadsheet software for preparing budgets and computer training received through a community college course. The results of three statistical analyses are presented in Table 20 . 
Table 20

Relationship Between Frequency of Computer Usage by Building-Level Public School

Administrators in West Virginia and Previous Computer Training Through Community College

\section{$\underline{\text { Course(s) }}$}

$\begin{array}{ccc}\text { Spearman's } & \text { Pearson Chi- } & \text { Mann- } \\ \text { Rho } & \text { Square } & \text { Whitney } \\ \text { p } & \underline{p} & \underline{p}\end{array}$

Usage of Database Software for Organizing

.859

.236

.859

Information

Usage of Word Processing Software for

$.021 *$

.163

$.021 *$

Communicating

Usage of E-Mail Software for

.717

.190

.717

Communicating

Usage of Presentation Software for Making

.196

.438

.195

Presentations

Usage of Desktop Publishing Software for

.076

.074

.076

Making Presentations

Usage of Electronic Spreadsheet Software for

$.006^{* *}$

$.028^{*}$

$.006 * *$

Preparing Budgets

$* \underline{p}<.05 . * * p<.01$. 
All administrators who had reported never using word processing in the management function of communicating on the job also reported no enrollment in a community college computer course. Ninety-eight percent of the administrators who reported never using electronic spreadsheet software for preparing budgets also reported never taking a computer training course through a community college.

Inservice Courses for Computer Training. No significant correlations were found between the frequency of computer usage by building-level administrators and computer training received through inservice opportunities. The results of three statistical analyses are presented in Table 21. 
Table 21

Relationship Between Frequency of Computer Usage by Building-Level Public School

Administrators in West Virginia and Previous Computer Training Through Inservice Course(s)

\begin{tabular}{|c|c|c|c|}
\hline & $\begin{array}{c}\text { Spearman's } \\
\text { Rho } \\
\text { p }\end{array}$ & $\begin{array}{c}\text { Pearson Chi- } \\
\text { Square } \\
\text { p }\end{array}$ & $\begin{array}{c}\text { Mann- } \\
\text { Whitney } \\
\text { p }\end{array}$ \\
\hline $\begin{array}{l}\text { Usage of Database Software for Organizing } \\
\text { Information }\end{array}$ & .404 & .628 & .404 \\
\hline $\begin{array}{l}\text { Usage of Word Processing Software for } \\
\text { Communicating }\end{array}$ & .341 & .293 & .341 \\
\hline $\begin{array}{l}\text { Usage of E-Mail Software for } \\
\text { Communicating }\end{array}$ & .670 & .867 & .670 \\
\hline $\begin{array}{l}\text { Usage of Presentation Software for Making } \\
\text { Presentations }\end{array}$ & .103 & .239 & .103 \\
\hline $\begin{array}{l}\text { Usage of Desktop Publishing Software for } \\
\text { Making Presentations }\end{array}$ & .387 & .501 & .386 \\
\hline $\begin{array}{l}\text { Usage of Electronic Spreadsheet Software for } \\
\text { Preparing Budgets }\end{array}$ & .357 & .775 & .356 \\
\hline
\end{tabular}


Self-Teaching for Computer Training. Positive correlations were found between previous computer training through self-teaching and the frequency of all categories of computer usage under study. The levels of significance were reported to be at the $\mathrm{p}<.01$ level in every case, as indicated in Table 22. 
Table 22

Relationship Between Frequency of Computer Usage by Building-Level Public School

Administrators in West Virginia and Previous Computer Training Through Self Teaching

\begin{tabular}{|c|c|c|c|}
\hline & $\begin{array}{c}\text { Spearman's } \\
\text { Rho } \\
\text { p }\end{array}$ & $\begin{array}{c}\text { Pearson Chi- } \\
\text { Square } \\
\text { p }\end{array}$ & $\begin{array}{c}\text { Mann- } \\
\text { Whitney } \\
\text { p }\end{array}$ \\
\hline $\begin{array}{l}\text { Usage of Database Software for Organizing } \\
\text { Information }\end{array}$ & $.000 * *$ & $.000 * *$ & $.000 * *$ \\
\hline $\begin{array}{l}\text { Usage of Word Processing Software for } \\
\text { Communicating }\end{array}$ & $.000 * *$ & $.000 * *$ & $.000 * *$ \\
\hline $\begin{array}{l}\text { Usage of E-Mail Software for } \\
\text { Communicating }\end{array}$ & $.000 * *$ & $.000 * *$ & $.000 * *$ \\
\hline $\begin{array}{l}\text { Usage of Presentation Software for Making } \\
\text { Presentations }\end{array}$ & $.000 * *$ & $.000 * *$ & $.000 * *$ \\
\hline $\begin{array}{l}\text { Usage of Desktop Publishing Software for } \\
\text { Making Presentations }\end{array}$ & $.000 * *$ & $.000 * *$ & $.000 * *$ \\
\hline $\begin{array}{l}\text { Usage of Electronic Spreadsheet Software for } \\
\text { Preparing Budgets }\end{array}$ & $.000 * *$ & $.005 * *$ & $.000 * *$ \\
\hline
\end{tabular}

$* * \mathrm{p}<.01$ 
One hundred eighty-four survey respondents, or 37 percent, indicated that they used database software on a daily basis and had received computer training through a self-teaching technique. Two hundred seventy-three, or 54 percent, of the survey respondents indicated that they used word processing on a daily basis for communicating and had undergone computer training through self-teaching. Ninety percent of those administrators who reported daily usage of word processing software for communicating had undergone self-training in computer applications. Four hundred five administrators reported that they had used self-teaching for computer training and used e-mail software for communicating at some level of frequency. This number represents 81 percent of those surveyed. All of the administrators who reported using presentation software on a daily basis also reported self-teaching as a method of computer training. Ninety-three percent of those individuals who reported using desktop publishing software on a daily basis received computer training through self-teaching. All respondents who indicated daily usage of spreadsheet software for preparing budgets also reported receiving computer training through self-teaching.

Peer Coaching for Computer Training. A positive correlation was found between the frequency of usage of database software for organizing information and peer coaching as a method of computer training. Further, a positive correlation was found between frequency of usage of word processing software for communicating and peer coaching as a method of computer training. The results of three statistical procedures are presented in Table 23. 
Table 23

Relationship Between Frequency of Computer Usage by Building-Level Public School

Administrators in West Virginia and Previous Computer Training Through Peer Coaching

\begin{tabular}{|c|c|c|c|}
\hline & $\begin{array}{c}\text { Spearman's } \\
\text { Rho } \\
\text { p }\end{array}$ & $\begin{array}{l}\text { Pearson Chi- } \\
\text { Square } \\
\text { p }\end{array}$ & $\begin{array}{c}\text { Mann- } \\
\text { Whitney } \\
\text { p }\end{array}$ \\
\hline $\begin{array}{l}\text { Usage of Database Software for Organizing } \\
\text { Information }\end{array}$ & $.046 *$ & .161 & $.046^{*}$ \\
\hline $\begin{array}{l}\text { Usage of Word Processing Software for } \\
\text { Communicating }\end{array}$ & $.030 *$ & .095 & $.030 *$ \\
\hline $\begin{array}{l}\text { Usage of E-Mail Software for } \\
\text { Communicating }\end{array}$ & .375 & .298 & .375 \\
\hline $\begin{array}{l}\text { Usage of Presentation Software for Making } \\
\text { Presentations }\end{array}$ & .309 & .380 & .309 \\
\hline $\begin{array}{l}\text { Usage of Desktop Publishing Software for } \\
\text { Making Presentations }\end{array}$ & .086 & .055 & .086 \\
\hline $\begin{array}{l}\text { Usage of Electronic Spreadsheet Software for } \\
\text { Preparing Budgets }\end{array}$ & .807 & .937 & .806 \\
\hline
\end{tabular}

$* \underline{p}<.05$. 
Seventy-five percent of the administrators who indicated daily usage of database software for organizing information also reported peer coaching as a route for computer training.

Similarly, 74 percent of the administrators who reported daily usage of word processing software for communicating also reported peer coaching as a method of computer training. No other relationships were found to be statistically significant.

\section{$\underline{\text { Research Question Seven }}$}

What is the relationship, if any, between the frequency of specific computer applications usage by building-level administrators in West Virginia and specific computer applications for which these administrators have received training within the last year?

No Specific Computer Application Training Within the Last Year. The frequency of usage of word processing software for communicating was found to be negatively correlated with having no previous specific computer application training. The results of three statistical analyses on having no previous specific computer application training are presented in Table 24. 
Table 24

Relationship Between Frequency of Computer Usage by Building-Level Public School

Administrators in West Virginia and No Previous Computer Application Training in the Last Year

\begin{tabular}{|c|c|c|c|}
\hline & $\begin{array}{c}\text { Spearman's } \\
\text { Rho } \\
\text { p }\end{array}$ & $\begin{array}{c}\text { Pearson Chi- } \\
\text { Square } \\
\text { p }\end{array}$ & $\begin{array}{c}\text { Mann- } \\
\text { Whitney } \\
\text { p }\end{array}$ \\
\hline $\begin{array}{l}\text { Usage of Database Software for Organizing } \\
\text { Information }\end{array}$ & .536 & .134 & .535 \\
\hline $\begin{array}{l}\text { Usage of Word Processing Software for } \\
\text { Communicating }\end{array}$ & $.001 * *$ & $.003 * *$ & $.001 * *$ \\
\hline $\begin{array}{l}\text { Usage of E-Mail Software for } \\
\text { Communicating }\end{array}$ & .105 & .406 & .105 \\
\hline $\begin{array}{l}\text { Usage of Presentation Software for Making } \\
\text { Presentations }\end{array}$ & .173 & .329 & .173 \\
\hline $\begin{array}{l}\text { Usage of Desktop Publishing Software for } \\
\text { Making Presentations }\end{array}$ & .088 & .190 & .088 \\
\hline $\begin{array}{l}\text { Usage of Electronic Spreadsheet Software for } \\
\text { Preparing Budgets }\end{array}$ & .477 & .965 & .476 \\
\hline
\end{tabular}

$* * \mathrm{p}<.01$ 
Fifty-seven percent of the administrators surveyed reported no previous specific computer application training and some level of usage of word processing for the management function of communicating. This was the only statistically significant relationship identified for no previous specific computer application training.

Word Processing Training Within the Last Year. West Virginia public school principals were asked to mark specific areas in which they had received training within the last year. One of these software areas was word processing. Table 25 presents the findings on the relationship between the frequency of computer usage by principals in West Virginia and having received word processing training within the last year. 
Table 25

Relationship Between Frequency of Computer Usage by Building-Level Public School

Administrators in West Virginia and Word Processing Training Received Within the Last Year

\begin{tabular}{|c|c|c|c|}
\hline & $\begin{array}{c}\text { Spearman's } \\
\text { Rho } \\
\text { p }\end{array}$ & $\begin{array}{c}\text { Pearson Chi- } \\
\text { Square } \\
\text { p }\end{array}$ & $\begin{array}{c}\text { Mann- } \\
\text { Whitney } \\
\text { p }\end{array}$ \\
\hline $\begin{array}{l}\text { Usage of Database Software for Organizing } \\
\text { Information }\end{array}$ & .705 & .187 & .705 \\
\hline $\begin{array}{l}\text { Usage of Word Processing Software for } \\
\text { Communicating }\end{array}$ & $.017 *$ & $.009 * *$ & $.018^{*}$ \\
\hline $\begin{array}{l}\text { Usage of E-Mail Software for } \\
\text { Communicating }\end{array}$ & .064 & .340 & .064 \\
\hline $\begin{array}{l}\text { Usage of Presentation Software for Making } \\
\text { Presentations }\end{array}$ & .214 & .599 & .214 \\
\hline $\begin{array}{l}\text { Usage of Desktop Publishing Software for } \\
\text { Making Presentations }\end{array}$ & .160 & .292 & .160 \\
\hline $\begin{array}{l}\text { Usage of Electronic Spreadsheet Software for } \\
\text { Preparing Budgets }\end{array}$ & .636 & .993 & .635 \\
\hline
\end{tabular}

$* \underline{p}<.05 . * * \underline{p}<.01$. 
A positive correlation was found between the frequency of computer usage by buildinglevel public school administrators in West Virginia and word processing training within the last year. Of the 21 administrators who indicated that they never used word processing in fulfilling their communication function, 18 reported that they had no word processing training within the last year. This number represents 86 percent of those who marked that they never use word processing software in their management function of communicating. No other correlations were found in these analyses.

Desktop Publishing Training Within the Last Year. A positive correlation was found between the frequency of computer usage by building-level administrators and having received desktop publishing training within the last year in five of six categories. No relationship was found between the frequency of database software usage for organizing information and having received desktop publishing training within the last year. The results from three statistical procedures are given in Table 26. 
Table 26

Relationship Between Frequency of Computer Usage by Building-Level Public School

Administrators in West Virginia and Desktop Publishing Training Received Within the Last Year

\begin{tabular}{|c|c|c|c|}
\hline & $\begin{array}{c}\text { Spearman's } \\
\text { Rho } \\
\text { p }\end{array}$ & $\begin{array}{c}\text { Pearson Chi- } \\
\text { Square } \\
\text { p }\end{array}$ & $\begin{array}{c}\text { Mann- } \\
\text { Whitney } \\
\text { p }\end{array}$ \\
\hline $\begin{array}{l}\text { Usage of Database Software for Organizing } \\
\text { Information }\end{array}$ & .081 & .246 & .081 \\
\hline $\begin{array}{l}\text { Usage of Word Processing Software for } \\
\text { Communicating }\end{array}$ & $.000 * *$ & $.003 * *$ & $.000 * *$ \\
\hline $\begin{array}{l}\text { Usage of E-Mail Software for } \\
\text { Communicating }\end{array}$ & $.003 * *$ & .055 & $.003 * *$ \\
\hline $\begin{array}{l}\text { Usage of Presentation Software for Making } \\
\text { Presentations }\end{array}$ & $.001 * *$ & $.015^{*}$ & $.001 * *$ \\
\hline $\begin{array}{l}\text { Usage of Desktop Publishing Software for } \\
\text { Making Presentations }\end{array}$ & $.000 * *$ & $.000 * *$ & $.000 * *$ \\
\hline $\begin{array}{l}\text { Usage of Electronic Spreadsheet Software for } \\
\text { Preparing Budgets }\end{array}$ & $.019 *$ & $.019 *$ & $.020 *$ \\
\hline
\end{tabular}

$* \underline{p}<.05 . * * \underline{p}<.01$ 
All 21 administrators who reported that they never used word processing software for communication also reported no desktop publishing training within the last year. Thirty-one administrators reported that they never used e-mail software in their management function of communicating. Ninety-four percent of these administrators also reported no desktop publishing software training within the last year. There were 110 administrators who reported that they never used presentation software for giving presentations. Ninety-five percent of these administrators reported that they had received no desktop publishing software training within the last year. One hundred twenty-four administrators reported that they did not use desktop publishing software in fulfilling their management role of making presentations. Ninety-seven percent of these administrators received no training in desktop publishing software within the last year. Ninety-one percent of those administrators who reported never using electronic spreadsheet software for preparing budgets also reported that they received no desktop publishing training within the last year.

Internet Browser Training Within the Last Year. No correlations were found between the frequency of computer usage by building-level public school administrators in West Virginia and Internet browser training within the last year. The results of Spearman's Rho, the Pearson ChiSquare, and the Mann-Whitney U tests are presented in Table 27. 
Table 27

Relationship Between Frequency of Computer Usage by Building-Level Public School

Administrators in West Virginia and Internet Browser Training Received Within the Last Year

\begin{tabular}{|c|c|c|c|}
\hline & $\begin{array}{c}\text { Spearman's } \\
\text { Rho } \\
\text { p }\end{array}$ & $\begin{array}{c}\text { Pearson Chi- } \\
\text { Square } \\
\text { p }\end{array}$ & $\begin{array}{c}\text { Mann- } \\
\text { Whitney } \\
\text { p }\end{array}$ \\
\hline $\begin{array}{l}\text { Usage of Database Software for Organizing } \\
\text { Information }\end{array}$ & .360 & .817 & .359 \\
\hline $\begin{array}{l}\text { Usage of Word Processing Software for } \\
\text { Communicating }\end{array}$ & .286 & .157 & .286 \\
\hline $\begin{array}{l}\text { Usage of E-Mail Software for } \\
\text { Communicating }\end{array}$ & .750 & .663 & .749 \\
\hline $\begin{array}{l}\text { Usage of Presentation Software for Making } \\
\text { Presentations }\end{array}$ & .918 & .951 & .918 \\
\hline $\begin{array}{l}\text { Usage of Desktop Publishing Software for } \\
\text { Making Presentations }\end{array}$ & .802 & .934 & .802 \\
\hline $\begin{array}{l}\text { Usage of Electronic Spreadsheet Software for } \\
\text { Preparing Budgets }\end{array}$ & .993 & .448 & .993 \\
\hline
\end{tabular}


Database Training Within the Last Year. Positive correlations were found between the frequencies of computer usage of database software, word processing software, and presentation software and having received database training within the last year. The results of three different statistical analyses are presented in Table 28. 
Table 28

Relationship Between Frequency of Computer Usage by Building-Level Public School

$\underline{\text { Administrators in West Virginia and Database Training Received Within the Last Year }}$

\begin{tabular}{|c|c|c|c|}
\hline & $\begin{array}{c}\text { Spearman's } \\
\text { Rho } \\
\text { p }\end{array}$ & $\begin{array}{c}\text { Pearson Chi- } \\
\text { Square } \\
\text { p }\end{array}$ & $\begin{array}{c}\text { Mann- } \\
\text { Whitney } \\
\text { p }\end{array}$ \\
\hline $\begin{array}{l}\text { Usage of Database Software for Organizing } \\
\text { Information }\end{array}$ & $.000 * *$ & $.001 * *$ & $.000 * *$ \\
\hline $\begin{array}{l}\text { Usage of Word Processing Software for } \\
\text { Communicating }\end{array}$ & $.025 *$ & .175 & $.025^{*}$ \\
\hline $\begin{array}{l}\text { Usage of E-Mail Software for } \\
\text { Communicating }\end{array}$ & .530 & .381 & .529 \\
\hline $\begin{array}{l}\text { Usage of Presentation Software for Making } \\
\text { Presentations }\end{array}$ & $.011 *$ & .091 & $.011^{*}$ \\
\hline $\begin{array}{l}\text { Usage of Desktop Publishing Software for } \\
\text { Making Presentations }\end{array}$ & .265 & .175 & .265 \\
\hline $\begin{array}{l}\text { Usage of Electronic Spreadsheet Software for } \\
\text { Preparing Budgets }\end{array}$ & .083 & .396 & .083 \\
\hline
\end{tabular}

$* \underline{p}<.05 . * * \underline{p}<.01$. 
Ninety-three percent of those administrators who indicated that they never used database software for organizing information also reported having received no database training within the last year. Ninety-one percent of the administrators who reported that they never used word processing for their management function of communicating also reported no database software training within the last year. Moreover, 88 percent of those administrators who reported never using presentation software for preparing presentations also reported no database software training within the last year.

Electronic Spreadsheet Training Within the Last Year. Positive correlations were found between the frequency of computer usage for five of six categories of software and receiving electronic spreadsheet training within the last year. The outcomes of three statistical analyses are presented in Table 29. 
Table 29

Relationship Between Frequency of Computer Usage by Building-Level Public School

Administrators in West Virginia and Electronic Spreadsheet Training Received Within the Last

$\underline{\text { Year }}$

$\begin{array}{ccc}\text { Spearman's } & \text { Pearson Chi- } & \text { Mann- } \\ \text { Rho } & \text { Square } & \text { Whitney } \\ \text { p } & \underline{p} & \underline{p}\end{array}$

Usage of Database Software for Organizing

.100

.418

.100

Information

Usage of Word Processing Software for

$.000 * *$

$.004 * *$

$.000 * *$

Communicating

Usage of E-Mail Software for

$.000 * *$

$.004 * *$

$.000 * *$

Communicating

Usage of Presentation Software for Making

$.005 * *$

.083

$.005 * *$

Presentations

Usage of Desktop Publishing Software for

$.023 *$

.127

$.023^{*}$

Making Presentations

Usage of Electronic Spreadsheet Software for

$.028 *$

.237

$.028 *$

Preparing Budgets

$* \underline{p}<.05 . * * \underline{p}<.01$. 
All administrators who reported never using word processing software for their management function of communicating also reported that they received no electronic spreadsheet training within the last year. Ninety-seven percent of the administrators who reported that they never used e-mail also reported receiving no electronic spreadsheet software training within the last year. Likewise, 91 percent of those administrators who reported never using presentation software for creating presentations also reported receiving no electronic spreadsheet computer training within the last year. Eighty-nine percent of those administrators who indicated that they never used desktop publishing software for creating presentations also reported that they had received no electronic spreadsheet computer training within the last year. This same percentage was reported by administrators who never used electronic spreadsheet software for preparing budgets.

E-Mail Training Within the Last Year. A positive correlation was found between the frequency of computer usage of word processing software and administrators having received email training within the last year. Another positive correlation was found between the frequency of computer usage of electronic mail software for communicating and administrators having received e-mail training within the last year. The results of the statistical procedures conducted on these data are presented in Table 30. 
Table 30

Relationship Between Frequency of Computer Usage by Building-Level Public School

Administrators in West Virginia and Electronic Mail Training Within the Last Year

\begin{tabular}{|c|c|c|c|}
\hline & $\begin{array}{c}\text { Spearman's } \\
\text { Rho } \\
\text { p }\end{array}$ & $\begin{array}{c}\text { Pearson Chi- } \\
\text { Square } \\
\text { p }\end{array}$ & $\begin{array}{c}\text { Mann- } \\
\text { Whitney } \\
\text { p }\end{array}$ \\
\hline $\begin{array}{l}\text { Usage of Database Software for Organizing } \\
\text { Information }\end{array}$ & .282 & .865 & .281 \\
\hline $\begin{array}{l}\text { Usage of Word Processing Software for } \\
\text { Communicating }\end{array}$ & $.002 * *$ & $.017 *$ & $.002 * *$ \\
\hline $\begin{array}{l}\text { Usage of E-Mail Software for } \\
\text { Communicating }\end{array}$ & $.009 * *$ & .066 & $.010^{*}$ \\
\hline $\begin{array}{l}\text { Usage of Presentation Software for Making } \\
\text { Presentations }\end{array}$ & .058 & .112 & .058 \\
\hline $\begin{array}{l}\text { Usage of Desktop Publishing Software for } \\
\text { Making Presentations }\end{array}$ & .211 & .637 & .210 \\
\hline $\begin{array}{l}\text { Usage of Electronic Spreadsheet Software for } \\
\text { Preparing Budgets }\end{array}$ & .313 & .273 & .312 \\
\hline
\end{tabular}

$* \underline{p}<.05 . * * \underline{p}<.01$ 
Seventy-six percent of those administrators who reported no usage of word processing in their jobs for communication also reported no electronic mail training within the last year. Further, 90 percent of those administrators who reported no usage of e-mail for communicating also reported no e-mail training within the last year.

\section{$\underline{\text { Research Question Eight }}$}

What is the relationship, if any, between the frequency of specific computer applications usage by building-level administrators in West Virginia and the amount of computer training received by these administrators within the last year?

The third question under computer training on the West Virginia Building-Level Administrator Computer Usage Survey 2000 form asked administrators to indicated the amount of computer training they had received within the last year. Administrators were asked to indicate the number of hours of training received within six given ranges. Two statistical analyses were performed on these data. The results of these tests are presented in Table 31. 
Table 31

$\underline{\text { Relationship Between Frequency of Computer Usage by Building-Level Public School }}$

Administrators in West Virginia and the Amount of Computer Training Received Within the Last

$\underline{\text { Year }}$

\section{Spearman's Rho}

Communicating

Usage of Presentation Software for Making

Presentations

Usage of Desktop Publishing Software for

Making Presentations

Usage of Electronic Spreadsheet Software for

Preparing Budgets $\mathrm{p}$

.073

$.015^{*}$

$.013 *$

.404

Pearson Chi-Square

p

.126

.275

$.002 * *$

$.045^{*}$

$.002 * *$

$.042 *$

.217

.171

$* \underline{p}<.05 . * * \underline{p}<.01$ 
A positive correlation was found between the frequency of word processing usage for communication and the amount of training received within the last year. Sixty-nine percent of the administrators who responded to the survey indicated some level of computer training within the last year. Fifty-six percent of the administrators surveyed indicated that they used word processing software daily or often and received some amount of computer training within the last year. Forty-seven percent of those surveyed reported that they used e-mail software for the management function of communicating and reported some amount of computer training within the last year. Thirty-eight percent of those administrators who indicated no usage of presentation software for creating presentations in their job also reported no amount of computer training received within the last year. Thirty-six percent of those administrators who reported no usage of desktop publishing software for making presentations also indicated that they received no amount of computer training within the last year.

\section{$\underline{\text { Research Question Nine }}$}

What is the relationship, if any, between the frequency of specific computer applications usage by building-level administrators in West Virginia and the perceptions and attitudes of these administrators toward technology?

Nine questions concerning perceptions and attitudes of administrators toward technology were asked. Survey respondents indicated their level of agreement with each statement by marking one of five categories from strongly agree to strongly disagree on a Likert-type scale. The nine statements in this section of the survey instrument were taken from the 1996 Benson survey instrument used in the Washoe County School District in Reno, Nevada. The relationship between the frequency of computer usage of building-level administrators and the responses to 
this statement was tested using two statistical analyses. The results of these two tests are presented in Table 32. 
Table 32

$\underline{\text { Relationship Between Frequency of Computer Usage by Building-Level Public School }}$

Administrators in West Virginia and Perceptions and Attitudes Toward Technology

\begin{tabular}{lcc}
\hline & Spearman's Rho & Pearson Chi-Square \\
& $\mathrm{p}$ & $.000^{* *}$ \\
\hline $\begin{array}{l}\text { Usage of Database Software for Organizing } \\
\text { Information }\end{array}$ & & $.000^{* *}$ \\
$\begin{array}{l}\text { Usage of Word Processing Software for } \\
\text { Communicating }\end{array}$ & $.000^{* *}$ & $.000^{* *}$ \\
$\begin{array}{l}\text { Usage of E-Mail Software for } \\
\text { Communicating }\end{array}$ & $.000^{* *}$ & .177 \\
$\begin{array}{l}\text { Usage of Presentation Software for Making } \\
\text { Presentations }\end{array}$ & $.000^{* *}$ & .062 \\
$\begin{array}{l}\text { Usage of Desktop Publishing Software for } \\
\text { Making Presentations }\end{array}$ & $.000^{* *}$ & \\
Usage of Electronic Spreadsheet Software for \\
Preparing Budgets
\end{tabular}

$* * \mathrm{p}<.01$ 
Spearman's Rho indicated statistically significant, positive relationships between the frequency of computer usage for all six categories of software under study. West Virginia building-level administrators who utilized database software for organizing information, word processing and e-mail software for communicating, presentation and desktop publishing software for making presentations, and electronic spreadsheet software for preparing budgets indicated positive attitudes toward computers and technology.

\section{$\underline{\text { Research Question Ten }}$}

What is the relationship, if any, between the frequency of specific computer applications usage by building-level administrators in West Virginia and the perception of

\section{the individual leadership outcome of extra effort expressed by these administrators?}

Nine questions were included on the West Virginia Building-Level Administrator Computer Usage Survey 2000 form to assess each administrator's perception of his/her leadership outcomes. According to Bass and Avolio (1996), leadership outcomes fall into three categories: extra effort, effectiveness, and satisfaction.

Extra effort is the ability to get others to do more than they expected to do, the ability to heighten others' desire to succeed, and the ability to increase others' willingness to try harder. Survey questions 20,23, and 25 relate to the leadership outcome of extra effort. Analyses were conducted on the data to determine if a relationship existed between the frequency of computer usage by building-level administrators and each administrator's perception of his/her leadership outcome of extra effort. Survey Question 20 stated that "I get others to do more than they expected to do." Survey item 23 stated that "I heighten others' desire to succeed." Item 25 on the survey instrument stated "I increase others' willingness to try harder." The results of two 
statistical procedures on the relationship of the individual leadership outcome of extra effort to the frequency of computer usage by building-level administrators are presented in Table 33 . 
Table 33

$\underline{\text { Relationship Between Frequency of Computer Usage by Building-Level Public School }}$

Administrators in West Virginia and Individual Leadership Outcome of Extra Effort

Spearman's Rho

Usage of Word Processing Software for

Communicating

Usage of E-Mail Software for

Communicating

Usage of Presentation Software for Making

Presentations

Usage of Desktop Publishing Software for

Making Presentations

Usage of Electronic Spreadsheet Software for

Preparing Budgets p

$.037 *$

.227

Pearson Chi-Square

p

$.047 *$

.310

.469

.902

$.005^{* *}$

$.005^{* *}$

$.001 * *$

$.049 *$

.386

.793

$* p<.05 . * * p<.01$. 
A positive correlation was found between the frequency of usage of database software for organizing information and the individual leadership outcome of extra effort. Positive correlations were also found between the frequencies of usage of presentation software and desktop publishing software for making presentations and the individual leadership outcome of extra effort. No relationships were found between extra effort and computer usage for communicating or preparing budgets.

\section{$\underline{\text { Research Question Eleven }}$}

What is the relationship, if any, between the frequency of specific computer applications usage by building-level administrators in West Virginia and the perception of

\section{the individual leadership outcome of effectiveness expressed by these administrators?}

Four questions were asked which related to the leadership outcome of effectiveness. Bass and Avolio (1996) describe effectiveness as being effective in meeting others' job-related needs, being effective in representing their group to higher authority, being effective in meeting organizational requirements, and being effective in leading a group that is effective. The first question on effectiveness was survey item 18 which read: "I am effective in meeting others' job related needs." The second question which related to the leadership outcome of effectiveness was survey item 21. This item stated: "I am effective in representing others to higher authority." The third question relating to the leadership outcome of effectiveness was survey item 24 . This item stated: "I am effective in meeting organizational requirements." The final question on effectiveness was survey item 26. This item read: "I lead a group that is effective." Table 34 presents the findings of two statistical procedures on the aforementioned data. 
Table 34

Relationship Between Frequency of Computer Usage by Building-Level Public School

Administrators in West Virginia and Individual Leadership Outcome of Effectiveness

\begin{tabular}{|c|c|c|}
\hline & $\begin{array}{l}\text { Spearman's Rho } \\
\text { p }\end{array}$ & $\begin{array}{c}\text { Pearson Chi-Square } \\
\underline{\mathrm{p}}\end{array}$ \\
\hline $\begin{array}{l}\text { Usage of Database Software for Organizing } \\
\text { Information }\end{array}$ & .075 & .628 \\
\hline $\begin{array}{l}\text { Usage of Word Processing Software for } \\
\text { Communicating }\end{array}$ & .069 & .833 \\
\hline $\begin{array}{l}\text { Usage of E-Mail Software for } \\
\text { Communicating }\end{array}$ & .108 & .542 \\
\hline $\begin{array}{l}\text { Usage of Presentation Software for Making } \\
\text { Presentations }\end{array}$ & $.022 *$ & .068 \\
\hline $\begin{array}{l}\text { Usage of Desktop Publishing Software for } \\
\text { Making Presentations }\end{array}$ & $.009 * *$ & .181 \\
\hline $\begin{array}{l}\text { Usage of Electronic Spreadsheet Software for } \\
\text { Preparing Budgets }\end{array}$ & .870 & .909 \\
\hline
\end{tabular}


Spearman's Rho indicated two positive relationships when comparing the individual leadership outcome of effectiveness with the frequency of computer usage by West Virginia building-level administrators. These relationships were between the frequencies of usage of presentation and desktop publishing software for making presentations. A stronger correlation was found between the use of desktop publishing software and effectiveness. No relationships were found between the individual leadership outcome of effectiveness and computer usage for organizing information, communicating, or preparing budgets.

\section{$\underline{\text { Research Question Twelve }}$}

\section{What is the relationship, if any, between the frequency of specific computer}

\section{applications usage by building-level administrators in West Virginia and the perception of the individual leadership outcome of satisfaction expressed by these administrators?}

The third area that was investigated for leadership outcomes was satisfaction. Bass and Avolio (1996) believe that satisfaction exists when one uses methods of leadership that are satisfying and could work with others in a satisfactory way. Survey items 19 and 22 related to satisfaction. Survey item 19 read: "I use methods of leadership that are satisfying." Statement 22 read: "I work with others in a satisfactory way." Two statistical analyses were conducted to determine if a relationship existed between the responses to these items and the frequency of computer usage by building-level administrators. The results of these tests are presented in Table 35. 
Table 35

$\underline{\text { Relationship Between Frequency of Computer Usage by Building-Level Public School }}$

$\underline{\text { Administrators in West Virginia and Individual Leadership Outcome of Satisfaction }}$

Spearman's Rho

$\mathrm{p}$

.117

.086

.918

Communicating

Usage of E-Mail Software for

.082

Communicating

Usage of Presentation Software for Making

Presentations

Usage of Desktop Publishing Software for

Making Presentations

Usage of Electronic Spreadsheet Software for

Preparing Budgets
$.006 * * \quad .007 *$

$.006 * * \quad .035^{*}$

.776
.345

.491
Pearson Chi-Square

p

$* \mathrm{p}<.05 . * * \mathrm{p}<.01$. 
Spearman's Rho indicated that the frequency of computer usage for the management function of making presentations was significantly related to the individual leadership outcome of satisfaction. The statistical significance using Spearman's Rho indicated $\underline{p}<.01$ for the frequency of usage of both presentation software and desktop publishing software. Pearson's Chi-Square found levels of significance for these items at the $p<.05$ level which allows the researcher to reject the null hypothesis that there is no association between the individual leadership outcome of satisfaction and the frequency of usage of software for making presentations. No relationships were found between the leadership outcome of satisfaction and the utilization of software for the management functions of organizing information, communicating, or preparing budgets.

\section{$\underline{\text { Research Question Thirteen }}$}

What demographic characteristics, if any, are predictors for the frequency of specific computer applications usage by building-level administrators in West Virginia for the management functions of organizing information, communicating, making presentations, and preparing budgets?

The final research question examined possible predictors for the frequency of computer usage by building-level administrators in West Virginia in completing their management tasks of organizing information, communicating, making presentations, and preparing budgets. Demographic data were collected on gender, age, ethnicity, education level, previous teaching experience, years of administrative experience, current school assignment, years at present site, student enrollment, number of professional staff, number of classified staff, and Regional Education Service Agency location. 
A stepwise forward multiple regression analysis was conducted to determine if there were any demographic characteristics which were predictors of computer usage of database software for organizing information, word processing software for communicating, e-mail software for communicating, presentation software for making presentations, desktop publishing software for making presentations, and electronic spreadsheet software for preparing budgets. Table 36 lists the demographic predictors for the frequency of computer usage of database software for the management function of organizing information. 
Table 36

Demographic Characteristics Which Predict the Usage of Database Software for the Management Function of Organizing information

\begin{tabular}{lll}
\hline & $\begin{array}{c}\text { Positive } \\
\text { Predictors }\end{array}$ & $\begin{array}{c}\text { Negative } \\
\text { Predictors }\end{array}$ \\
\hline $\begin{array}{l}\text { Usage of Database Software for Organizing } \\
\text { Information }\end{array}$ & Gender \\
& $\begin{array}{l}\text { Regional Education } \\
\text { Service Area } \\
\text { (RESA) Location }\end{array}$ \\
\hline
\end{tabular}


The stepwise forward multiple linear regression analysis pointed out two negative predictors for the frequency of use of database software for the management function of organizing information. These predictors were gender and Regional Education Service Agency. Further analysis of the data indicated that 47 percent of the male respondents reported daily usage of database software for organizing information while only 31 percent of female respondents reported daily usage of this same software. Only 6.2 percent of respondents from RESA VI indicated daily usage of database software for organizing information. Further, only 8.1 percent of respondents from RESA VIII reported daily usage of database software for organizing information. The percentages for the other RESA locations ranged from 12 to 18 percent.

The frequency of usage of word processing software for the management function of communicating was the next category to be examined. Again, a stepwise forward multiple linear regression analysis was conducted to determine the predictors of the frequency of word processing software usage for communicating. The results of this analysis are provided in Table 37. 
Table 37

Demographic Characteristics Which Predict the Usage of Word Processing Software for the Management Function of Communicating

\begin{tabular}{|c|c|c|}
\hline & $\begin{array}{c}\text { Positive } \\
\text { Predictors }\end{array}$ & $\begin{array}{l}\text { Negative } \\
\text { Predictors }\end{array}$ \\
\hline $\begin{array}{l}\text { Usage of Word Processing Software for } \\
\text { Organizing Information }\end{array}$ & $\begin{array}{l} \\
\text { Ethnicity } \\
\text { Gender } \\
\text { Regional Education } \\
\text { Service Area (RESA) } \\
\text { Location } \\
\text { Current School } \\
\text { Assignment at a } \\
\text { Vocational School }\end{array}$ & $\begin{array}{l}\text { Years at Present } \\
\text { Site Assignment } \\
\text { Previous Teaching } \\
\text { Experience in } \\
\text { Secondary Physical } \\
\text { Education }\end{array}$ \\
\hline
\end{tabular}


The stepwise forward multiple linear regression analysis found two negative demographic predictors and four positive demographic predictors for the frequency of word processing usage for the management function of communicating. The negative predictors identified were years at present site assignment and previous teaching experience in secondary physical education. Sixtyseven percent of the building level administrators who reported never using word processing for the management function of communicating had been at their present site for more than 10 years. The four positive predictors identified were ethnicity, gender, RESA location, and a current administrative assignment at a vocational school. Ninety-eight percent of the administrators who reported using word processing on a daily basis for the management function of communication were white, not of Hispanic origin. However, it should be noted that 97.2 percent of the survey respondents reported being white, not of Hispanic origin. Sixty percent of the administrators who reported using word processing on a daily basis were men. Also, 70 percent of the administrators who indicated that they used word processing often were men. Thirty-seven percent of the administrators who reported daily or often usage of word processing software for the management function of communicating indicated that they were located in RESA VII.

A stepwise forward multiple linear analysis was also conducted to determine predictors for the frequency of e-mail software usage for the management function of communicating. The results of this procedures are given in Table 38 . 
Table 38

Demographic Characteristics Which Predict the Usage of E-Mail Software for the Management Function of Communicating

\begin{tabular}{|c|c|c|}
\hline & $\begin{array}{l}\text { Positive } \\
\text { Predictors }\end{array}$ & $\begin{array}{l}\text { Negative } \\
\text { Predictors }\end{array}$ \\
\hline \multirow[t]{4}{*}{ Usage of E-Mail Software for Communicating } & & Age \\
\hline & & $\begin{array}{l}\text { Previous Teaching } \\
\text { Experience in } \\
\text { Secondary Physical } \\
\text { Education }\end{array}$ \\
\hline & Educational Level & \\
\hline & $\begin{array}{l}\text { Number of Professional } \\
\text { Staff }\end{array}$ & \\
\hline
\end{tabular}


Through the stepwise forward multiple analysis on the frequency of e-mail usage and demographic data, two negative predictors were identified, and two positive predictors were discovered. The two negative characteristics identified with the frequency of usage of e-mail software were age and previous teaching experience in secondary physical education. Seventyone percent of the administrators who reported no usage of e-mail software for communicating also reported an age over 50 years. The two positive predictors for the frequency of usage of email software for the management function of communicating were educational level and the number of professional staff. Seventy-two percent of the administrators who reported daily usage of e-mail software also indicated an educational level of a master's degree plus 45 hours. However, it should also be noted that 72.4 percent of the administrators surveyed indicated a current educational level of a master's degree plus 45 hours. Thirty-seven percent of the administrators who indicated daily usage of e-mail software for communicating also reported the number of professional staff at their site to be 10 to 25 .

The stepwise forward multiple linear regression analysis was ran on the frequency of usage of presentation software for the management function of making presentations and demographic characteristics to determine possible predictors for usage of this software. The outcome of this analysis is displayed in Table 39. 
Table 39

Demographic Characteristics Which Predict the Usage of Presentation Software for the

Management Function of Making Presentations

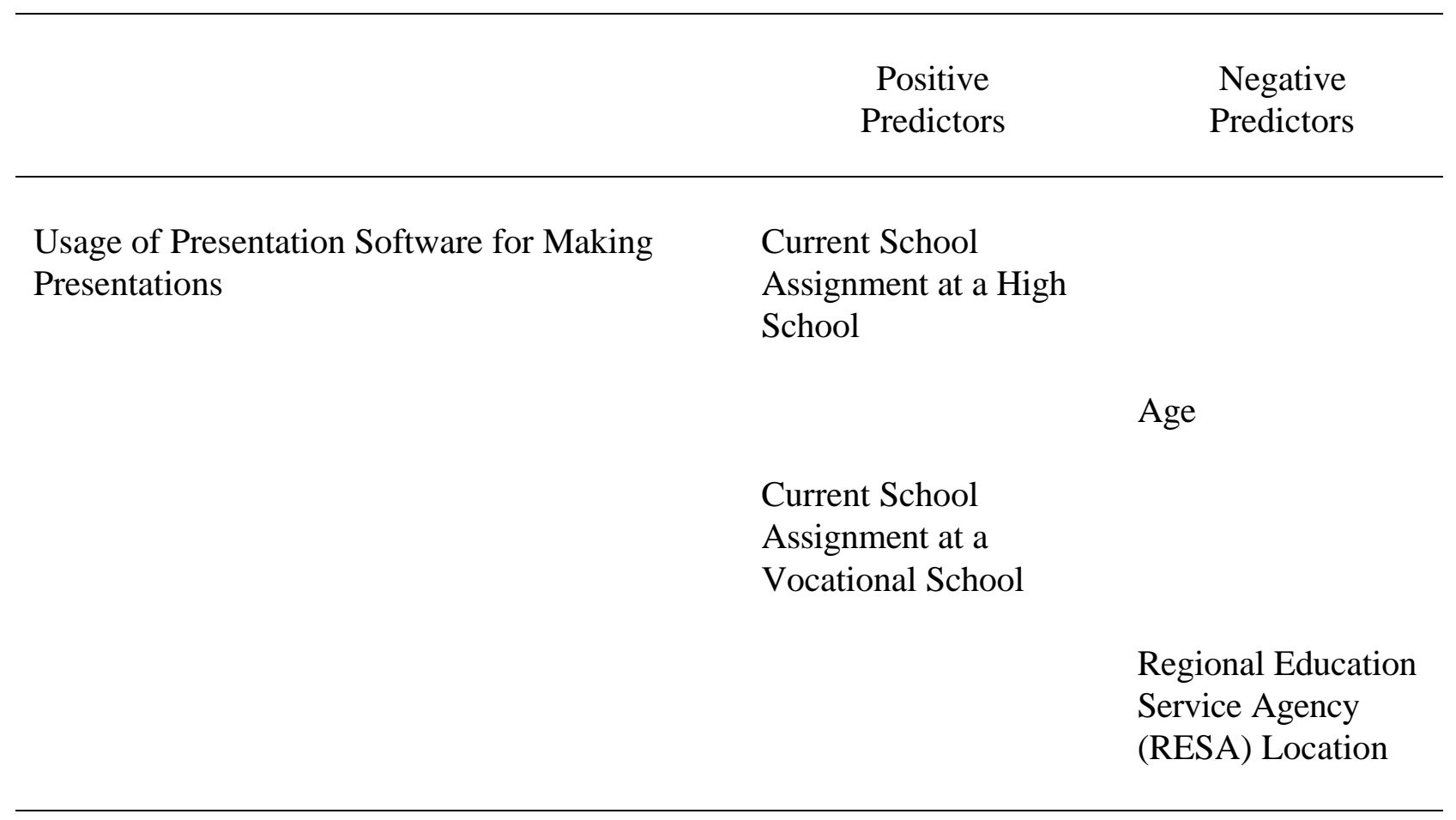


The results of the stepwise forward multiple linear regression procedures indicated two positive demographic predictors and two negative demographic predictors for the frequency of the usage of presentation software for the management function of making presentations. The two positive demographic predictors discovered were current school assignment at a high school and current school assignment at a vocational school. The two negative predictors that were identified were age and RESA location. Sixty-four percent of the administrators who reported that they never used presentation software for making presentations indicated ages over 50 years. Thirty-eight percent of the building-level administrators who reported that they either never or rarely used presentation software indicated being located in RESA VII.

Another category of software used for making presentations is desktop publishing. The stepwise forward multiple linear regression analysis was conducted on the frequency of usage of desktop publishing software in conjunction with demographic variables to determine predictors of desktop publishing computer software for making presentations. The results of this analysis are presented in Table 40. 
Table 40

Demographic Characteristics Which Predict the Usage of Desktop Publishing Software for the Management Function of Making Presentations

\begin{tabular}{lll}
\hline & \multicolumn{1}{c}{$\begin{array}{c}\text { Positive } \\
\text { Predictors }\end{array}$} & $\begin{array}{c}\text { Negative } \\
\text { Predictors }\end{array}$ \\
\hline $\begin{array}{l}\text { Usage of Desktop Publishing Software for } \\
\text { Making }\end{array}$ & & Age \\
& & \\
& & \\
& & \\
& Previous Teaching \\
Extations & School-Grades 5-8 & \\
& \\
\hline
\end{tabular}


Two demographic predictors were found after utilizing the stepwise forward multiple linear regression analysis. Previous teaching experience at the middle school level was found to be a positive predictor for the frequency of computer usage by building-level administrators for the management function of making presentations. Age was found to be a negative predictor for the frequency of desktop publishing software usage. Sixty-five percent of the administrators who reported never using desktop publishing software for making presentations also indicated ages over 50 years.

The final category of software usage to be examined was electronic spreadsheet usage for the management function of preparing budgets. Again, a stepwise forward multiple linear regression analysis was performed to determine predictors of the frequency of electronic spreadsheet usage for preparing budgets. The results of this procedure are presented in Table 41 . 
Table 41

Demographic Characteristics Which Predict the Usage of Electronic Spreadsheet Software for the Management Function of Preparing Budgets

\begin{tabular}{lll}
\hline & Positive & Negative \\
Predictors & Predictors \\
\hline $\begin{array}{l}\text { Usage of Electronic Spreadsheet Software for } \\
\text { Preparing }\end{array}$ & & Age \\
Budgets & & \\
& $\begin{array}{l}\text { Current School } \\
\text { Assignment at a } \\
\text { Vocational School }\end{array}$ \\
\hline
\end{tabular}


The results of the stepwise forward multiple linear regression analysis found two demographic predictors for the frequency of usage of electronic spreadsheet software for the management function of preparing budgets. A current school assignment at a vocational school was found to be a demographic characteristic which was a positive predictor of the frequency of electronic spreadsheet usage. Age was identified as a negative predictor for the frequency of usage of electronic spreadsheet software for preparing budgets. Fifty-six percent of the administrators who indicated no usage of electronic spreadsheets for preparing budgets also reported ages over 50 years.

\section{Ancillary Findings}

The researcher wondered if there were any correlations between the types of computer training taken by building-level administrators in West Virginia and the gender of the administrator. The researcher analyzed these data from the West Virginia Building-Level Administrator Computer Usage Survey 2000 form using Spearman’s Rho, Pearson’s Chi Square, and the Mann-Whitney U tests in SPSS Version 10.0 for Windows. The types of computer training examined were those asked in survey item six. Only one significant correlation was found. A statistically significant relationship was found between building-level administrators receiving training through a community college course or courses and gender. Spearman's Rho indicated a correlation coefficient of .011. Ten percent of female survey respondents indicated that they had received some training through community college courses. Only three percent of their male counterparts reported the same information. 


\section{Summary of Chapter}

The purpose of this study was to determine the frequency with which building-level administrators, or principals, in West Virginia public schools used office productivity software to complete their management tasks of organizing information, communicating, making presentations, and preparing budgets. The West Virginia Building-Level Administrator Computer Usage Survey 2000 form was mailed to all public school principals in the state of West Virginia. Five hundred three usable responses were obtained. The researcher asked if a relationship existed between the frequency of computer usage by building-level administrators and eleven independent variables. These variables were having a computer in the home, the types of computer platforms/operating systems previously used, the number of years of usage of a personal computer, the types of computer applications used at home, types of computer training received, specific computer application training received within the last year, the amount of computer training received within the last year, perceptions and attitudes toward computers and technology, the individual leadership outcome of extra effort, the individual leadership outcome of effectiveness, and the individual leadership outcome of satisfaction. Demographic data were analyzed to determine predictors for the frequency of computer usage.

The first research question asked about the current status of the frequency of specific computer applications usage by building-level administrators in West Virginia as it relates to the management functions of organizing information, communicating, making presentations, and preparing budgets. Forty-two percent of the administrators surveyed reported daily usage of database software for organizing information. For the management task of communicating, 60 percent of the administrators surveyed reported daily usage of word processing software and 51 
percent of this same group reported daily usage of e-mail programs. For the management function of making presentations, the percentages were smaller. Less than one percent of thebuilding-level administrators surveyed reported using presentation software on a daily basis. However, three percent of the building-level administrators surveyed reported daily usage of desktop publishing software for making presentations. Slightly more than two percent of the administrators surveyed reported daily usage of electronic spreadsheet software for the management task of preparing budgets.

Research questions two through five were asked to determine the relationships between the frequency of specific computer applications usage by building-level administrators and four general computer usage independent variables. These four items on the survey instrument which related to general computer were taken from the Benson 1996 survey. The first of these items asked the administrators if they had a computer in their home. Positive correlations were found between the frequency of usage of database, word processing, e-mail, presentation, desktop publishing, and electronic spreadsheet software and having a home personal computer. These building-level administrators were more likely to use database software for the management function of organizing information on the job if they had a home personal computer. Buildinglevel administrators were more likely to use word processing and e-mail software for communicating in their work if they had a home personal computer. Administrators were more likely to use presentation and desktop publishing software for making presentations if they had a home personal computer. Finally, administrators were more likely to use electronic spreadsheet software for preparing budgets at work if they had a home personal computer. 
The second item under General Computer Use asked administrators what types of computer platforms they had previously used. Administrators could have chosen none, DOS, Windows, and/or Macintosh/Apple. Administrators who marked none in this category were likely not to use the computer on the job for supporting management functions of organizing information, communicating, making presentations, or budgeting. Administrators who had previously used DOS were more likely to use database, word processing, e-mail, and presentations software on the job. Administrators with previous experience using Windows were more likely to use all the office productivity programs for supporting the management functions of organizing information, communicating, making presentations, and preparing budgets. Buildinglevel administrators with previous experience with Macintosh/Apple operating systems were more likely to use word processing and e-mail for communicating. These administrators were also more likely to use desktop publishing software for making presentations.

The third item under General Computer Use asked administrators to indicate the number of years they had used a personal computer. Results indicated that building-level administrators were more likely to use office productivity software for supporting their management functions of organizing information, communicating, making presentations, and preparing budgets if they had used a personal computer for at least four years. Positive correlations were found in all categories of frequency of computer usage.

The last item under General Computer Use asked administrators to identify the computer applications they had previously used at home. Positive correlations were found between the frequency of usage of office productivity software at work and previous home usage of word processing, desktop publishing, Internet browsing, database, spreadsheet, and e-mail software. 
Administrators who identified previous home usage of any office productivity software at home were more like to use the computer at work for supporting their management functions of organizing information, communicating, making presentations, and preparing budgets.

Research questions six through eight related to computer training received by buildinglevel administrators in West Virginia. The independent variables under the category of computer training received were types of computer training received, specific computer application training received within the last year, and the amount of computer training received within the last year. The researcher sought to determine if there were relationships between these three independent variables and the frequency of specific computer application usage by building-level administrators in performing their management functions of organizing information, communicating, making presentations, and preparing budgets. The first question under Computer Training Received asked the administrators to identify the types of computer training they have previously received. A negative correlation was found between the frequency of usage of database software for organizing information and administrators receiving no type of computer training. Another negative correlation was identified between the frequency of usage of electronic spreadsheet software for preparing budgets and administrators receiving no type of computer training. A positive correlation was found between the frequency of word processing software usage for communicating and computer training received through a required university or college course. Positive correlations were found between training through elective university or college computer courses and the frequency of usage of word processing, e-mail, presentation, and desktop publishing software. For training received through a community college course, positive correlations were found in the frequency of word processing and electronic spreadsheet 
usage in fulfilling management roles. No correlations were found between training received through inservice courses and the frequency of computer usage of office productivity software. Positive correlations were reported between administrators receiving training through selfteaching and the frequency of usage of all software types under study. For training through peer coaching, positive correlations were found between the frequency of usage of database and word processing usage to perform management functions.

The second item under Computer Training Received asked administrators to identify the specific computer application programs for which they had received training in the last year. The frequency of usage of word processing software for communicating was found to be negatively correlated with having no previous specific computer application training. A positive correlation was identified between administrators receiving word processing training within the last year and the frequency of word processing usage on the job for communicating. The receiving of training within the last year for desktop publishing was found to be positively correlated with the frequency of usage of word processing, e-mail, presentation, desktop publishing, and electronic spreadsheet software by building-level administrators. No correlations were found between building-level administrators receiving Internet training within the last year and the frequency of usage of any office productivity software. Positive correlations were found between the receiving of database training within the last year and the frequency of usage of database, word processing, and presentation software by building-level administrators. The receiving of electronic spreadsheet software training within the last year was found to be positively correlated with the frequency of usage of word processing, e-mail, presentation, desktop publishing, and electronic spreadsheet software by building-level administrators in performing their management 
functions. Positive correlations were found between the receiving of e-mail training within the last year and the frequency of usage of word processing and e-mail software by building-level administrators in performing the management task of communicating.

The final question under Computer Training Received asked West Virginia building-level administrators to identify how much computer training they had received in the last year. The administrators could have chosen none, 0-4 hours, 5-8 hours, 9-12 hours, 13-16 hours, or over 16 hours. The frequency of usage of word processing, e-mail, presentation, and desktop publishing by building-level administrators was positively correlated to the amount of computer training received within the last year.

The ninth research question asked if there was a relationship between the frequency of specific computer applications usage by building-level administrators in West Virginia and the perceptions and attitudes of these administrators toward technology. Nine statements were made in this section of the survey instrument. Administrators indicated their level of agreement to these statements by checking the appropriate box from strongly agree to strongly disagree on a fivepoint Likert-type scale. Statistically significant positive correlations were found between the building-level administrators' perceptions and attitudes toward technology and the frequency of usage of database software for organizing information, word processing and e-mail software for communicating, presentation and desktop publishing software for making presentations, and electronic spreadsheet software for preparing budgets.

The tenth research question asked if a relationship existed between the frequency of specific computer applications usage by building-level administrators in West Virginia and the perception of the individual leadership outcome of extra effort expressed by these administrators. 
Three statements were made about the individual leadership outcome of extra effort. Statistically significant positive relationships were found between the building-level administrators' perceptions of their individual leadership outcome of extra effort and their frequency of usage of database software for organizing information and the frequency of usage of presentation and desktop publishing software for making presentations.

The eleventh research question asked if a relationship existed between the frequency of specific computer applications usage by building-level administrators in West Virginia and the perception of the individual leadership outcome of effectiveness expressed by these administrators. Four statements were made about the leadership outcome of effectiveness. Statistically significant positive relationships were found between the building-level administrators' perception of the individual leadership outcome of effectiveness and the frequency of usage of presentation and desktop publishing software for making presentations.

The twelfth research question asked if a relationship existed between the frequency of specific computer applications usage by building-level administrators in West Virginia and the perception of the individual leadership outcome of extra effort expressed by these administrators. Two items on the Individual Leadership Outcomes section of the survey examined the leadership outcome of satisfaction. Statistically significant positive relationships were found between the building-level administrators' perception of the individual leadership outcome of satisfaction and the frequency of usage of presentation and desktop publishing software for making presentations.

The final research question asked what demographic characteristics were predictors for the frequency of specific computer applications usage by building-level administrators in West Virginia for the management functions of organizing information, communicating, making 
presentations, and preparing budgets. A stepwise forward multiple linear regression analysis was conducted between the demographic data and the frequency of usage of database, word processing, e-mail, presentation, desktop publishing, and electronic spreadsheet software. Two negative demographic predictors were found for the frequency of usage of database software for the management function of organizing information. These were gender and RESA location. Fewer female building-level administrators used database software for organizing information on a daily basis than their male counterparts. Furthermore, building-level administrators in RESA VI were not as likely to use database software for organizing information as their counterparts from other RESA regions.

In examining demographic predictors for the frequency of word processing application usage for the management function of communicating, two negative predictors were identified and four positive predictors were found. The two negative predictors for the frequency of word processing usage for communicating were years at the present site and previous teaching experience in secondary physical education. Sixty-seven percent of the building-level administrators who reported no usage of word processing software had been at their present site for more than ten years. The positive demographic characteristics that were identified were ethnicity, gender, RESA location, and a current school assignment at a vocational school. Ninetyeight percent of the administrators who reported using word processing on a daily basis for the management function of communicating were white, not of Hispanic origin. Sixty percent of the administrators who reported using word processing on a daily basis were men. Also, 70 percent of the administrators who indicated that they used word processing often were men. Thirty-seven percent of the administrators who reported daily or often usage of word 
processing software for the management function of communicating reported that they were located in RESA VII.

In identifying demographic predictors for the frequency of usage of e-mail software for the management function of communicating, two negative demographic predictors and two positive demographic predictors were found. The two negative predictors were age and previous teaching experience in secondary physical education. Seventy-one percent of the administrators who reported no usage of e-mail software for communicating also reported an age over 50 years. On the positive side, 72 percent of the administrators who reported daily usage of e-mail software also indicated an educational level of a master's degree plus 45 hours. Thirty-seven percent of the administrators who indicated daily usage of e-mail software for communicating also reported the number of professional staff at their site to be 10 to 25 .

In looking at demographic predictors for the frequency of usage of presentation software for the management function of making presentations, two positive demographic predictors and two negative demographic predictors were found. The two positive demographic predictors for the frequency of usage of presentation software for the management function of making presentations were a current school assignment at a high school and a current school assignment at a vocational school. The two negative demographic predictors were age and RESA location. Sixty-four percent of the administrators who reported that they never used presentation software for making presentations indicated ages over 50 years. Thirty-eight percent of the building-level administrators who reported that they either never or rarely used presentation software indicated being located in RESA VII. 
For frequency of usage of desktop publishing software for the management function of making presentations, one positive demographic predictor and one negative demographic predictor were identified. The positive demographic predictor was previous teaching experience in middle school (grades 5-8). The negative demographic predictor identified was age. Sixty-five percent of the administrators who reported never using desktop publishing software for making presentations also indicated ages over 50 years.

The last category of software usage under study was the usage of electronic spreadsheet software for the management function of preparing budgets. One positive demographic predictor and one negative demographic predictor were identified. The positive demographic predictor for the frequency of usage of electronic spreadsheet software for preparing budgets was a current school assignment at a vocational school. The negative demographic predictor identified for the frequency of usage of electronic spreadsheet software for the management function of preparing budgets was age. Fifty-six percent of the administrators who indicated no usage of electronic spreadsheets for preparing budgets also reported ages over 50 years. 


\section{CHAPTER 5}

\section{Summary of Study}

This chapter includes the purpose of the study, a summary of the procedures used, and a summary of the descriptive data. The conclusions of the study and discussion are then presented. The chapter closes with implications of the study and recommendations for further research.

\section{Purpose of the Study}

The purpose of this study was to determine the frequency with which building-level administrators in West Virginia public schools used office productivity software to complete their management tasks of organizing information, communicating, making presentations, and preparing budgets. This study also examined general four independent variables for computer usage, three independent variables related to computer training, perceptions and attitudes toward technology, the individual leadership outcome of extra effort, the individual leadership outcome of effectiveness, and the individual leadership outcome of satisfaction. Demographic data were examined to identify predictors of computer usage among building-level administrators in West Virginia public schools. The following specific research questions guided the study:

Q1. What is the current frequency of specific computer applications usage by building-level administrators in West Virginia for the management function of organizing information, communicating, making presentations, and preparing budgets?

Q2. What is the relationship, if any, between the frequency of specific computer applications usage by building-level administrators in West Virginia and these building-level administrators having a computer in their home? 
Q3. What is the relationship, if any, between the frequency of specific computer applications usage by building-level administrators in West Virginia and the building-level administrators usage of previous software platforms/operating systems?

Q4. What is the relationship, if any, between the frequency of specific computer applications usage by building-level administrators in West Virginia and the building-level administrators usage of previous software platforms/operating systems?

Q5. What is the relationship, if any, between the frequency of specific computer applications usage by building-level administrators in West Virginia and the building-level administrators previous usage of the application software at home?

Q6. What is the relationship, if any, between the frequency of specific computer applications usage by building-level administrators in West Virginia and the types of computer training received by theses administrators?

Q7. What is the relationship, if any, between the frequency of specific computer applications usage by building-level administrators in West Virginia and the specific computer applications for which these administrators have received training within the last year?

Q8. What is the relationship, if any, between the frequency of specific computer applications usage by building-level administrators in West Virginia and the amount of computer training received by these administrators within the last year?

Q9. What is the relationship, if any, between the frequency of specific computer applications usage by building-level administrators in West Virginia and the perceptions and attitudes of these administrators toward technology? 
Q10. What is the relationship, if any, between the frequency of specific computer applications usage by building-level administrators in West Virginia and the perception of the individual leadership outcome of extra effort expressed by these administrators?

Q11. What is the relationship, if any, between the frequency of specific computer applications usage by building-level administrators in West Virginia and the perception of the individual leadership outcome of effectiveness expressed by these administrators?

Q12. What is the relationship, if any, between the frequency of specific computer applications usage by building-level administrators in West Virginia and the perception of the individual leadership outcome of satisfaction expressed by these administrators?

Q13. What demographic characteristics are predictors for the frequency of specific computer applications usage by building-level administrators in West Virginia for the management functions of organizing information, communicating, making presentations, and preparing budgets?

Summary of Procedures

The West Virginia Building-Level Administrator Computer Usage Survey 2000 form was developed by the researcher to be sent to all building-level public school administrators in the state of West Virginia (Appendix A). This instrument was adapted from a survey given in 1996 (Benson) in the Washoe County School District in Reno, Nevada. The West Virginia BuildingLevel Administrator Computer Usage Survey 2000 form was read by a panel of experts in August 2000 for validity. This instrument was mailed to 824 public school principals on October 24, 2000. A cover letter was also sent with the pre-posted survey forms (Appendix B). A follow-up, postcard reminder was sent to all principals in West Virginia one week after the 
mailing of the survey form. Five of the original 824 surveys were returned because of school consolidations and closings.

Five hundred three usable surveys were returned. The researcher utilized Spearman's Rho, the Mann-Whitney U, and Pearson's Chi-Square tests in the Statistical Package for the Social Sciences Version 10.0 for Windows in determining possible relationships between the variables under study. A stepwise forward multiple linear regression analysis was conducted on the demographic data to identify positive and negative predictors of computer usage by buildinglevel administrators in West Virginia public schools. Spearman's Rho is a bivariate correlation measure which examines the closeness of association between two ordinal variables. The MannWhitney test and Pearson's Chi-Square were used to examine the null hypothesis that there was no true difference or association between each set of variables tested. The Mann-Whitney test is a nonparametric alternative to the t test. Pearson's Chi-Square and the Mann-Whitney U tests allowed the researcher to reject the null hypothesis when statistically significant values were found $(\underline{p}<.05)$. Pearson's Chi-Square was performed as a post-hoc analysis.

\section{Descriptive Data}

All public school principals in the state of West Virginia were mailed the West Virginia Building-Level Administrator Computer Usage Survey 2000 form. This survey instrument was comprised of six sections. The first section asked building-level administrators to identify the frequency with which they used database, word processing, e-mail, presentation, desktop publishing, and electronic spreadsheet software for the management functions of organizing information, communicating, making presentations, and preparing budgets. The second section of this instruments asked administrators to indicate general computer usage. Computer training 
received was the topic of the third section of this instrument. The fourth section examined perceptions and attitudes of building-level administrators toward computers and technology. Section five examined the individual leadership outcomes of extra effort, effectiveness, and satisfaction. The last section of this survey examined demographic data of the administrators surveyed.

Five hundred three usable surveys were returned. Two of the surveys returned were damaged by the United States Postal System during delivery and were not usable. Five of the original surveys were returned because of school closings and consolidations. The response rate for this survey instrument was 61.2 percent.

\section{Conclusions}

Internal Reliability of the Instrument

Cronbach's Coefficient Alpha was used to determine the internal reliability of the survey instrument prior to analyses being conducted. The internal consistency for each item was within an acceptable range. Cronbach's Coefficient Alpha measured the internal consistency of the variables at 0.7841 . Furthermore, while this research instrument differed somewhat from that used in the 1996 Benson study, this researcher's internal reliability coefficient was very similar to that identified by Benson's survey of 0.78 .

Q1. What is the current status frequency of specific computer applications usage by building-level administrators in West Virginia for the management functions of organizing information, communicating, making presentations, and preparing budgets?

The frequency of computer usage by building-level, public school administrators in West Virginia was greater for the management tasks of organizing information and communicating. 
More than half of the survey respondents indicated daily or often usage of database software for organizing information, word processing software for communicating, and e-mail software for communicating. The frequency of computer usage by these same administrators for the management functions of making presentations and preparing budgets were not as high. Less than one-fourth of the administrators surveyed reported daily or often usage of presentation software for making presentations, desktop publishing software for making presentations, or electronic spreadsheet software for preparing budgets.

Q2. What is the relationship, if any, between the frequency of specific computer applications usage by building-level administrators in West Virginia and these building-

\section{level administrators' having a computer in their home?}

Statistically significant relationships were found between building-level administrators who had a computer in their home and the frequency of usage of all office productivity software for the management functions of organizing information, communicating, making presentations, and preparing budgets. While Benson's 1996 study did not examine all of the software categories undertaken in this current study, she also found a positive correlation between the frequency of usage of word processing, database, and spreadsheet software and the building-level administrator having a computer at home.

Q3. What is the relationship, if any, between the frequency of specific computer applications usage by building-level administrators in West Virginia and the building-level administrators' usage of previous software platforms/operating systems?

Building-level administrators who had not used any previous operating system software or platform were not likely to use office productivity software on the job for completing their 
management functions. Those administrators who had previously used disk operating system (DOS) software were more likely to use database software for organizing information, word processing and e-mail software for communicating, and desktop publishing software for making presentations. Building-level administrators who had previously used any version of Windows operating system software were likely to use all office productivity software under study for organizing information, communicating, making presentations, and preparing budgets. Those administrators who had previously used a Macintosh/Apple computer system were more likely to use word processing and e-mail software for communicating and desktop publishing software for making presentations.

Q4. What is the relationship, if any, between the frequency of specific computer applications usage by building-level administrators in West Virginia and the number of years these building-level administrators have used a personal computer?

Statistically significant positive relationships were found between the number of years of previous computer usage and computer usage on the job. Building-level administrators who had used the personal computer for a greater number of years were more likely to use the computer at work in completing the management functions of organizing information, communicating, making presentations, and preparing budgets.

Q5. What is the relationship, if any, between the frequency of specific computer applications usage by building-level administrators in West Virginia and the building-level administrators' previous usage of application software at home?

Building-level administrators with no previous home usage of office productivity software were not likely to use this software on the job for the management tasks of organizing 
information, communicating, making presentations, and preparing budgets. Those administrators who used word processing, desktop publishing, Internet browsing, database, spreadsheet, or email software at home were more likely to utilize office productivity software on the job for the management functions of organizing information, communicating, making presentations, and preparing budgets.

\section{Q6. What is the relationship, if any, between the frequency of specific computer} applications usage by building-level administrators in West Virginia and the types of computer training received by these administrators?

Building-level administrators who had received no computer training of any type were not likely to use database software at work for organizing information. Those administrators who had taken required university/college courses for computer training were more likely to use word processing software for the function of communicating. Administrators who had taken elective university/college courses were more likely to use word processing and e-mail software for communicating as well as presentation and desktop publishing software for making presentations. Building-level administrators who had taken community college courses in computer training were more likely to use word processing software for communicating and electronic spreadsheet software for preparing budgets. No correlations were found between inservice computer training programs for administrators and the use of office productivity software on the job for completing management tasks. Administrators who used self-teaching as a computer training strategy were likely to use all office productivity programs under study for completing their management roles. Those administrators who had received peer coaching were 
more likely to use database software for organizing information and word processing software for communicating.

\section{Q7. What is the relationship, if any, between the frequency of specific computer}

applications usage by building-level administrators in West Virginia and the specific

computer applications for which these administrators have received training within the last

year?

Those building-level administrators who had received no computer training within the last year of any kind were less likely to use word processing software for the management function of communicating. Administrators who received word processing software training within the last year were more likely to use word processing for communicating. Building-level administrators who had received desktop publishing software within the last year were more likely to use word processing and e-mail software for communicating, presentation and desktop publishing software for making presentations, and electronic spreadsheet software for preparing budgets. No relationships were found for administrators receiving Internet browser software training within the last year and the usage of any other software on the job. Building-level administrators who had received database software training within the last year were more likely to use database software for organizing information and presentation software for making presentations. Administrators who had received electronic spreadsheet software within the last year were more likely to use word processing, e-mail, presentation, desktop publishing, and electronic spreadsheet software in completing their management functions. Those administrators who had reported e-mail software training within the last year were more likely to use word processing and e-mail software in their management function of communicating. 


\section{Q8. What is the relationship, if anv, between the frequency of specific computer}

\section{applications usage by building-level administrators in West Virginia and amount of}

\section{computer training received by these administrators within the last year?}

The final question under the computer training section of the survey asked the administrators to indicate how much computer training they had received within the last year. The categories for this item included none, 0-4 hours, 5-8 hours, 9-12 hours, 13-16 hours, and over 16 hours. Those administrators who had received some amount of computer training within the last year were more likely to use word processing and e-mail software for communicating as well as presentation and desktop publishing software for making presentations.

\section{Q9. What is the relationship, if any, between the frequency of specific computer}

\section{applications usage by building-level administrators in West Virginia and the perceptions}

\section{and attitudes of these administrators toward technology?}

The West Virginia Building-Level Administrator Computer Usage Survey 2000 form included nine questions about perceptions and attitudes toward computers and technology. Spearman's Rho found statistically significant positive relationships between building-level administrators' perceptions and attitudes toward computer and technology and computer usage for the management functions of organizing information, communicating, making presentations, and preparing budgets. The levels of significance reported by Spearman's Rho were all at the $\mathrm{p}<$ .01 level. 
Q10. What is the relationship, if any, between the frequency of specific computer applications usage by building-level administrators in West Virginia and the perception of the individual leadership outcome of extra effort expressed by these administrators?

Bass and Avolio (1996) put leadership outcomes into three different areas: extra effort, effectiveness, and satisfaction. They define extra effort as the ability to get others to do more than they expected to do, the ability to heighten others' desire to succeed, and the ability to increase others' willingness to try harder. Statistically significant positive correlations were found between the building-level administrators' perception of the leadership outcome of extra effort and the frequency of usage of database software for organizing information and for the usage of presentation and desktop publishing software usage for making presentations.

Q11. What is the relationship, if any, between the frequency of specific computer applications usage by building-level administrators in West Virginia and the perception of the individual leadership outcome of effectiveness expressed by these administrators?

Bass and Avolio (1996) define the second leadership outcome of effectiveness as the ability to be effective in meeting others' job-related needs, the ability to be effective in representing their group to higher authority, the ability to be effective in meeting organizational requirements, and the ability to lead a group that is effective. Statistically significant positive relationships were found between building-level administrators' perceptions of the individual leadership outcome of effectiveness and the frequency of usage of presentation and desktop publishing software for the management function of making presentations. 
Q12. What is the relationship, if any, between the frequency of specific computer applications usage by building-level administrators in West Virginia and the perception of the individual leadership outcome of satisfaction expressed by these administrators?

Bass and Avolio (1996) further define satisfaction as the ability to use methods of leadership that are satisfying and the ability to work with others in a satisfactory way. Statistically significant positive relationships were found between building-level administrators' perceptions of the leadership outcome of satisfaction and the frequency of usage of presentation and desktop publishing software for making presentations.

Q13. What demographic characteristics are predictors for the frequency of specific computer applications usage by building-level administrators in West Virginia for the management functions of organizing information, communicating, making presentations,

\section{and preparing budgets?}

The final section of the West Virginia Building-Level Administrator Computer Usage Survey 2000 instrument asked administrators to answer 12 demographic items. A stepwise forward multiple linear regression analysis was performed on the data to determine predictors of the frequency of computer usage of database software for the management function of organizing information, word processing and e-mail software for the management function of communicating, presentation and desktop publishing software for the management function of making presentations, and electronic spreadsheet software for the management function of preparing budgets.

For the usage of database software for organizing information, two negative predictors were identified. These were gender and RESA location. Building-level administrators who were 
female were less likely to use database software frequently for organizing information.

Furthermore, building-level administrators in RESA VI were not as likely to use database software on a frequent basis to organize information.

When the usage of word processing for the management function of communicating was examined, four positive demographic predictors and two negative demographic predictors were identified. The positive demographic predictors included ethnicity, gender, RESA location, and a current school assignment at a vocational school. Ninety-eight percent of the administrators who reported using word processing on a daily basis for the management function of communicating were white, not of Hispanic origin. Sixty percent of the administrators who reported using word processing on a daily basis were men. Also, 70 percent of the administrators who indicated that they used word processing often were men. This disputes information found in the Benson (1996) study where it was indicated that women were more likely to use word processing on a frequent basis than were their male counterparts. Thirty-seven percent of the administrators who reported daily or often usage of word processing software for the management function of communicating indicated that they were located in RESA VII. The two negative demographic predictors for the frequency of usage of word processing software for the management function of communicating were years at present site and previous teaching experience in secondary physical education. Sixty-seven percent of the building-level administrators who reported never using word processing for the management function of communicating had been at their present site for more than 10 years.

For the category of the frequency of usage of e-mail software for the management function of communicating, two positive demographic predictors and two negative demographic 
predictors were identified. The two positive demographic predictors were educational level and number of professional staff. Seventy-two percent of the administrators who reported daily usage of e-mail software also indicated an educational level of a master's degree plus 45 hours. Thirtyseven percent of the administrators who indicated daily usage of e-mail software for communicating also reported the number of professional staff at their site to be 10 to 25 . The two negative demographic predictors discovered were age and previous teaching experience in secondary physical education. Seventy-one percent of the administrators who reported daily usage of e-mail software also indicated an age over 50 years.

When a stepwise forward multiple linear regression analysis was conducted on the frequency of usage of presentation software for the management function of making presentations, two positive demographic predictors and two negative demographic predictors were identified. The two positive demographic predictors were a current school assignment at a high school and a current school assignment at a vocational school. The two negative demographic predictors found were age and RESA location. Sixty-four percent of the administrators who reported that they never used presentation software for making presentations indicated ages over 50 years. Thirty-eight percent of the building-level administrators who reported that they either never or rarely used presentation software indicated being located in the RESA VII region.

Two demographic predictors were found for the frequency of usage of desktop publishing software when the stepwise forward multiple linear regression analysis was conducted. One predictor was positive and the other one was negative. The positive demographic predictor for the frequency of usage of desktop publishing software for making presentations was previous 
teaching experience in middle school (grades 5-8). The negative demographic predictor found was age. Sixty-five percent of the administrators who reported never using desktop publishing software for making presentations also indicated ages over 50 years.

The final category to be examined was the frequency of usage of electronic spreadsheet software for the management function of preparing budgets. The stepwise forward multiple linear regression analysis indicated one positive demographic predictor and one negative demographic predictor. The positive demographic predictor for the frequency of usage of electronic spreadsheet software for preparing budgets was a current school assignment at a vocational school. The negative demographic predictor found was age. Fifty-six percent of the administrators who indicated no usage of electronic spreadsheet software for preparing budgets also reported ages over 50 years.

Ancillary Findings

One ancillary finding that should be noted is that when computer usage was compared to administrators' previous teaching experience, only two negative correlations were found. These correlations were found between computer usage by building-level administrators and previous secondary social studies teaching as well as previous secondary physical education teaching. Administrators with previous secondary social studies experience were not as likely to use word processing for communicating or desktop publishing software for making presentations. Building-level administrators who reported previous teaching experience at the secondary level in physical education were not as likely to use word processing or e-mail to perform communication roles as their counterparts from other levels or disciplines. The majority of 
sports activities coaches in the state of West Virginia come from physical education or social studies education backgrounds.

\section{Discussion}

A 1996 (Benson) study of Washoe County School District building-level administrators examined the overall use of the personal productivity applications of word processing, database, and spreadsheet software for managerial functions. This study, conducted in Reno, Nevada, found that 59 percent of the administrators surveyed were using word processing applications on a daily basis. This researcher found that 60.2 percent of West Virginia building-level administrators were using word processing software on a daily basis. Benson further pointed out that she found that overall the application of word processing was used by 80 percent of the administrators at least weekly. While the percentage for daily users of word processing are quite similar, the percentage of West Virginia building-level administrators using word processing at least weekly was somewhat higher. Almost 87 percent of West Virginia building-level administrators reported using word processing at least weekly. The Benson study found that 20 percent of building-level administrators were using database software daily and that 43 percent reported at least weekly usage. The results of the 2000 West Virginia building-level administrator survey instrument found that 41.7 percent of the administrators used database software daily for organizing information and 71.1 percent of these administrators used this software at least weekly. The 1996 study by Benson reported that spreadsheet application usage by building-level administrators in the Washoe County School District was rare. Benson's study found that 4 percent used this software daily and that 21 percent used spreadsheet programs at least weekly. The percentages found for West Virginia building-level administrators were 
somewhat similar. Just over 2 percent of the administrators surveyed in West Virginia reported daily usage of spreadsheet software for preparing budgets while 16.2 percent of the administrators reported at least weekly usage of this software. The Benson study found that school building administrators used word processing applications frequently and database and spreadsheet applications less frequently. The findings of the West Virginia Building-Level Administrator Computer Usage Survey 2000 were similar.

The 1996 Benson study found that 78 percent of the school building administrators had a home computer and 90 percent had used a personal computer for at least one year. The results of the West Virginia Building-Level Administrator Computer Usage Survey 2000 form indicated that 88.7 percent of West Virginia building-level administrators had a home computer and 96.6 percent of these administrators had used a personal computer for at least one year. Benson further found that the use of word processing applications was positively affected by previous computer experience. This researcher found that the use of database, word processing, e-mail, presentation, desktop publishing, and electronic spreadsheet software were all positively affected by previous computer experience. The Benson study only examined the usage of word processing, database, and spreadsheet software.

The Benson (1996) study also looked at sources of training for office productivity software. Benson reported that over 75 percent of the school building administrators had received computer applications training at the inservice, peer-coached, or self-taught levels. In West Virginia, over 70 percent of the school building-level administrators had received computer applications training at the inservice, peer-coached, or self-taught levels. The percentages of those administrators in West Virginia who reported inservice and self-taught levels of training 
were 86.5 and 84.1, respectively. However, only 70.8 of West Virginia building-level administrators indicated having received training through peer coaching. Less than one-third of the administrator surveyed by Benson indicated training through university, college, or community college courses. The findings of this researcher were similar. Less than 14 percent of the administrators surveyed received computer application training through required university or college courses. Slightly more than one-fourth, 26.4 percent, of the West Virginia building-level administrators reported computer training through an elective university or college course. The percentage of administrators who received training through community college courses was 5.6. When Benson compared the level of use of word processing and database applications to training received, no significance was found. The 2000 West Virginia study found that the frequency of word processing usage was positively correlated to training through required university/college courses, elective university/college courses, community college courses, self-teaching, and peer coaching. However, no relationship was found between the frequency of usage of word processing software and having received training through inservice courses. The frequency of database usage by West Virginia building-level administrators was positively related to selfteaching and peer coaching. In the West Virginia study, the researcher found that there was a significant relationship between the frequency of usage of electronic spreadsheet software and having received computer training through self-teaching.

In the 1996 Benson study, respondents either agreed or strongly agreed to most of the statements in the perceptions and attitudes toward computers and technology section of that survey instrument. This researcher asked the same questions about attitudes and perceptions towards computers and technology. There was a statistically significant relationship between the 
perceptions and attitudes of West Virginia building-level administrators and the frequency of computer usage for the management functions of organizing information, communicating, making presentations, and preparing budgets. The need for more preservice computer training and recognition that computers are an important tool were strongly supported in the Benson study, with over 90 percent of her participants either agreeing or strongly agreeing to these statements. Ninety-five percent of West Virginia building-level administrators either agreed or strongly agreed that the computer is an important tool in educational administration. Furthermore, 88 percent of the West Virginia administrators believed that administrator training programs should place greater emphasis on computers and computer usage in administration. At least 90 percent of the respondents in the Benson study either agreed or strongly agreed that school building administrators should search for new uses for computers in school administration. Eighty-nine percent of West Virginia administrators believed that an effective building-level administrator should explore new uses for computers in completing administrative functions. Only about 47 percent of the Washoe County administrators agreed or strongly agreed that computer reliably store information. Slightly more than 50 percent of West Virginia administrators agreed or strongly agreed with this same statement. Sixty-seven percent of the respondents in the Benson study agreed or strongly agreed that information was easy to retrieve if store in computers. The percentage of West Virginia administrators who agreed or strongly agreed with this statement was 80 .

The final research question in the Benson (1996) study asked if there was a difference between certain demographic factors of school building administrators and the use of computer applications by school building administrators in their administrative functions. The Benson 
study found that female administrators were more likely to use word processing applications than were male administrators. The West Virginia Building-Level Administrator Computer Usage Survey 2000 found that male administrators were more likely to use word processing application than were female administrators. The West Virginia study refutes this finding of the Benson study. The West Virginia study also found that male administrators were more likely to use database software than their female counterparts.

The Benson (1996) study found that older administrators were less likely to use word processing applications. The West Virginia 2000 study did not obtain a similar finding. However, while age was not a negative demographic predictor for the frequency of word processing usage, the West Virginia study found that the number of years at the current site was a negative predictor. The West Virginia study of building-level administrators found that 49 percent of the administrators who indicated daily usage of word processing software were over 50 years of age. Fifty-four percent of those administrators who reported using word processing software often indicated that they were over 50 years of age.

The 1996 Benson study found that years of administrative experience was negatively correlated to personal productivity applications. The West Virginia study did not find the years of administrative experience to be either a positive or negative predictor for any category of computer usage.

A 1990 (Witten, et al.) study of administrative computer use by secondary principals in Kentucky found that a majority of the principals were uninformed and poorly trained to use computers in the management of their schools. That study revealed that only 20 percent of the administrators in Kentucky had any computer training at that time. It was found that a majority 
of secondary principals in the Commonwealth of Kentucky were not using computers to assist them in managing the schools in which they worked. These principals received little or no formal training in the use of computers. In a majority of the school systems, there was no centralized computer coordinator to assist the administrators in learning how to use computers. There was also a very evident lack of planning and commitment to computer use in the administrative areas of Kentucky's schools. While a significant amount of time has elapsed since that study, the findings of the West Virginia study did not point to the haphazard use of computers that was reported in Kentucky. However, it should be noted that no correlations were found between inservice training in West Virginia and the frequency of computer usage in performing management functions.

The United States is not the only place where computer usage by administrators has been examined. As early as 1983, Streatfield and Thompson began looking at computer usage by education administrators in England and Wales. Streatfield and Thompson found that local education authorities in England and Wales were working toward computer-based management systems. At the time this study was conducted mainframes, minicomputers, microcomputers, and dedicated word processors were being used across England and Wales. At that time, the sharing of information was a difficult task because of the lack of uniformity among the various types of technologies and platforms utilized. Today, however, Microsoft and International Business Machines have created what have become industry standards around the globe.

Experts say there is a link between administrators' ability to make informed technology decisions and their personal use of technology (Trotter, 1997). Principals should have keyboarding skills — that is, they should be able to type (Isherwood, 1985). They should 
understand word processing, how to construct and report from a database, how to use a spreadsheet to solve financial problems, how to create reports and link them with a mail-merge package, how to create and maintain files on a disk, how to use hardware available in their district, and how to use specific applications programs in use in their school. Isherwood believes that principals need to know modern administrative techniques to manage their schools effectively.

The development of the silicon chip and the microcomputer has caused the current age to be termed the information age (Vacca, 1983). Vacca believes that the most effective implementers of technology are administrators with high task and high relationship styles who are both people- and task-oriented. For education to successfully move through the information age, it must use the computer as a tool for the future.

In a 1986 article by Mojkowski, the author made a point that principals are looking for levers and switches that will help them form a coherent vision and select appropriate means to actualize it. Mojkowski believes that principals are attempting to focus their energies on two major, interrelated efforts, which are implementing a systematic school improvement process and developing their own leadership and management skills. Mojkowski also believes that blending school effectivenss with leadership and management development into a program for revitalization is the way for schools to thrive into the future. He believes that this can be done if technology is utilized in these processes. This author further believes that the school leader should not only automate, but renovate as well. The decisions principals make now about using technology are critical to their growth as leaders and managers and to the improvement of schools. 
Sharman and Cothern (1985) warned administrators that they did not have much choice in the coming years because computers were in their future. Sharman and Cothern believed that most of the administrators would accept computers because they would recognize their potential for increasing productivity and for freeing them to provide the leadership they were hired to provide. These authors did have one thing to say to those administrators who wanted to hold out on computers. Sharman and Cothern said that these administrators would be afraid that they would have to accept computers to survive. These authors pointed out that these administrators would simply not be able to keep up with their colleagues without computers.

Administrators have given several reasons for not using technology in the past (Hanna, et al., 1994). Some administrators believe that their assistants should be computer experts. Still others say that they have intended to learn to use computers for years but have not had time to place this activity into their busy schedule. Other administrators have said that technology keeps changing so fast that re-learning will only be required within six months. Another reason for not obtaining computer training has been the belief that software has not yet been developed to meet all of the complex needs of the administrator while providing ease of use.

In 1987 Rees published a paper detailing her findings concerning computer usage by secondary school principals in Ontario. In order to ensure that educational administrators would use computer technology in both the routine and more creative or entrepreneurial activities of a school, a series of recommendations was made from this study. One recommendation for change was that a policy be developed, either in the form of legislation or objectives, articulated, and communicated on a school board basis concerning the desirability of the use of computer technology within the educational institutions. This policy would have to be augmented by 
concrete support directed to the intended users, the educational administrators, in the form of resource commitment and allocation. Another recommendation made in this study was to ensure that the computer be used on a daily basis and be in a visible location with easy access by its users. Educational administrators as instructional leaders were to encourage others within the school or educational community to develop professionally in the area of computer technology. A push toward computer usage by these secondary principals was being made so that the administrators within the Ontario educational system would become proactivists as the information era progressed.

In 1987, a reform movement began to restructure preparation programs in educational administration (House, 1989). This movement can be traced to the political, social, and economic trends of the 1980s. As important as these forces and the profession's response may have been, the technological trends of that decade, particularly personal computer technology, also exerted pressure on the shape of educational administrator preparation programs. House believed, at the time his article was published, that administrative computing was ill-defined and lacking a practical or research-based body of knowledge. House, while pushing for the inclusion of computer training courses in educational administration preparation programs, pointed out that alternative methods of delivery would have to be considered as well. Training could come in the form of a conventional course, workshop, or guided independent study.

Today, almost every technology savvy principal will say that productivity and effectiveness increase when contemporary technology is employed as an administrative tool (Donatucci, 1995). For many principals, however, using technology as an effective administrative tool is not a reality. School system computer networks are sometimes unfriendly 
or poorly structured. In addition, training tends to be on a one-shot basis and is often quickly forgotten-especially when the school secretary is computer literate. The technology savvy principal is the type of administrator who has integrated the use of technology into all areas of responsibility. To develop administrators who are comfortable and innovative with technology, more effective training is needed. School systems must find ways of creating and nurturing a nonthreatening environment where administrators not only are computer competent but are encouraged to be creative and innovative.

Lou Gerstner (1994) Chief Executive Officer of International Business Machines claimed that nothing matters more to America's schools than finding competent principals to lead them. Although the role of the school principal is frequently cited as the key element in school reform, it is not the solitary role of times past. It is a role that demands skills in enhanced team building, shared decision making, and increased technological competency.

Technology is the means to increasing learning efficiency. Technology can be used to better display information, increase access to information, improve information sharing, and organize better presentations. Technology is not a panacea for educational problems, but by combining technology with common sense and proactive leadership, the overall quality of education is enhanced (MacNeil \& Delafield, 1998).

School administrators and teachers are increasingly relying on sophisticated technology systems to provide support and service in completing their daily tasks in schools. A myriad of tasks assigned with operating a school has been affected dramatically over the past few years as computer and telecommunication technologies have been integrated into the school's instructional and administrative functions (Clark \& Denton, 1998). Between 1997 and 2010, 
schools should integrate technology into instructional management and administration. The timing is critical for integrating technology into the operation of schools.

Just as teachers need computer skills to perform their job tasks more effectively, so do school administrators. And just as staff development activities enable teachers to acquire useful computer skills, similar activities provide administrators with the tools and competencies they need to do their jobs more efficiently. To become effective computer users, school administrators need at least five basic competencies. First, they should use computers for personal productivity by learning the basic operations of word processing, database, and spreadsheet software. As they become comfortable with these packages, they can issue their own correspondence, create and manipulate name and address lists, and develop and analyze rudimentary budget information. Their competence in these functions leads to autonomy in basic administrative tasks, freeing more time to interact with students, teachers, and parents. By introducing computers as personal tools, staff development programs cultivate participants' enthusiasm for work-related tasks (Hancock, 1990). As administrators participate in staff

development activities, they should anticipate increased independence in performing administrative tasks, more cooperative work with building computer committees, better communication with district technology coordinators, and more satisfaction with the efficiency of school operations. As informed advocates of computer use and more effective managers of computer-literate students and teachers, administrators can expect an additional benefitincreased credibility with their school faculties.

Basic technology skills will remain essential for administrators who want to assume a technology leadership role (Bozeman, Raucher, \& Spuck, 1991). Questions remain about the 
ways in which technology courses should be structured to help administrators who are uneasy or intimidated by computers. Administrators with limited technology experience often need support to deal with new technologies. Hands-on practice time, a low-risk environment, individualized instruction or small group projects, and instruction based on a variety of learning styles should be offered whenever possible.

Administrators should learn their skills in context, with applications learned in the role they will be employed in the school (Ritchie, 1996). Activities may begin with administrative duties such as budgets, memoranda, and strategic plans, and advance to technology-related activities in which staff training, technology plans, or technology-based grant applications are generated.

Aside from the basic desktop personal computers, administrators may enjoy the extra benefits of a laptop or notebook computer. Joseph Byers, the principal of Pangborn Elementary School in Hagerstown, Maryland, purchased a laptop computer in 1990 (Byers, 1991). Byers indicated that he wanted to save time in completing some of his management tasks and functions. This administrator found that it was useful for a variety of administrative purposes in school and at home. However, he believed that its most useful feature was its ability to be taken to a teacher's classroom to complete teacher evaluations during the observation instead of trying to transcribe scrawled out notes later on. He found that the notebook-size unit was very effective for most tasks, including word processing, graphics, forms, databases, directories, and class lists. Byers also pointed out that the portability of the laptop computer made effective use of situations which required waiting. He indicated that airports, doctor's offices, and even shopping malls were places he had made use of his portable computer. In advising others about laptop 
computers, Byers said that an administrator should borrow one from a colleague or the central office and try it out first. Then, if the administrator is comfortable with the computer's small size, a laptop may be purchased.

The selection of a computer for administrative use should receive as much consideration as the selection of a new member of the administrative team (Crawford, 1985). Personal computers do not solve problems for principals. They perform tasks. These tasks may be part of the solution, but the overall solution also includes tasks performed manually as well as possibly by other equipment. There is a subtle distinction between treating a computer as the solution and regarding it as a tool which humans use to solve problems.

Technology brings a value-added component associated with its cost (Rhodes, 1997). Value is added as the technology helps support more effective relationships, enabling new organizational structures to be created and sustained. These values seldom have been factored into school technology costs. Research in industry and education demonstrates that until these new technologies become functional, practically transparent tools for everyone in the district, the understanding and supportive culture will be lacking for fully capitalizing on technology's obvious values (Rhodes, 1997).

Technology has been moving rapidly into all levels of administrative practices (Cooper, 1989). Business functions, student accounting, and major central office activities have been among the major uses of computers in the schools and will account for much of school districts' core computer use. Today, with the wide acceptance of microcomputers and ease of access to these machines, many principals can use a wide array of computer applications to facilitate daily administrative functions. Principals are beginning to discover that the same little 
microcomputers that third graders use to play learning games can provide a surprising amount of help with administrative tasks as well (Crawford, 1987).

Information technology can make school administration and management more effective, freeing time and resources to enhance student learning (Dede, 1997). Beyond these gains in efficiency, major changes in current organizational practices are necessary to attain the full benefits of technology-enhanced learning. The advantages of using information technology in education should be equitably available to all learners and communities. Administrators must master not only how to use information technology to make existing organizational practices more efficient, but also how to create and sustain innovative institutional processes that support new models of teaching. Aside from the basic administrative functions of a principal, he/she also must serve as the instructional leader.

Many school executives within the past decade have been adopting the same word processing, database, spreadsheet, e-mail, presentation, and budget tools used by their counterparts in business (Wall, 1994). Wall notes that ten years ago computers really were not used much by administrators. He goes on to say that the turnover in school and central office administrators has brought a new generation of individuals who feel more comfortable using technology in the office because many of them used it in the classroom as teachers. School administrators say four applications of technology are growing rapidly: organizing information with tools such as database software; communicating with e-mail and word processing; using graphics or multimedia software to make presentations more powerful and visually attractive; and using budget software to plan and track spending. In addition, many administrators say laptop computers are becoming the hardware of choice for these applications. 
If technology is to be integrated into the school curriculum, the meaning of educational leadership and the role of the school principal within a technological paradigm must be redefined. Principals are among those who have elected to take a leadership role in educational reform measures that will lead to more effective schools (Bennett, 1996). Principals cannot succeed by using management and leadership strategies that do not support the integration of information technology into daily practice. Today's administrators must be knowledgeable users of technology themselves and effective managers of technology in their schools. Today's principals must also take a leadership role in advancing technology in education. They must rethink teaching and learning within a new paradigm to prepare students for the challenges of today and tomorrow. Within the context of a changing technological world, principals must understand the capabilities of educational hardware and software to intelligently guide teachers and students in their use. Principals must be wise leaders and wise shoppers in an increasingly technical and monetarily tight educational arena.

As a final note, Kerlinger (1964) said that scientific research is the systematic, controlled, empirical, and critical investigation of hypothetical propositions about the presumed relations among natural phenomena. To the degree possible, this study was designed to reflect this view of research. However, Campbell and Stanley (1966) note that while problems of internal validity are solvable within the limits of the logic of probability statistics, the problems of external validity are not logically solvable in any neat, conclusive way. Campbell and Stanley also note that the oneshot case study often involves the tedious collection of specific details, careful observation, testing, and the like. This researcher found Campbell and Stanley's analysis of this research design to be true. 


\section{Implications}

The researcher believed at the time this study was conceptualized that the information obtained through this study could have major implications on staffing enablement or training. In looking for possible topics of study, this researcher could find no studies completed which involved computer usage by building-level administrators, principals, in the state of West Virginia. In fact, this researcher found only two such studies. One study was done in Kentucky (Witten, et al., 1990). However this study had very few positive comments or implications for administrative use of the personal computer by school principals. Another study was found which was completed in Reno, Nevada (Benson, 1996). This study was more current and provided a starting point for this researchers project conceptualization. Aside from these two studies, reports on two other projects outside the United States were found (Rees, 1987; Streatfield \& Thompson, 1983). However, these studies had been completed more than a decade ago and provided little useful information for the current field of technology usage.

During the course of this research project, the researcher received information requests from two individuals which assisted in validating the usefulness of this study. The first request came from the Director of Program Development and Support Services from Regional Education Service Agency VI based in Wheeling (Appendix C). This request asked for information which would enable this director to more effectively develop training opportunities for RESA VI principals. The second request was sent by Brenda Williams, Executive Director of the Office of Technology for the West Virginia Department of Education (Appendix D). Mrs. Williams said 
that she was interested in the results of this study because she was in the process of scheduling administrator training for the instructional technology support of teachers.

When this researcher was conceptualizing this study, he stated in the prospectus that he hoped that the information would be useful to the Regional Education Service Agencies and to individuals at the West Virginia Department of Education. Indeed it must have been. Prior to completion of this research project, the researcher was contacted by a representative of each of these organizations.

\section{Recommendations for Further Research}

Further studies in the area of school building-level administrators' experience and use of computer applications are needed. Such studies could focus on one of the following questions.

1. Which type of training (required college/university course, elective college/university course, community college course, inservice course, self-taught, peer coached) results in the highest level of computer usage by a building-level school administrator?

2. What factors, if any, will increase computer usage by building-level school administrators?

3. What impact, if any, does the acceptance and use of computer applications by buildinglevel school administrators have upon the effectiveness of their leadership?

4. What relationships, if any, are there between computer usage by building-level administrators and the administrator's categorization under situational leadership theory? 


\section{References}

Adams, J. M. (1982). Data processing: An introduction. Albany, NY: Delmar

Publishers.

Avolio, B. J., Bass, B. M., \& Jung, D. I. (1995). MLQ multifactor leadership questionnaire: Technical report. Redwood City, CA: Mind Garden.

Bass, B. M., \& Avolio, B. J. (Eds.). (1994). Improving organizational effectiveness through transformational leadership. Thousand Oaks, CA: Sage.

Bass, B. M., \& Avolio, B. J. (1996). Multifactor Leadership. [On-line]. Available: http://205.231.84.242

Bates, J. A. (2000). Cyberphobia. The world of computers [On-line]. Available: admin.nj.devry.edu/ jbates/comp108/lecture/intro/sld010.htm

Bennett, C. K. (1996, February). Schools, technology, and educational leadership: A framework for change. NASSP Bulletin, 80(577), 57-65.

Benson, P. A. (1996). School administrators $\Rightarrow$ cceptance and use of computers. University of Nevada: Reno.

Beskeen, D. W., Friedrichsen, L., Reding, E. E., \& Swanson, M.L. (2000). Microsoft office 2000 premium edition: Illustrated introductory. Cambridge, MA: Thompson Learning.

Bozeman, W. C., Raucher, S. M., \& Spuck, D. W. (1991). Application of computer technology to educational administration in the united states. Journal of Research on Computing in Education, 62-67.

Brennan, J. (1997). Point to the future: A principal technology planning guide. (ERIC Document Reproduction Service No. ED 415 847) 
Burns, J. M. (1978). Leadership. New York, NY: Harper \& Row.

Byers, J. W. (1991, November). A computer in your lap. Principal, 14-15.

Campbell, D. T., \& Stanley, J. D. (1963). Experimental and quasi-experimental designs for research. New York: Rand McNally.

Campbell-Kelly, M., \& Aspray, W. (1996). Computer: A history of the information machine. New York, NY: BasicBooks.

Carnine, D., Miller, S., \& Woodward, J. (1984). The role of technology in school improvement: A presenter guide on research-based training for school administrators. (ERIC Document Reproduction Service No. ED 271 847)

Certo, S. C. (2000). Modern management $\left(8^{\text {th }}\right.$ ed.). Upper Saddle River, NJ: Prentice Hall.

Ceruzzi, P. E. (1998). A history of modern computing. Cambridge, MA: Massachusetts Institute of Technology.

Cheng, Y. C. (1997). The transformational leadership for school effectiveness and development in the new century. (ERIC Document Reproduction Service No. ED 407 727) (41)

Clark, J. F., \& White, K. B. (1986). Computer confidence: A challenge for today. Cincinnati, OH: South-Western Publishing.

Clark, S. E., \& Denton, J. J. (1998). Integrating technology in the school environment: Through the principal lens. (ERIC Document Reproduction Service No. ED 417 696)

Conger, J. A., \& Kanungo, R. A. (1987). Towards a behavioral theory of charismatic leadership in organizational settings. Academy of Management Review, 12, 637-647. 
Cooper, L. G. (1989, April). Are you making effective administrative use of computers? NASSP Bulletin, 73(516), 93-94.

Crawford, C. W. (1987, November). A principal guide to the administrative computer. Principal, 67(2), 8-13.

Crawford, C. W. (1985a, March). Administrative use of microcomputers, Part I: Needs evaluation. NASSP Bulletin, 69(479), 70-72.

Crawford, C. W. (1985b, April). Administrative use of microcomputers, Part II: Specific tasks. NASSP Bulletin, 69(480), 53-60.

Crouse, D. (1997, May). The principal rules for school technology. NASSP Bulletin, 81(589), 86-89.

Crow, G. M., \& Glascock, C. H. (1995, July). Transformational leadership: Attractions of women and minority recruits to the principalship. Journal of School Leadership, 5(4), 356-78.

Dede, C. (1997, December 15). IAS education reform institute: Using technology as a tool for education reform. (Handouts from research presenter Chris Dede). Available FTP: www.ncbe.gwu.edu Directory: iasconferences/1997/institutes/technology/dede.htm

Dede, C. (1995, October 12). Testimony to the U.S. Congress, House of Representatives, joint hearing on educational technology in the $21^{\text {st }}$ century.

Dessler, G. (1999). Essentials of management. Upper Saddle River, NJ: Prentice Hall. Donatucci, F. J. (1995, February). The wired principal: Creating a supportive technology environment. School Business Affairs, 61(2), 13-15.

Drucker, P. F. (November/December 1969). Managements new role. Harvard Business Review, 54. 
Drury, T. R. (1995). Working without a net: Cyberphobia. Business First of Buffalo, $\underline{11}(52), 22-23$.

DuBrin, A. J. (2000). Essentials of management $\left(5^{\text {th }}\right.$ ed. $)$. Cincinnati, OH: SouthWestern Publishing.

Edmonds, R. (1979). Effective schools for the urban poor. Educational Leadership, $\underline{37}(1), 15-24$.

Education Service Center Region 20, An Antonia, Texas. (1986). Welcome to the world of computers: Part I. (1986). (ERIC Document Reproduction Service No. ED 269 638)

Engel, R. A. (1971). Trends in administrative technology. Education, 92(1), 134-136.

Evans, T. J. (1996a). Transformational leadership and supervision: Promoting reflective inquiry in schools. (ERIC Document Reproduction Service No. ED 396 407)

Evans, T. J. (1996b). Transformational leadership: Overview of a human resources administrative practice. (ERIC Document Reproduction Service No. ED 402 640)

Ewell, P. T. (1985). Transformation leadership for improving student outcomes: NCHEMS Monograph 6. (ERIC Document Reproduction Service No. ED 310 653)

Fileto, B., \& Hoopes, B. (1997, January). From chaos to change. Thrust for Educational Leadership, 26(4), 4-5.

Filipczak, R. (1994, January). Technoliteracy, technophobia, and programming your VCR. Training, 48.

Fornell, C., \& Larcker, D. F. (1981). Evaluating structural equation models with unobservable variables and measurement error. Journal of Applied Psychology, 73, 695-702. 
Frankel, S. (1987, March). The do-it-yourself guide to automating the school office. NASSP Bulletin Special Edition, 71(497), 34-41.

Gay, L. R. (1992). Educational research: Competencies for analysis and application. Columbus, OH: Charles E. Merrill Publishing Company.

Gerstner, L, Semerad, R., Doyle, D. \& Johnston, W. (1994). Reinventing education: Entrepreneurship in America public schools. New York: Dutton.

Grauer, R. T., \& Barber, M. (1999). Exploring microsoft office 2000 professional: Volume I. Upper Saddle River, NJ: Prentice-Hall.

Groff, W. H. (1993). Toward the $21^{\text {st }}$ century: Preparing proactive visionary transformational leaders for building learning through multi-technology: Leadership IBFormative evaluation of cluster 54. (ERIC Document Reproduction Service No. ED 357 829)

Gulick, L. H., \& Urwick, J. D. (Eds.). (1937). Papers on the science of administration. New York: Institute of Public Administration, Columbia University.

Hancock, V. (1990, October). Technology. Educational Leadership, 48(2), 85-86.

Hanna, R. M., Ross-Ganguly, R., \& Katz, B. (1994). The wired administrator: Technology training and lifelong learning. School Business Affairs, 61(2), 4-6, 8-12.

Hipp, K. A. (1997). Documenting the effects of transformational leadership behavior on teacher efficacy. (ERIC Document Reproduction Service No. ED 407 734)

House, J. E. (1989). Administrative use of computers by local education authorities: Report of a questionnaire survey. (ERIC Document Reproduction Service No. ED 387 895) Hunt, J. (1991). Leadership: A new synthesis. Thousand Oaks, CA: Sage. 
Isherwood, G. B. (1985 Winter). The principal and the pauper: Administrator training in computer technology. Education Canada, 25(4), 4-9.

Johnson, W. L., \& Snyder, K. J. (1990). Leadership for productive schools. (ERIC Document Reproduction Service No. ED 329 014)

Kaufman, C. C. (1997, March). Using technology to upgrade the principal frole as instructional leader. NASSP Bulletin, 81(587), 98-101.

Kearsley, G., Ed., \& Lynch, W., Ed. (1994). Educational technology: Leadership perspectives. (ERIC Document Reproduction Service No. ED 366 114)

Kerlinger, F. N. (1964). Foundations of behavioral research $\left(2^{\text {nd }}\right.$ ed. $)$. New York: Holt, Rinehart and Winston.

Kirby, P.C., et al. (1992, May/June). Extraordinary leaders in education: Understanding transformational leadership. Journal of Educational Research, 85(5), 303-11.

Kosakowski, J. (1998, August). The benefits of information technology. ERIC Digest. Available FTP: ericir.syr.edu Directory: ithome/digests/edoir9804.html

Lamb, B., Rhinehart, M., \& Still, J. (1996). Delivering the Avrite@message: The memo and transformational leadership. (ERIC Document Reproduction Service No. ED 394 558)

Lauda, D. P. (1994). Responding to the call for technological literacy. NASSP Bulletin, $\underline{78}(563), 44-48$.

Leithwood, K. (1993). Contributions of transformation leadership to school restructuring. (ERIC Document Reproduction Service No. ED 367 061)

Leithwood, K., Jantzi, D., Silins, H., \& Dart, B. (1992). Transformational leadership and school restructuring. (ERIC Document Reproduction Service No. ED 342 126) 
Leithwood, K. A. (1992, February). The move toward transformational leadership. Educational Leadership, 49(5), 8-12.

Lewis, P. S., Goodman, S. H., \& Fandt, P. M. (1998). Management: Challenges in the $21^{\text {st }}$ century ( $2^{\text {nd }}$ ed.). Cincinnati, OH: South-Western Publishing.

Lewis, R. B. (1997, July/August). Changes in technology use in California special education programs. Remedial \& Special Education, 18(4), 233-243.

Liontos, L. B. (1993, July). Transformation leadership: Profile of a high school principal. OSSC Bulletin, 36(9). (ERIC Document Reproduction Service No. ED 359 652)

Liontos, L. B. (1992). Transformational leadership. ERIC Digets 72. (ERIC Document Reproduction Service No. ED 347 636)

MacNeil, A. J., \& Delafield, D. P. (1998). Principal leadership for successful school technology implementation. (ERIC Document Reproduction Service No. ED 421 126)

MacNeil, A. J., \& Harmon, S. W. (1998). Facilitating interpersonal communication with technology in principal preparation programs. (ERIC Document Reproduction Service No. ED 421 127)

Mandell, S. L. (1979). Computers and data processing concepts and applications: With basic. St. Paul, MN: West Publishing.

Marshall, D. G. (1982 Summer). The school administrator and the microcomputer: Some points to ponder. Education Canada, 4-11.

McCormack, M. (1996). The tragic flow of educational administration. (ERIC Document Reproduction Service No. ED 411 106) 
Miller, R. (1983). Your leadership style: A management development module for educational leaders. (ERIC Document Reproduction Service No. ED 243 232)

Mintzberg, H. (July/August 1975). The manager job: Folklore and fact. Harvard Business Review, 49-61.

Mojkowski, C. (1986, March). The principal and technology: Beyond automation to revitalization. Educational Leadership, 43(6), 45-48.

Montgomery, D. J. \& Murphy, J. (Eds.). (2001). The new york times guide to management. Cincinnati, OH: South-Western Publishing.

Northouse, P. G. (1997). Leadership: Theory and practice. Thousand Oaks, CA: SAGE Publications.

Ortiz, F. I. (1986). A comparison of leadership styles and organizational cultures. (ERIC Document Reproduction Service No. ED 269 874)

Pejza, J. P. (1994). Lead, follow, or get out of the way: Transformational leadership. (ERIC Document Reproduction Service No. ED 375 496)

Picciano, A. G. (1994). Computers in the schools. MacMillan Publishing Company. Rees, R. (1987). The application of computer technology to educational administration: A pilot study. (ERIC Document Reproduction Service No. 296 438)

Rhodes, L. A. (1997, April). Building leadership technology: The missing link between a superintendent vision and the school district actions. The School Administrator, 54(4), 12-16. Ritchie, D. (1996, October). The administrative role in the integration of technology. NASSP Bulletin, 80(582), 42-52. 
Ritchie, D. \& Rodriquez, S. (1996). (in press). The role of technology in school leadership. Journal of Information Technology for Teacher Education.

Robbins, S. P. \& Coulter, M. (1999). Management ( $6^{\text {th }}$ ed.). Upper Saddle River, NJ: Prentice Hall.

Rockman, S., \& Sloan, K. R. (1993). A program that works: Indiana principals= technology leadership training program. (ERIC Document Reproduction Service No. 368 350)

Rue, L. W. \& Byars, L. L. (1992). Management skills and applications $\left(6^{\text {th }}\right.$ ed.).

Homewood, IL: Irwin.

Salant, P., \& Dillman, D. A. (1994). How to conduct your own survey. John Wiley \& Sons.

Sayers, S. (1978). Leadership styles: A behavioral matrix. (ERIC Document Reproduction Service No. ED 208 593)

Sharman, C. C., \& Cothern, H. L. (1986, March). Take advantage of technology to boost principal power. Executive Educator, 8(3), 29, 33.

Shelly, G. B., \& Cashman, T. J. (1982). Introduction to BASIC programming. Brea, CA: Anaheim Publishing.

Shelly, G. B., Cashman, T. J., Gunter, R. E., \& Gunter, G. A. (1999). Teachers discovering computers: A link to the future. Cambridge, MA: International Thompson Publishing.

Shelly, G. B., Cashman, T. J., \& Walker, T. J. (1997). A record of discovery for exploring computers (2nd ed.). Cambridge, MA: International Thompson Publishing. 
Singer, H., \& Phelps, P. (1982). The history of computers and their use in education. (ERIC Document Reproduction Service No. ED 261 351)

Slack, P. J. (1990). Transforming transformational leadership: Learning with the power of the mind eye. (ERIC Document Reproduction Service No. ED 320 304)

Smith, P. B., \& Peterson, M. F. (1988). Leadership, organizations and culture. New York: Sage.

Smith, R. C., \& Lischin, S. (1986). The culturally fluent leader of the twenty-first century. (ERIC Document Reproduction Service No. ED 278 611)

Splittgerber, F. G., \& Stirzaker, N. A. (1984, February). Computer technology for administrative information and instructional management in school districts. Education Technology, 24(2), 36-38.

Sprinthall, R. C. (1990). Basic statistical analysis. Prentice Hall.

Spuck, D. W. \& Bozeman, W. D. (1988). Training school administrators in computer use. Journal of Research on Computing in Education, 21(2), 229-239.

Stone, P. (1992). Transformational leadership in principals: An analysis of the multifactor leadership questionnaire results. Professional leadership development monograph series, 2(1). (ERIC Document Reproduction Service No. ED 355 613)

Stover, N. G. (1990, October). Principals and programmers: Partners in the use of technology. NASSP Bulletin, 74(528), 72-77.

Streatfield, D., \& Thompson, S. (1983). Administrative use of computers by local education authorities: Report of a questionnaire survey. (ERIC Document Reproduction Service No. ED 242 032) 
Thomas, L. G., \& Knezek, D. (1991, Winter). Providing technology leadership for restructured schools. Journal of Research on Computing in Education, 24(2), 265-79. (ERIC Document Reproduction Service No. ED 443 396)

Trotter, A. (1997). A test of leadership. Education Week, 17(11), 30-33.

Turan, S., \& Sny, C. L. (1996). An exploration of transformational leadership and its role in strategic planning: A conceptual framework. (ERIC Document Reproduction Service No. ED 407 426)

Vacca, A. M. (1983). The computer as a tool for the future. (ERIC Document Reproduction Service No. ED 247 651)

Wall, T. J. (1994, April). Working Smarter. The Executive Educator, 16(4), 48-51. West Virginia Department of Education. (2000). West Virginia education information system. West Virginia department of education. In West Virginia education information system [On-line]. Available: www.wveis.k12.wv.us/welcomeb.htm

Williams, C. (2000). Management. Cincinnati, OH: South-Western Publishing. Witten, D. W., Richardson, M. D., \& Prickett, R. L. (1990). An analysis of administrative computer use by secondary principals in kentucky. (ERIC Document Reproduction Service No. ED 343 258)

Wren, D. A. (1972). The evolution of management thought. New York: The Ronald Press Company.

Yukl, G. (1994). Leadership in organization. Englewood Cliffs, NJ: P rentice-Hall. 
Appendix A

Survey Instrument 

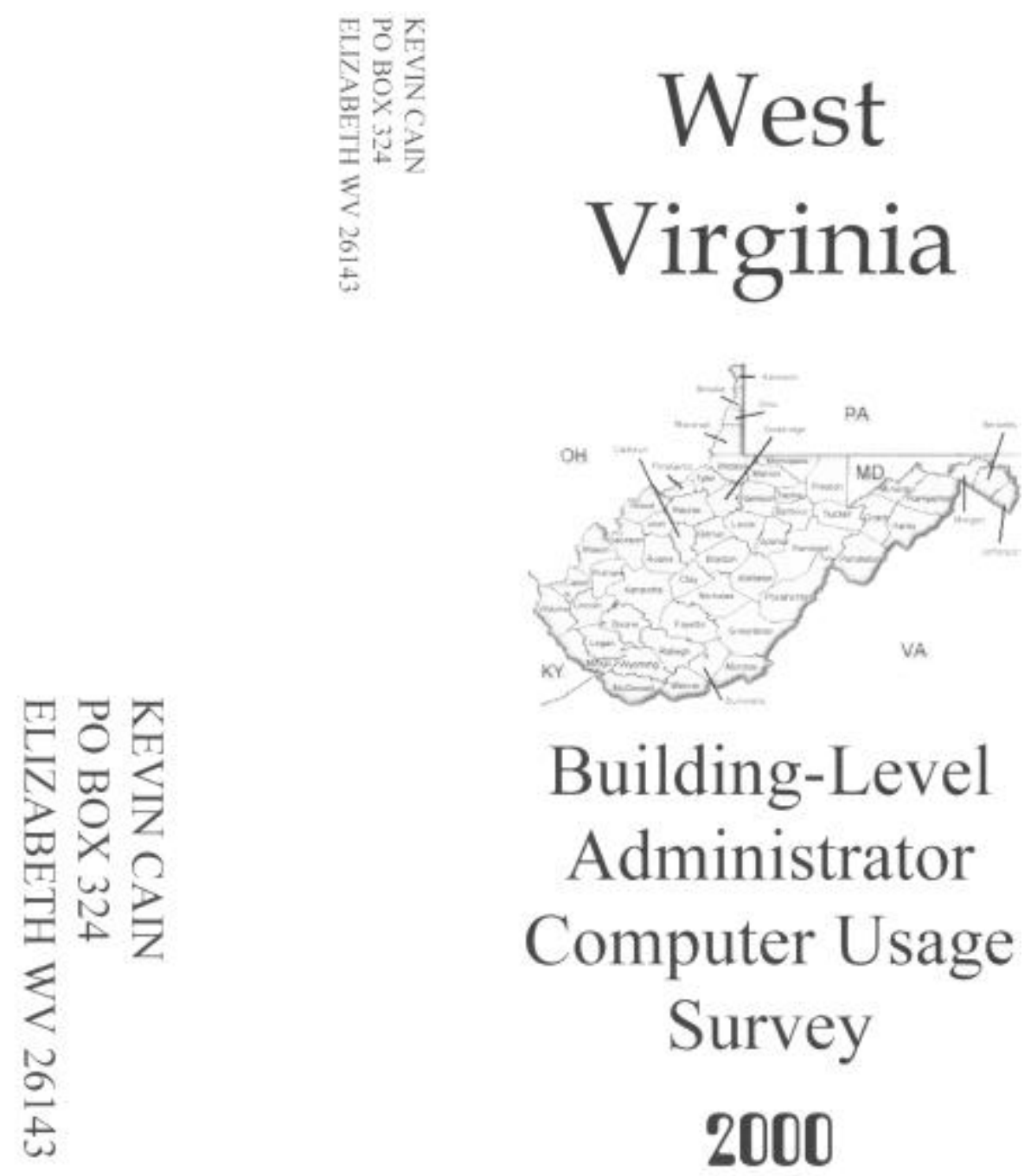


\begin{tabular}{|c|c|c|c|c|c|c|}
\hline \multicolumn{7}{|c|}{ Section 1-Specific Computer Applications Used } \\
\hline & $\begin{array}{l}\text { Identify the frequency with which you } \\
\text { use each of the following personal } \\
\text { productivity computer applications for } \\
\text { the administrative task specified in bold: } \\
\text { ganizing Information }\end{array}$ & Daily & Often & Weekly & Rarely $\mathrm{Ne}$ & Never \\
\hline & Database & ] & J & 」 & ב & 口 \\
\hline \multicolumn{7}{|c|}{ Communicating } \\
\hline & Word Processing & ] & 」 & 山 & 口 & 口 \\
\hline & E-Mail & Ј & $\overline{\lrcorner}$ & Ј & 口 & 」 \\
\hline \multicolumn{7}{|c|}{ Making Presentations } \\
\hline & Presentation Software & 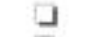 & $\therefore$ & ] & ] & 口 \\
\hline & Desktop Publishing & 丁 & $\sqsupset$ & 」 & 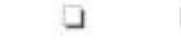 & a \\
\hline \multicolumn{2}{|c|}{ Preparing Budgets } & د & $\square$ & 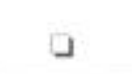 & ב & $\square$ \\
\hline \multicolumn{7}{|c|}{ Section 2-General Computer Use } \\
\hline 2. & Do you have a computer in your home? & \multicolumn{5}{|c|}{$\square$ Yes a No } \\
\hline & $\begin{array}{l}\text { What type(s) of computer platform(s) have } \\
\text { you previously used (check all that apply)? }\end{array}$ & \multicolumn{2}{|c|}{$\begin{array}{l}\text { None } \\
\text { DOS }\end{array}$} & \multicolumn{3}{|c|}{$\begin{array}{l}\text { Windows } \\
\text { Macintosh/Apple }\end{array}$} \\
\hline & $\begin{array}{l}\text { How many years have you used a PC } \\
\text { (personal computer)? }\end{array}$ & \multicolumn{3}{|c|}{$\begin{array}{l}\text { None } \\
\text { Less than I year } \\
1-3 \text { years }\end{array}$} & \multicolumn{2}{|l|}{$\begin{array}{l}4-7 \text { years } \\
7+\text { years }\end{array}$} \\
\hline & $\begin{array}{l}\text { Which computer application type(s) } \\
\text { have you previously used at home } \\
\text { (check all that apply)? }\end{array}$ & \multicolumn{3}{|c|}{$\begin{array}{l}\text { None } \\
\text { Word Processing } \\
\text { Desktop Publishing } \\
\text { Internet Browsing }\end{array}$} & \multicolumn{2}{|c|}{$\begin{array}{l}\square \text { Database } \\
\text { Spreadsheet } \\
\square \text { E-Mail }\end{array}$} \\
\hline \multicolumn{7}{|c|}{ Section 3-Computer Training Received } \\
\hline & $\begin{array}{l}\text { Identify the type(s) of computer training } \\
\text { you have received. }\end{array}$ & \multicolumn{5}{|c|}{$\begin{array}{l}\text { None } \\
\text { Required university/college course(s) } \\
\lrcorner \text { Elective university/college course(s) } \\
\lrcorner \text { Community college course(s) } \\
\text { Inservice course(s) } \\
\text { Self-taught } \\
\lrcorner \text { Peer coached }\end{array}$} \\
\hline & $\begin{array}{l}\text { Identify the specific computer applica- } \\
\text { tion programs for which you have } \\
\text { received training in the last year (check } \\
\text { all that apply)? }\end{array}$ & \multicolumn{3}{|c|}{$\begin{array}{l}\text { None } \\
\text { Word Processing } \\
\text { Desktop Publishing } \\
\text { Internet Browsing }\end{array}$} & \multicolumn{2}{|c|}{$\begin{array}{l}\text { Database } \\
\text { Spreadsheet } \\
\text { E-Mail }\end{array}$} \\
\hline & $\begin{array}{l}\text { How much computer training have you } \\
\text { received in the last year? }\end{array}$ & \multicolumn{3}{|c|}{$\begin{array}{l}\square \text { None } \\
\text { Less than } 1 \text { day } \\
1 \text { day }\end{array}$} & \multicolumn{2}{|l|}{$\begin{array}{l}\square 2 \text { days } \\
3 \text { days } \\
3+\text { days }\end{array}$} \\
\hline
\end{tabular}




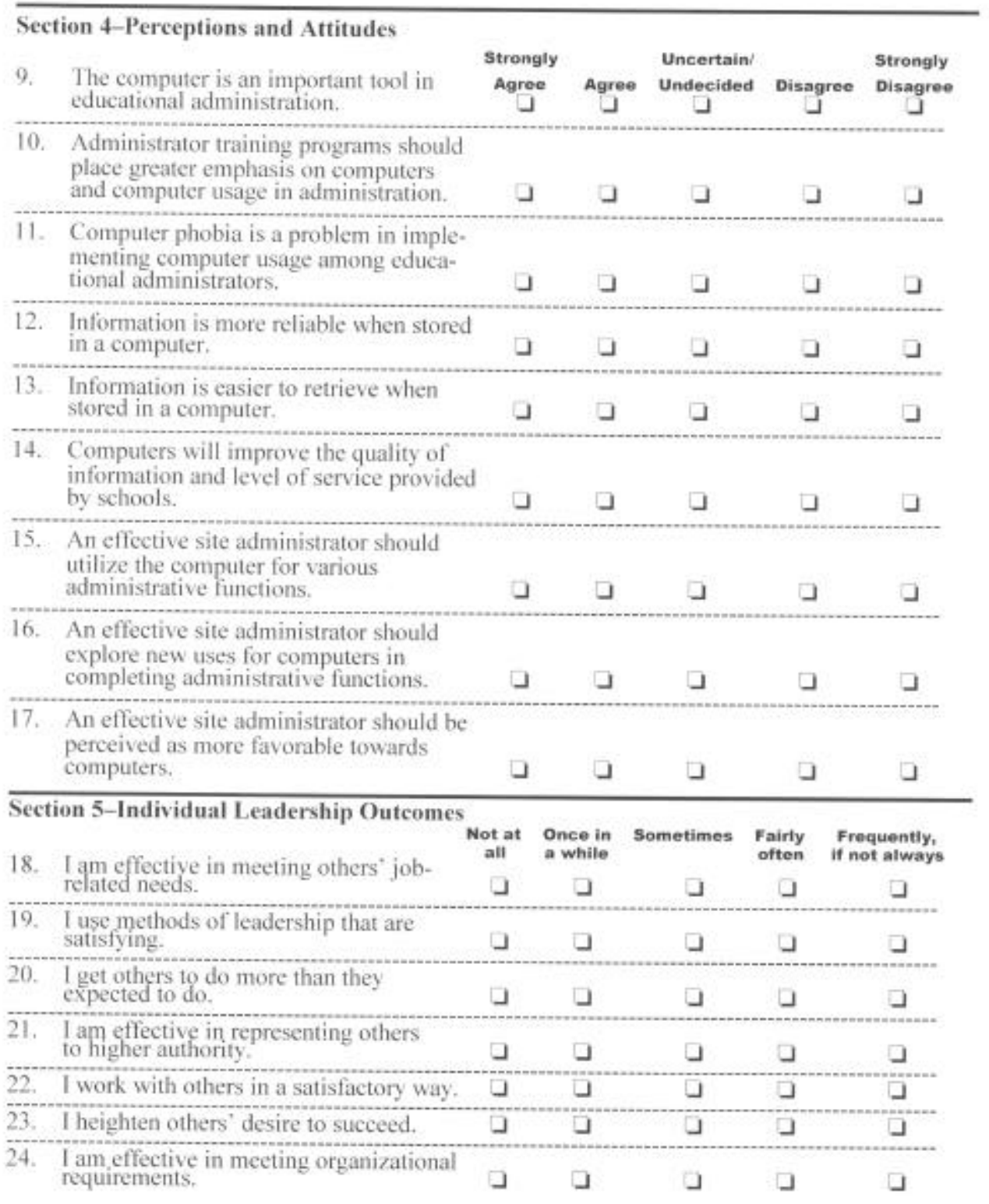




\begin{tabular}{|c|c|c|c|c|c|}
\hline & $\begin{array}{l}\text { I increase others willingness to try } \\
\text { harder. }\end{array}$ & ] & 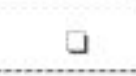 & 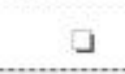 & ] \\
\hline 26. & I lead a group that is effective. & ప & $\bar{u}$ & ప & 丁 \\
\hline \multicolumn{6}{|c|}{ Section 6-Demographic Data } \\
\hline 27. & Giender & \multicolumn{4}{|c|}{ Dale JFemale } \\
\hline 28. & Age & $\begin{array}{l}\text { Under } 35 \\
36-40\end{array}$ & \multicolumn{2}{|c|}{$\begin{array}{l}41-45 \\
46-50\end{array}$} & $\square$ Over 50 \\
\hline 29. & Ethnicity (check only one) & \multicolumn{4}{|c|}{$\begin{array}{l}\text { American Indian or Alaskan Native } \\
\text { Asian or Pacific Islander } \\
\text { African-American, not of Hispanic origin } \\
\text { Hispanic }\end{array}$} \\
\hline 30. & $\begin{array}{l}\text { Education Level (check highest level } \\
\text { earned) }\end{array}$ & \multicolumn{3}{|l|}{$\begin{array}{l}\square \text { Master } \\
\square \text { Master } \\
\square \text { Master }\end{array}$} & Degree +45 \\
\hline \multirow[t]{2}{*}{31.} & Previous teaching experience (check all th & at apply) & & & \\
\hline & $\begin{array}{l}\text { Nonc } \\
\text { Elementary Education-Grades K-4 } \\
\text { Middle School Education-Grades 5-8 } \\
\text { Secondary Education-English } \\
\text { S Secondary Education-Math }\end{array}$ & \multicolumn{4}{|c|}{$\begin{array}{l}\text { J Secondary Education-Physical Education } \\
\text { Secondary Education-Science } \\
\text { J Secondary Education-Social Studies } \\
\text { Secondary Education-Special Education } \\
\text { J Secondary Education-Voc/Occup Education }\end{array}$} \\
\hline 32. & Years of administrative experience & \multicolumn{2}{|c|}{$\begin{array}{l}\text { Less than } 3 \text { years } \\
3-5 \text { years }\end{array}$} & $\begin{array}{l}\text { G-10 } \\
\text { More }\end{array}$ & 0 years \\
\hline 33. & $\begin{array}{l}\text { Current school assignment } \\
\text { (check more than one if in a } \\
\text { combined facility) }\end{array}$ & \multicolumn{2}{|c|}{$\begin{array}{l}\text { Flementary School } \\
\text { Middle/Jr. High } \\
\text { High School }\end{array}$} & $\begin{array}{l}\square \text { Voca } \\
\text { Alter }\end{array}$ & $\begin{array}{l}\text { School } \\
\text { School }\end{array}$ \\
\hline 34. & Years at present site assignment & \multicolumn{2}{|c|}{$\begin{array}{l}\text { Less than } 3 \text { years } \\
3-5 \text { years }\end{array}$} & $\begin{array}{l}6-10 \\
\text { Mor }\end{array}$ & 10 years \\
\hline 35. & $\begin{array}{l}\text { Approximate student enrollment at } \\
\text { present site assignment }\end{array}$ & \multicolumn{2}{|c|}{$\begin{array}{l}\text { Less than } 250 \\
250-750 \\
751-1250\end{array}$} & 1251 & 1750 \\
\hline 36. & Number of professional staff & \multicolumn{2}{|c|}{$\begin{array}{l}\text { Less than } 10 \\
10-25\end{array}$} & $\begin{array}{l}26-40 \\
41-55\end{array}$ & $555+$ \\
\hline 37. & Number of classified staff & \multicolumn{2}{|l|}{$\begin{array}{l}\text { Less than } 5 \\
5-15\end{array}$} & \multicolumn{2}{|c|}{$\begin{array}{l}16-25 \\
\text { More than } 25\end{array}$} \\
\hline 38. & In which RESA are you located? & \multicolumn{2}{|l|}{$\begin{array}{l}\square \text { RESA I } \\
\text { RESA II } \\
\text { RESA III }\end{array}$} & $\begin{array}{l}\text { IV a } \\
\text { vi } \\
\text { vi }\end{array}$ & VIII \\
\hline
\end{tabular}


Appendix B

Cover Letter 
October 24,2000

APPROVED BY THE COLLEE OF

Dear Principal:

Enclosed you will find a copy of the West Virginia Building-Level Administrator Computer Usage Survey $\mathbf{2 0 0 0}$ form. This form has been designed to take less than ten minutes to complete. Furthermore, a self-adhesive tab has been provided so that the preposted, brochure-style form can simply be folded and deposited in your outgoing mail after completion. The goal of my research is to examine the frequency with which principals in West Virginia use office productivity software to complete management tasks. The information gathered will be used for my doctoral dissertation.

Your participation is entirely voluntary, and you do not have to respond to every item or question. Your responses will remain anonymous, and confidentiality will be maintained. Neither your class standing, athletic status, or grades will be affected by refusing to participate or by withdrawing from the study.

Because your time is so valuable, I have created this data-gathering form to require only "checks" or Xs" in the appropriate box or boxes provided in responding to each item. No writing on your part is required. Please return the completed form by Tuesday,

November 7 .

Sincerely,

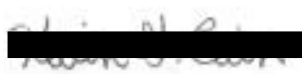

Kevin G. Cain

Enclosure: Computer Usage Survey

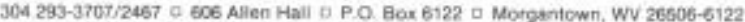
Equal Opportunity / Aflirmutims Action Institution 
Appendix C

Information Request from RESA VI 
October 30,2000

Kevin Cain

PO Box 324

Elizabeth, WV 26143

Dear Mr. Cain:

A principal in RESA-6 notified me that you were doing a West Virginia principals and technology use survey as a topic for your dissertation.

As Director of Programs and Support Services at RESA-6, I am responsible for staff development. As you know, technology application and use is an on-going area with the principals' knowledge and use at various levels. Therefore, I am interested in the results of your survey. The information I desire is that from RESA-6 principals. It would be used to develop technology staff development opportunities.

I would greatly appreciate any data that will enable me to more effectively develop training opportunities for RESA-6 principals. I can be reached at RESA-6, 30 G. C. \& P. Road, Wheeling, West Virginia. You may also reach me via phone - 304-243-0440 or 1 800-234RESA, fax-304-243-0443, or e-mail-britz@access.k12,wv,us.

Best wishes on your dissertation and complection of your doctorate.

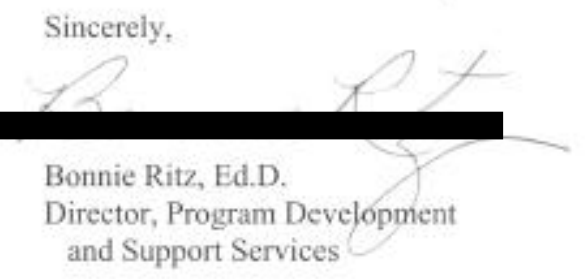

$\mathrm{BR} / \mathrm{lce}$ 


\begin{abstract}
Appendix D
Information Request from Brenda Williams,

Executive Director of the Office of Technology

of the West Virginia Department of Education
\end{abstract}




\section{$\underline{\text { Kevin G. Cain }}$}

From: $\quad$ Brenda Williams [brendaw@access.k12.wv.us]

Sent: $\quad$ Wednesday, March 21, 2001 11:22 PM

To: Kevin G. Cain (E-mail)

Subject: $\quad$ Information Request

Kevin,

Did you finish your research project? If so, I would be interested in your results. We are in the process of scheduling administrator training for instructional technology support of teachers.

Thanks,

Brenda Williams

Executive Director

Office of Technology

WVDE

558-7880 